\title{
Microwave-assisted Synthesis of Coordination and Organometallic Compounds
}

\author{
Oxana V. Kharissova, Boris I. Kharisov and Ubaldo Ortiz Méndez \\ Universidad Autónoma de Nuevo León, Monterrey, \\ México
}

\section{Introduction}

Microwave irradiation (MW) as a "non-conventional reaction condition" (Giguere, 1989) has been applied in various areas of chemistry and technology to produce or destroy diverse materials and chemical compounds, as well as to accelerate chemical processes. The advantages of its use are the following (Roussy \& Pearce, 1995):

1. Rapid heating is frequently achieved,

2. Energy is accumulated within a material without surface limits,

3. Economy of energy due to the absence of a necessity to heat environment,

4. Electromagnetic heating does not produce pollution,

5. There is no a direct contact between the energy source and the material,

6. Suitability of heating and possibility to be automated.

7. Enhanced yields, substantial elimination of reaction solvents, and facilitation of purification relative to conventional synthesis techniques.

8. This method is appropriate for green chemistry and energy-saving processes.

The substances or materials have different capacity to be heated by microwave irradiation, which depends on the substance nature and its temperature. Generally, chemical reactions are accelerated in microwave fields, as well as those by ultrasonic treatment, although the nature of these two techniques is completely distinct.

Microwave heating $(\mathrm{MWH})$ is widely used to prepare various refractory inorganic compounds and materials (double oxides, nitrides, carbides, semiconductors, glasses, ceramics, etc.) (Ahluwulia, 2007), as well as in organic processes (Oliver Kappe et al, 2009; Leadbeater, 2010): pyrolisis, esterification, and condensation reactions. Recent excellent reviews have described distinct aspects of microwave-assisted synthesis of various types of compounds and materials, in particular organic (Martínez-Palou, 2007; Oliver Kappe et al, 2009; Besson et al, 2006) and organometallic (Shangzhao Shi and Jiann-Yang Hwang, 2003) compounds, polymers, applications in analytical chemistry (Kubrakova, I.V., 2000), among others. Microwave syntheses of coordination and organometallic compounds, discussed in this chapter, are presented by relatively a small number of papers in the available literature in comparison with inorganic and organic synthesis. The use of microwaves in coordination chemistry began not long ago and, due to the highly limited number of results, these works can be considered as a careful pioneer experimentation, in order to establish the suitability of this technique for synthetic coordination chemistry. Classic ligands, whose numerous 
derivatives have been used as precursors for obtaining their metal complexes, are shown in Table 1.

\section{Physical principles of microwave irradiation and laboratory equipment}

Microwave heating is a physical process where the energy is transferred to the material through electromagnetic waves. Frequencies of microwaves are higher of $500 \mathrm{MHz}$. It is known that a non-conductive substance can be heated by an electric field, which polarizes its charges without rapid reversion of the electric field. For some given frequencies, the current component, resulting in the phase with electric field, produces a dissipation of the potency within the dielectric material. Due to this effect, a dielectric can be heated through the redistribution of charges under the influence of external electric fields. The potency dissipated within the material depends on the established electric field within the material. This potency is diminished as the electromagnetic field penetrates to the dielectric.

The most common microwave application is that of multimode type which accepts broad range thermal charges with problems of microwave uniformity. The application of multimode type is given in a closed metallic box with dimensions of various wave lengths and which supports a large number of resonance modes in a given range of frequencies. A resonance cavity or heater consists on a metallic compartment that contains a microwave signal with polarization of the electromagnetic field; it has many reflections in preferential directions. The superposition of the incident and reflected waves gives place to a combination of stationary waves. If the configuration of the electric field is precisely known, the material to be treated can be put to a position of electric field maximum for an optimal transference of electromagnetic energy.

Typical microwave equipment consists of a magnetron tube (Fig. 1) (Roussy \& Pearce, 1995). Just as other vacuum tubes, the anode has a higher potential with respect to the cathode (source of electrons). So, the electrons are accelerated to the anode in the electric field. The cathode is heated till the high temperature expulse electrons. Generally, the anode is close to earth potential and the cathode has a high negative potential. The difference between the magnetron and other vacuum tubes is that the electron flow passes along a spiral; this route is created by external magnetic field B (Fig. 1). The electron cloud produces resonance cavities several times in its trip to the anode. These cavities work as Helmholtz resonators and produce oscillations of fixed frequency, which is determined by the cavity dimensions: small cavities produce higher frequencies, large cavities give smaller frequencies. The antenna in the right zone collects the oscillations.

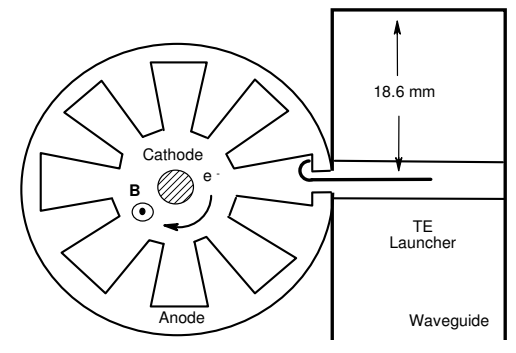

Fig. 1. Scheme of microwave equipment. 


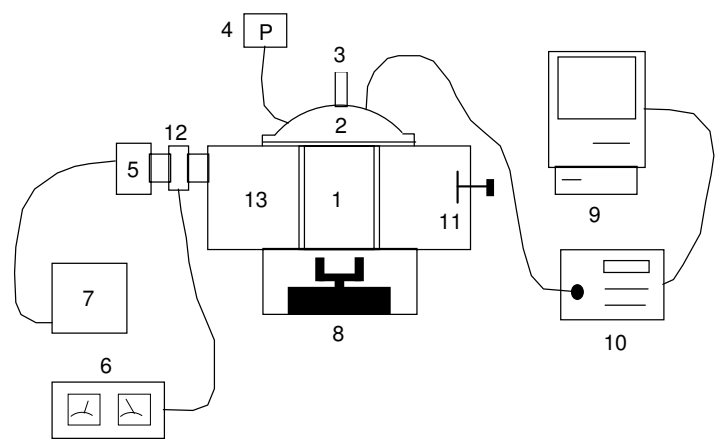

Fig. 2. Reactor for batchwise organic synthesis (with permission): 1 , reaction vessel; 2 , top flange; 3 , cold finger; 4 , pressure meter; 5 , magnetron; 6 , forward/reverse power meters; 7 , magnetron power supply; 8 , magnetic stirrer; 9 , computer; 10 , optic fiber thermometer; 11 , load matching device; 12, waveguide; 13, multimodal cavity (applicator).

The use of a microwave reactor for batchwise organic synthesis (Raner et al, 1995), described in Fig. 2), permits to carry out synthetic works or kinetic studies on the $20-100 \mathrm{~mL}$ scale, with upper operating limits of $260^{\circ} \mathrm{C}$ and $10 \mathrm{MPa}(100 \mathrm{~atm})$. Microwave-assisted organic reactions can be conducted safely and conveniently, for lengthy periods when required, and in volatile organic solvents. The use of water as a solvent is also explored.

A typical reactor used for organic and/or organometallic syntheses (Matsumura-Inoue et al, 1994) is presented in Fig. 3, which can be easily implemented using a domestic microwave

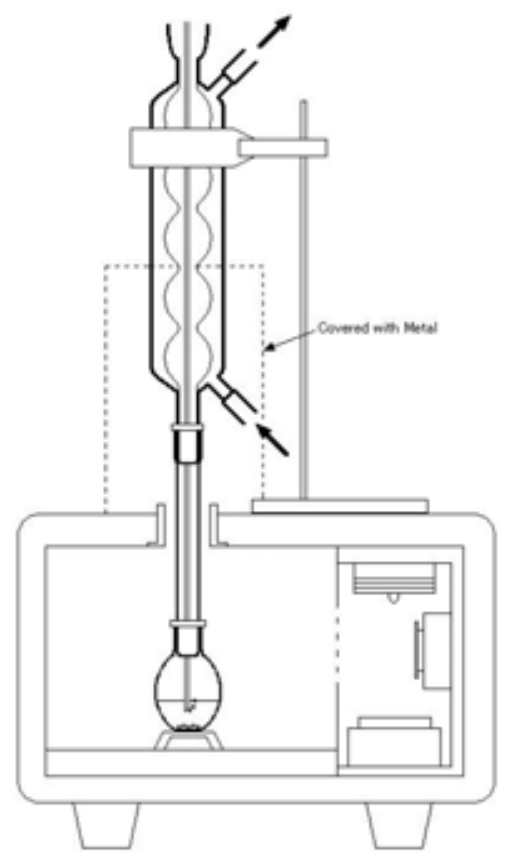

Fig. 3. Typical MW-reactor for organic and/or organometallic synthesis. With permission. 


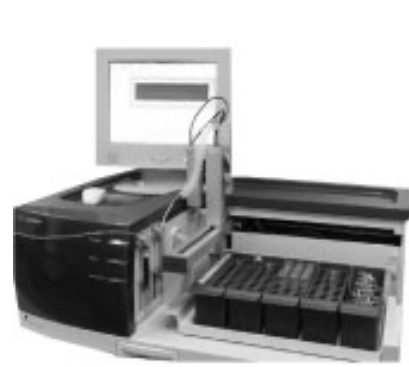

A

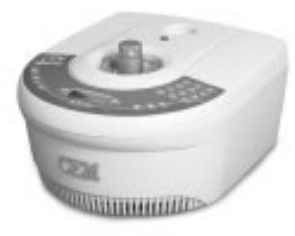

B

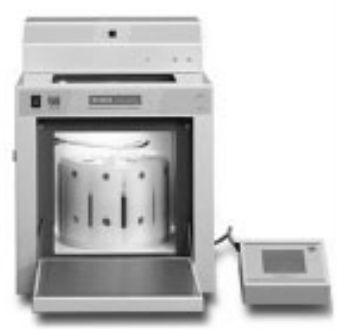

C

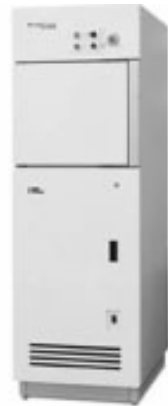

D

Fig. 4. Microwave reactors for chemical syntheses. A: Emrys Liberator (Biotage, Sweden, www.biotage.com); B: CEM Discover BenchMate (CEM, USA, www.cem.com) Copyright CEM Corporation; C: Milestone Ethos TouchControl (Milestone, Italy, www.milestonesci.com); D: Lambda MicroCure2100 BatchSystem (Lambda, USA, www.microcure.com). With permission.

oven. Due to some problems occurring during microwave treatment, for example, related with the use of volatile liquids (they need of an external cooling system via copper ports), original solutions to these problems are frequently found in the reported literature. More modern laboratory MW-reactors (Wiesbrock et al, 2004) are shown in Fig. 4.

A combination of different techniques can frequently improve yields of final compounds or synthetic conditions. Reunion of microwave and ultrasonic treatment was an aim to construct an original microwave-ultrasound reactor (Chemat et al, 1996) suitable for organic synthesis (pyrolysis and esterification) (Fig. 5). The ultrasound (US) system is a cup horn type; the emission of ultrasound waves is made at the bottom of the reactor. The US probe is not in direct contact with the reactive mixture. It is placed a distance from the electromagnetic field in order to avoid interactions and short circuits. The propagation of the US waves into the reactor is made by means of decalin introduced into the double jacket. This liquid was chosen because of its low viscosity that induces good propagation of US and its inertia towards MW.

Some years ago, an alternative method for performing microwave-assisted organic reactions, termed "Enhanced Microwave Synthesis" (EMS), has been examined in an excellent review (Hayes, 2004). By externally cooling the reaction vessel with compressed air, while simultaneously administering microwave irradiation, more energy can be directly applied to the reaction mixture. In "Conventional Microwave Synthesis" (CMS), the initial microwave power is high, increasing the bulk temperature (TB) to the desired set point very quickly. However, upon reaching this temperature, the microwave power decreases or shuts off completely in order to maintain the desired bulk temperature without exceeding it. When microwave irradiation is off, classical thermal chemistry takes over, losing the full advantage of microwave-accelerated synthesis. With CMS, microwave irradiation is predominantly used to reach TB faster. Microwave enhancement of chemical reactions will only take place during application of microwave energy. This source of energy will directly activate the molecules in a chemical reaction. EMS ensures that a high, constant level of microwave energy is applied. 


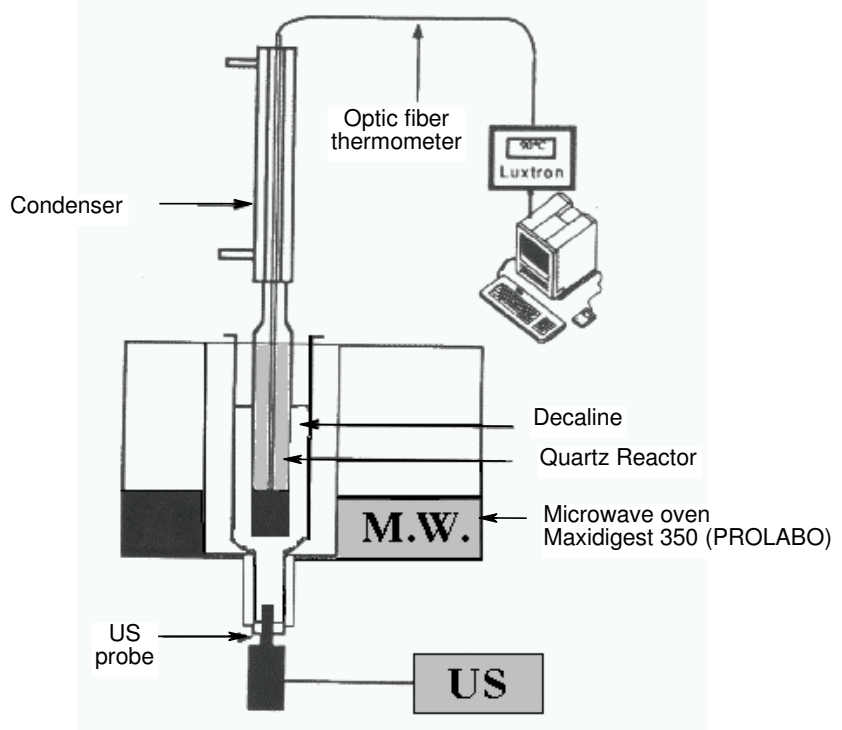

Fig. 5. Combined MW-US reactor. With permission.

\section{Complexes with O-containing ligands}

\section{1 $\beta$-Diketonates, alkoxides and alcohol adducts}

The MWH of metal $\beta$-diketonates or their precursors, represented by acetylacetonates, has been used both for their synthesis (rarely) and destruction (mainly), leading, in the last case, to various inorganic materials, nanostructures and nanocomposites. Synthesis route is represented by only a few examples. Thus, a rapid and environmentally benign method for the coupling of 2-naphthols is described using copper(II) acetylacetonate under microwave irradiation in dry media (Meshram et al, 2003). The procedure was found to be very convenient and avoids the use of excess solvent for reaction. Microwave synthesis method was developed for the synthesis of a series of cyclometalated platinum complexes with long chain $\beta$-diketone ancillary ligands, with which reaction time was greatly reduced from $32 \mathrm{~h}$ to several minutes (Luo et al, 2007; Luo et al, 2007). The formed compounds were used for fabrication of organic light-emitting diodes. A protected ethynyl group was introduced into a $\gamma$-position of a ( $\beta$-diketonato)bis(bipyridine)ruthenium(II) complex through the reaction of the bromo complex and (triisopropylsilyl)-acetylene with very good yield under $\mathrm{MWH}$ (Munery et al, 2008). Two mononuclear mixed-ligand ruthenium(II) complexes with bipyridine (bpy) and functionalized acetylacetonate ion (acac-), $\left[\mathrm{Ru}(\mathrm{bpd})(\mathrm{bpy})_{2}\right]\left(\mathrm{PF}_{6}\right)(\mathrm{bpy}=$ 2,2'-bipyridine, bpd = 3-Bromo-2,4-pentanedionate ion) and [Ru(tipsepd)(bpy) $\left.{ }_{2}\right]\left(\mathrm{PF}_{6}\right)$ \{tipsepd $=3-(($ triisopropylsilyl)ethynil)-2,4-pentanedionate ion $\}$ were then prepared as candidates for building blocks. Also, microwave-assisted synthesis method enabled the preparation of the (tris-acetylacetonate)(2,9-dimethyl-4,7-diphenyl-1,10-phenanthrolinate) terbium(III) $\left\{\mathrm{Tb}(\mathrm{acac})_{3}(\mathrm{dmdpphen})\right\}$ complex with outstanding high green luminescence and 
good thermal stability (Nakashima et al, 2008). This complex was expected to be used in functional materials for electronic products. Zirconium acetylacetonate, $\mathrm{Zr}(\mathrm{acac})_{4}$, was prepared from its hydrate $\mathrm{Zr}(\mathrm{acac})_{4} \cdot 10 \mathrm{H}_{2} \mathrm{O}$ by microwave dehydration of the latter (Berdonosov et al, 1992). Additionally, a convenient method for ${ }^{68} \mathrm{Ga}-$ labeling under anhydrous conditions using solid-phase derived gallium-68-acetylacetonate $\left\{\left[{ }^{68} \mathrm{Ga}\right] \mathrm{Ga}(\mathrm{acac})_{3}\right\}$ in a microwave-enhanced radiosynthesis was offered (Zoller et al, 2010). ${ }^{68} \mathrm{Ga}$ was absorbed quantitatively in a cation exchange resin; more than $95 \%$ of the generator-eluted ${ }^{68} \mathrm{Ga}$ was obtained from the cation exchange resin with a $98 \%$ acetone/ $2 \%$ acetylacetone mixture providing $\left[{ }^{68} \mathrm{Ga}\right] \mathrm{Ga}(\mathrm{acac})_{3}$ as labeling agent for further use in labeling porphyrin derivatives $\left({ }^{68} \mathrm{Ga}\right.$-labeled porphyrins may facilitate the medical application for molecular imaging via positron emission tomography).

$M W$-decomposition of metal acetylacetonates is represented much more frequently. Thus, silicalite (Si-MFI) zeolite crystals with incorporated tetravalent metal ions were used to MWsynthesize metallosilicalite (M-MFI; $\mathrm{M}=\mathrm{Sn}, \mathrm{Zr}, \mathrm{Sn} / \mathrm{Zr}, \mathrm{Ti} / \mathrm{Zr}$ ) zeolites crystals (Hwang et al, 2006). Acetylacetonates were applied as chelating ligands of the metal precursors, to reduce their hydrolysis rates and, therefore, to enhance framework incorporation of each metal in the syntheses of M-MFI zeolites. The resulting zeolite crystals formed showed puck-like morphology and were stacked to form fibers with the degree of self-assembly varied depending on the nature of the tetravalent metal ion used. Chromium-substituted $\beta$ diketonate complexes of aluminum were synthesized and employed as precursors for a "soft chemical" process, wherein $\mathrm{MWH}$ of a solution of the complex yielded, within minutes, well-crystallized needles of $\alpha-\left(\mathrm{Al}_{1-x} \mathrm{Cr}_{x}\right)_{2} \mathrm{O}_{3}$ measuring 20-30 $\mathrm{nm}$ in diameter and $50 \mathrm{~nm}$ long (Gairola et al, 2009). By varying the microwave irradiation parameters and using a surfactant such as polyvinyl pyrrolidone, the crystallite size and shape can be controlled and their agglomeration prevented. Mg-Al hydrotalcite-like compounds $\{\mathrm{HT}$, $\left.\mathrm{Mg}_{6} \mathrm{Al}_{2}\left(\mathrm{CO}_{3}\right)(\mathrm{OH})_{16} \bullet 4\left(\mathrm{H}_{2} \mathrm{O}\right)\right\}$ were prepared by the microwave method with ethoxideacetylacetonate or acetylacetonate as precursors (Paredes et al, 2006; Paredes et al, 2006). Hydrotalcites prepared with ethoxide-acetylacetonate were found to be better sorbents for 131I- than those with acetylacetonate. Also, it was established that organic residues presented in the samples prepared by the microwave method favored the sorption of radioactive anions, in particular 131 I- if compared with nitrate and/or carbonate interlayered hydrotalcites. Ferric acetylacetonate, among other iron salts, was used as a precursor to obtain black magnetic $\mathrm{Fe}_{3} \mathrm{O}_{4}$ nanoparticles in polyhydric alcohols in presence of surfactants (polyethylene glycol, cetyltrimethylammonium bromide, sodium dodecyl benzene sulfonate, etc.) and cosolvents (ethylenediamine, formamide, 1,4-butanediamine and/or butanolamine) (Gao et al, 2009). The product can be used in biomedical, mechanic or electronic fields with strong magnetism, controllable size, and good dispersibility. Additionally, as described in a related work (Bilecka et al, 2008),highly crystalline metal oxide nanoparticles such as $\mathrm{CoO}, \mathrm{ZnO}, \mathrm{Fe}_{3} \mathrm{O}_{4}, \mathrm{MnO}, \mathrm{Mn}_{3} \mathrm{O}_{4}$, and $\mathrm{BaTiO}_{3}$ were synthesized in just a few minutes by reacting metal alkoxides, acetates or acetylacetonates with benzyl alcohol under microwave heating. At last, organically dispersible nanoalloys were prepared from mixture of salts and metal acetates/acetylacetonates in oleyamine (OAm) and oleic acid (OA), for instance $\mathrm{Pd}(\mathrm{acac})_{2}-\mathrm{Ni}\left(\mathrm{HCO}_{2}\right)_{2}$-OAm-OA (nanoalloy $\mathrm{PdNi}$ ) or $\mathrm{Ag}(\mathrm{ac})-\mathrm{Cu}(\mathrm{ac})_{2}-$ OAm-OAc (AgCu) (Abdelsayed et al, 2009). High activity and thermal stability have been observed for the nanoalloys according to the order $\mathrm{CuPd}>\mathrm{CuRh}>\mathrm{AuPd}>\mathrm{AuRh}>\mathrm{PtRh}>\mathrm{PdRh}>\mathrm{AuPt}$. 
CVD techniques have been successfully applied to decompose metal complexes, in particular microwave plasma aerosol-assisted chemical vapor deposition (MWAACVD), which was used, among other varieties of AACVD, to prepare $\mathrm{Y}_{2} \mathrm{O}_{3}$ stabilized $\mathrm{ZrO}_{2}, \mathrm{Y}_{2} \mathrm{O}_{3}$ doped $\mathrm{CeO}_{2}, \mathrm{Gd}_{2} \mathrm{O}_{3}$ doped $\mathrm{CeO}_{2}$ and $\mathrm{La}_{0.8} \mathrm{Sr}_{0.2} \mathrm{MnO}_{3}$ thin films on various ceramic substrates starting froml $\beta$-diketonate chelates as the source materials (Meng et al, 2004). Amorphous $\mathrm{GaF}_{3}$ and $\mathrm{GaF}_{3}-\mathrm{BaF}_{2}$ thin films were synthesized by electron cyclotron resonance microwave plasma-enhanced CVD (MWPECVD) using metal $\beta$-diketonates and a $\mathrm{NF}_{3}$ gas as starting materials and a fluorinating reagent, respectively (Takahashi et al, 2003). A thin zirconia electrolyte film for a solid oxide fuel cell was prepared on a porous $\mathrm{Al}_{2} \mathrm{O}_{3}$ substrate by MPE CVD using two zirconia sources: zirconium acetylacetonate and zirconium tetra- $n$-butylate (Okamura et al, 2003). As-deposited electrolyte film grown indicated the columnar structure, but this was deformed to a crystal structure with a large crack or pore occurred at grain boundary in film by annealing at $400^{\circ} \mathrm{C}$. Additionally, MWPECVD was shown to be a promising method for the solvent free preparation of catalytic materials (Dittmar \& Herein, 2009), such as, for example catalytic active chromia species on zirconia and lanthanum doped zirconia supports. During this process, the adsorption of $\mathrm{Cr}(\mathrm{acac})_{3}$ probably took place by cleavage of one ligand on both supports. Furthermore, the utilization of the PECVD method can inhibit the formation of large $\mathrm{CrO}_{x}$ agglomerates or $\alpha-\mathrm{Cr}_{2} \mathrm{O}_{3}$ on both supports and, after upscaling, this method can be used for the preparation of catalysts for fine chemicals in larger scale. In a related work (Dittmar et al, 2004), where cobalt oxide supported on titania, $\mathrm{CoO}_{x} / \mathrm{TiO}_{2}$, was obtained starting from cobalt(III) acetylacetonate, $\mathrm{Co}(\mathrm{acac})_{3}$, (precursor) and $\mathrm{TiO}_{2}$ (support), the $\mathrm{Co}(\mathrm{acac})_{3}$ was evaporated and adsorbed on carrier surface in a first step and afterwards decomposed during the microwave-plasma treatment in oxygen atmosphere. Volatile copper(II) acetylacetonate was used for preparation of copper thin films in $\mathrm{Ar}-\mathrm{H}_{2}$ atmosphere at ambient temperature by MWPECVD (Pelletier et al, 1991). The formed pure copper films with a resistance of 2-3 $\mu \Omega \cdot \mathrm{cm}$ were deposited on $\mathrm{Si}$ substrates. It was noted that oxygen atoms were never detected in the deposited material since $\mathrm{Cu}-\mathrm{O}$ intramolecular bonds were totally broken by microwave plasma-assistant decomposition of the copper complex.

Additionally to the examples described above on the use of $\beta$-diketonate-alkoxide mixtures, alkoxides themselves were also reported as precursors for MW-obtaining of inorganic films and structures. Thus, synthesis of $\mathrm{TiO}_{2}$ and $\mathrm{V}$-doped $\mathrm{TiO}_{2}$ thin layers was significantly improved and extended under application of microwave energy during the drying and/or calcination step (Zabova et al, 2009). Thin nanoparticulate titania layers were prepared via the sol-gel method using titanium $n$-butoxide as a precursor. The photocatalytic activities of prepared layers were quantified by the decoloring rate of Rhodamine B.

Another type of coordination compounds, molecular adducts of alcohols of the composition VOPO $_{4} \cdot \mathrm{C}_{n} \mathrm{H}_{2 n+1} \mathrm{OH}$ (1-alkanols, $\left.\mathrm{n}=1-18\right)$ and $\mathrm{VOPO}_{4} \cdot \mathrm{C}_{\mathrm{n}} \mathrm{H}_{2 \mathrm{n}}(\mathrm{OH})_{2}$ (1, $\omega$-alkanediols, $\left.\mathrm{n}=2-10\right)$ were prepared long ago (Beneš et al, 1997) by the direct reaction of various liquid alcohols with solid and finely ground $\mathrm{VOPO}_{4} \cdot 2 \mathrm{H}_{2} \mathrm{O}$ in a $\mathrm{MW}$ field. According to X-ray diffraction data, the structures of all these polycrystalline complexes retained the original layers of $\left(\mathrm{VOPO}_{4}\right)_{\infty}$. Alcohol molecules were placed between the host layers in a bimolecular way, being anchored to them by donor-acceptor bonds between the oxygen atom of an $\mathrm{OH}$ group and a vanadium atom as well as by hydrogen bonds. Other adducts, $\left[(n \text {-Bu })_{4} \mathrm{~N}\right]\left[\mathrm{TlMS}_{4}\right]$ $(\mathrm{M}=\mathrm{Mo}, \mathrm{W})$, were also prepared in the conditions of microwave treatment and their nonlinear optical properties were studied (Lang et al, 1996). 


\subsection{Carboxylates}

MW-synthesized carboxylates are represented mainly by aromatic derivatives possessing multiple carboxylic groups. These complexes are sometimes isolated as adducts with stabilizing ligands as 2,2'-bipy or 1,10-phen, as well as solvent molecules. Thus, by treating $\mathrm{Cu}\left(\mathrm{NO}_{3}\right)_{2} \cdot 3 \mathrm{H}_{2} \mathrm{O}$ with a $\mathrm{V}$-shaped ligand 4,4'-oxydibenzoic acid $\left(\mathrm{H}_{2} \mathrm{Oba}\right)$, a dynamic metalcarboxylate framework $\left[\mathrm{Cu}_{2}(\mathrm{oba})_{2}(\mathrm{DMF})_{2}\right] \cdot 5.25 \mathrm{DMF} \quad(\mathrm{MCF}-23 ; \mathrm{DMF}=\mathrm{N}, \mathrm{N}-$ dimethylformamide) was synthesized, which features a wavelike layer with rhombic grids based on the paddle-wheel secondary building units (Wang et al, 2008). These layers stack via strong offset $\pi-\pi$ stacking of the Ph groups of oba ligands to give 3D porosity. A MWAS solvothermal method was proven to be a faster and greener approach to synthesize phasepure MCF-23 in high yield without impurities, typical for conventional synthesis. In contrast, the product obtained by the conventional solvothermal method was not phasepure. Two isostructural coordination polymers, $\mathrm{M}_{3}(\mathrm{NDC})_{3}(\mathrm{DMF})_{4}\left(\mathrm{M}=\mathrm{Co}, \mathrm{Mn} ; \mathrm{H}_{2} \mathrm{NDC}=\right.$ 2,6-naphthalenedicarboxylic acid), crystallizing in the monoclinic system with space group $\mathrm{C} 2 / \mathrm{c}$, were prepared through conventional and MWAS solvothermal methods (Liu et al, 2008). These microporous cobalt(II) and manganese(II) coordination polymers underwent reversible structural change upon desolvating, giving stable microporous frameworks containing unsaturated metal sites.

Trimesic acid $\mathbf{1}$ and its analogue, containing four carboxylate units, have been reported in a series of publications related to MWAS of metal complexes. Thus, two isostructural coordination polymers $(\mathrm{EMim})_{2}\left[\mathrm{M}_{3}(\mathrm{TMA})_{2}(\mathrm{OAc})_{2}\right](\mathrm{M}=\mathrm{Ni}$ or $\mathrm{Co}$, EMim = 1-ethyl-3methylimidazolium, $\mathrm{H}_{3} \mathrm{TMA}=$ trimesic acid) with anionic metal-organic frameworks were synthesized under microwave conditions using an ionic liquid EMIm-Br as solvent and template (Lin et al, 2006). In a related report, the microwave solvothermal reaction of nickel nitrate with trimesic acid provided the $\left[\mathrm{Ni}_{3}(\mathrm{BTC})_{2}\left(\mathrm{H}_{2} \mathrm{O}\right)_{12}\right]_{n} \quad(\mathrm{BTC}=$ benzene-1,3,5tricarboxylate anion of trimesic acid), which is a metal coordination polymer composed of 1D zigzag chains (Hsu et al, 2009). In the asymmetric unit, two types of Ni atoms were found: one of the $\mathrm{NiO}_{6}$ groups was coordinated to only one carboxylate group and thus terminal, the other is bridging, forming the coordination polymer. Magnesium coordination polymers, $\left[\mathrm{Mg}_{2}(\mathrm{BTEC})\left(\mathrm{H}_{2} \mathrm{O}\right)_{4}\right] \cdot 2 \mathrm{H}_{2} \mathrm{O}$, $\left[\mathrm{Mg}_{2}(\mathrm{BTEC})\left(\mathrm{H}_{2} \mathrm{O}\right)_{6}\right]$, and $\left[\mathrm{Mg}_{2}(\mathrm{BTEC})\left(\mathrm{H}_{2} \mathrm{O}\right)_{8}\right](\mathrm{BTEC}=$ $1,2,4,5$-benzenetetracarboxylate anion), were synthesized from magnesium nitrate and 1,2,4,5-benzenetetracarboxylic acid with variable ratios of organic base under MW solvothermal reactions at $150-180^{\circ} \mathrm{C}$ (Liu et al, 2009). Structure of MW-synthesized complex $\left\{\left[\mathrm{Co}_{2}\left(\mathrm{C}_{2} \mathrm{O}_{4}\right)\left(\mathrm{C}_{6} \mathrm{H}_{2}(\mathrm{COO})_{4}\right)\left(\mathrm{H}_{2} \mathrm{O}\right)\right]_{4} \cdot 4 \mathrm{H}_{2} \mathrm{O} \cdot\left(\mathrm{NH}_{2} \mathrm{CH}_{2} \mathrm{COOH}\right)\right\}_{n}$ (crystallized in the monoclinic system and the space group $\mathrm{Cc}$ ), had a flattened octahedral configuration ( $\mathrm{Xu} \& \mathrm{Fan}, 2007)$. Three mixed-ligand cobalt(II) complexes $\left[\mathrm{Na}_{2} \mathrm{Co}\left(\mu_{4}-\mathrm{btec}\right)\left(\mathrm{H}_{2} \mathrm{O}\right)_{8}\right]_{n}, \quad\left[\mathrm{Co}_{2}\left(\mu_{2}-\right.\right.$ btec)(bipy) $\left.)_{2}\left(\mathrm{H}_{2} \mathrm{O}\right)_{6}\right] \cdot 2 \mathrm{H}_{2} \mathrm{O}$, and $\left[\mathrm{Co}_{2}\left(\mu_{2}\right.\right.$-btec $\left.)(\text { phen })_{2}\left(\mathrm{H}_{2} \mathrm{O}\right)_{6}\right] \cdot 2 \mathrm{H}_{2} \mathrm{O} \quad\left(\mathrm{H}_{4}\right.$ btec $=1,2,4,5-$ benzenetetracarboxylic acid, bipy $=2,2^{\prime}$-bipyridine, phen $=1,10$-phenanthroline) were synthesized using hydrothermal and microwave methods (Shi et al, 2009). All three complexes were found to be bridged by the ligands to form 3D (first complex) and binuclear (other complexes) structures.

Three isostructural 2D metal-organic frameworks, $\left[\mathrm{M}\left(\text { bpydc) }\left(\mathrm{H}_{2} \mathrm{O}\right) \cdot \mathrm{H}_{2} \mathrm{O}\right]_{n}\right.$ (where $\mathrm{M}=\mathrm{Zn}$; $\mathrm{Co}$; $\mathrm{Ni}$ and bpydc is 2,2'-bipyridine-5,5'-dicarboxylate), were prepared by hydrothermal, ultrasonic and MWAS methods (Huh et al, 2010).The coordination environment of the metal ions was found to be a distorted octahedral geometry. The metal ions were found to be coordinated by two nitrogen atoms from the bipyridyl moiety, two oxygen atoms from one 


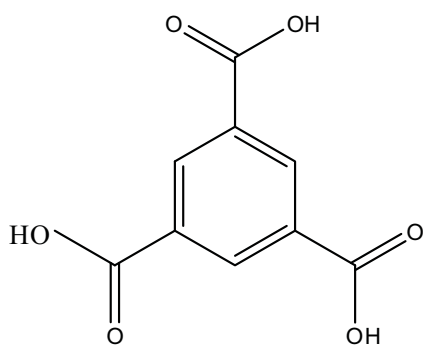

1

carboxylate in a bidentate manner, one oxygen atom from another carboxylate in a monodentate manner, and one oxygen atom from the aqua ligand. [ $\left.\mathrm{Zn}(\mathrm{bpydc})\left(\mathrm{H}_{2} \mathrm{O}\right) \cdot \mathrm{H}_{2} \mathrm{O}\right]_{n}$ displayed strong solid state blue luminescence. Additionally, the green synthesis of a variety of 3,4-disubstituted-1-H-pyrrole-2-carboxylates was described (Dickhoff et al, 2006).

As an example of MW-decomposition of metal carboxylates leading to nanostructures, $\mathrm{Ni}$ nanoparticles with average sizes of 43,71, and $106 \mathrm{~nm}$ were obtained by the intramolecular reduction of $\mathrm{Ni}^{2+}$ ion contained in a formate complex having long-chain amine ligands \{oleylamine $(=(Z)-9$-octadecenylamine), myristylamine (=tetradecylamine), and laurylamine (=dodecylamine)\} within an extremely short time under MW conditions (Yamauchi et al, 2009). Formate ion coordinated to $\mathrm{Ni}^{2+}$ ion acted as a reducing agent for $\mathrm{Ni}^{2+}$ in this reaction and finally decomposed to hydrogen and carbon dioxide. Also, microwave synthesis of metal oxide nanoparticles, $\gamma-\mathrm{Fe}_{2} \mathrm{O}_{3}, \mathrm{NiO}, \mathrm{ZnO}, \mathrm{CuO}$ and $\mathrm{Co}-\gamma-\mathrm{Fe}_{2} \mathrm{O}_{3}$ were carried out by microwave-assisted route through the thermal decomposition of their respective metal oxalate precursors employing polyvinyl alcohol as a fuel (Lagashettya et al, 2007).

\subsection{Nitrogen-containing ligands}

$\mathrm{N}$-Containing ligands are widely represented (although lesser in comparison with N,Oligands) by substituted derivatives of classic heterocycles with $1 \div 3$ nitrogen atoms (Table 1 ), such as azoles, azines (in particular polypyridines), frequently together with carboxylate anions (see also the section on $\mathrm{N}, \mathrm{O}$-containing ligands) or $\mathrm{CO}$-groups. Thus, among azole complexes, MWAS of the neutral complex fac- $\left[\operatorname{ReL}(\mathrm{CO})_{3} \mathrm{Cl}\right]$ and isomers thereof were carried out by reacting the chelating ligand 4-[4,6-bis(3,5-dimethyl-1H-pyrazol-1-yl)-1,3,5-triazin-2yl]-N,N-diethyl-benzenamine, L, with pentacarbonylchlororhenium in toluene (Salazar et al, 2009). Further substitution of the carbonyl and/or the chloride attained multiple products with remarkable luminescence properties that included thermochromism, rigidochromism, solvatochromism, and/or vapochromism. Cobalt(II) pyrazolate metal-organic frameworks comprising bridging bis-pyrazolyl ligands $\left(3,5-\mathrm{R}_{1,2} \mathrm{C}_{3} \mathrm{HN}_{2}\right)-\left(1,4-\mathrm{C}_{6} \mathrm{H}_{3} \mathrm{R}_{2}\right)_{n}-\left(3,5-\mathrm{R}_{1,2} \mathrm{C}_{3} \mathrm{HN}_{2}\right)$ $\left(\mathrm{C}_{3} \mathrm{H}_{3} \mathrm{~N}_{2}=1 \mathrm{H}\right.$-pyrazol-4-yl; $\mathrm{n}=0-3, \mathrm{R} 1, \mathrm{R}^{2}=\mathrm{H}$, halo, $\mathrm{CF}_{3}, \mathrm{OH}, \mathrm{NH}_{2}, \mathrm{CHO}, \mathrm{C}_{1-6}$ alkyl, alkenyl, alkynyl, alkoxy), tetrahedrally coordinated to $\mathrm{Co}(\mathrm{II})$ ions, useful as redox-active materials, oxidation catalysts, adsorbents and storage materials for $\mathrm{H}_{2}$ and methane, gas sensors, were prepared by conventional or MWH of solutions containing $\mathrm{Co}(\mathrm{II})$ salts with $\mathrm{F}^{-}, \mathrm{Cl}^{-}, \mathrm{Br}^{-}, \mathrm{I}^{-}$, $\mathrm{NO}_{3}^{-}, \mathrm{SO}_{4}^{2-}, \mathrm{AcO}-$ anions, and the bis-pyrazolyl ligands above in water, $\mathrm{MeOH}, \mathrm{EtOH}, \mathrm{DMF}$, $\mathrm{N}, \mathrm{N}$-diethylformamide, $\mathrm{PhCl}, \mathrm{N}$-methylpyrrolidone at $80-140^{\circ} \mathrm{C}$ for $1-150 \mathrm{~h}$ (Bahnmueller et al, 2009). The complex $\left[\mathrm{ReO}_{3}\left\{\mu_{3}-\mathrm{SO}_{3} \mathrm{C}(\text { pyz) })_{3}\right\}\right] \mathbf{2}$ was prepared in $42 \%$ yield by reacting lithium tris(1-pyrazolyl)methanesulfonate with rhenium(VII) oxide in water at ambient temperature during $5 \mathrm{~h}$ (or $30 \mathrm{~min}$ under microwave irradiation at $20^{\circ} \mathrm{C}$ ) (Pombeiro et al, 
2007). These complexes were used as catalysts in the following reactions: a) partial oxidation of ethane into acetic acid or its carboxylation into propionic acid in the atmosphere of $\mathrm{CO} ; \mathrm{b}$ ) partial oxidation of ethane into acetaldehyde; c) partial peroxidative oxidation of cyclohexane into cyclohexanol and cyclohexanone.

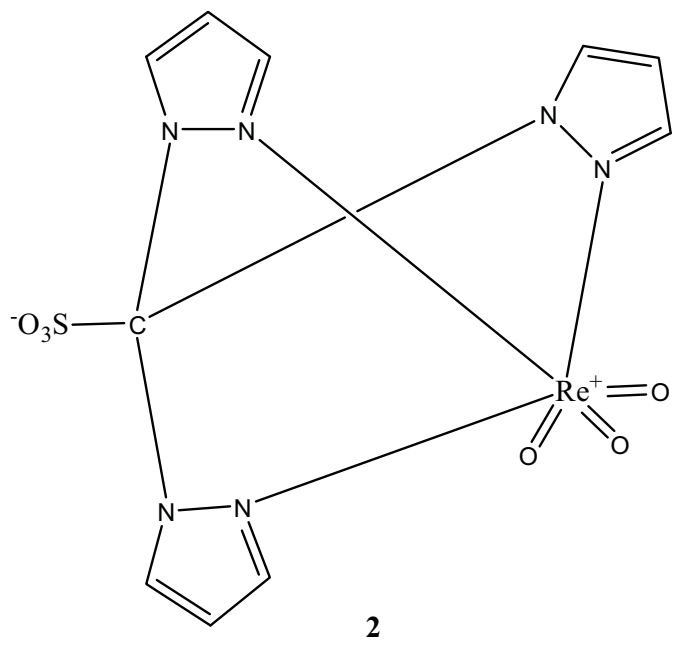

Benzimidazole complexes have also been MW-prepared. Thus, a cobalt(II) complex, [Co( $\left.\left(\mathrm{H}_{2} \text { bzimpy }\right)_{2}\right]\left(\mathrm{ClO}_{4}\right)_{2}$, with tridentate ligand 2,6-bis(benzimidazol-2-yl)pyridine ( $\mathrm{H}_{2}$ bzimpy) was synthesized by microwave irradiation method (Tan et al, 2004). The bis(2benzimidazolylmethyl)amine was synthesized under the microwave irradiation, and the complex $\left(\left[\mathrm{DyL}_{2}\left(\mathrm{NO}_{3}\right)_{2}\right] \mathrm{NO}_{3}\right) \quad$ \{where $\mathrm{L}$ is bis(2-benzimidazolylmethyl)amine was synthesized (Ouyang et al, 2009). The dysprosium (III) complex was found to bind to DNA base pairs by partial intercalation and electrostatic binding. Additionally, pincer-type, pyridine-bridged bis(benzimidazolylidene)-palladium complexes $3\left(\mathrm{R}=n-\mathrm{C}_{16} \mathrm{H}_{33}, \mathrm{X}=\mathrm{Br}\right.$; $\mathrm{R}$ $=n-\mathrm{C}_{16} \mathrm{H}_{33}, \mathrm{X}=\mathrm{I} ; \mathrm{R}=n-\mathrm{C}_{8} \mathrm{H}_{17}, \mathrm{X}=\mathrm{I} ; \mathrm{R}=n-\mathrm{C}_{4} \mathrm{H}_{9}, \mathrm{X}=\mathrm{I}$ ) were synthesized from cheap commercial precursors under microwave assistance

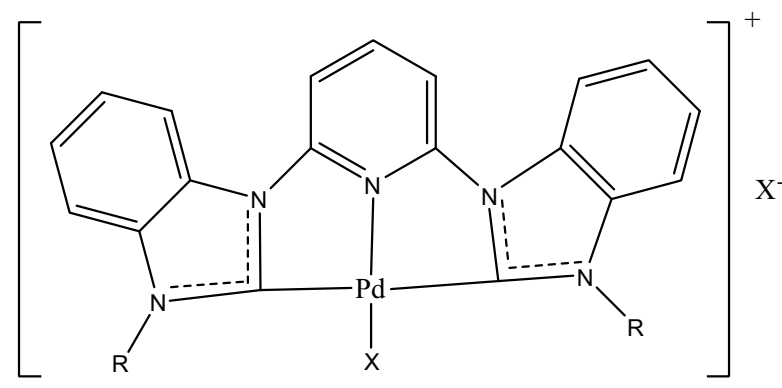

3

Among azine metallocomplexes, cyclometalated chloroplatinum complexes containing neutral monodentate ligands such as 2-phenylpyridine, 2-(2'-thienyl)pyridine or 4- 
methoxypyridine, as well as the cyclometalated benzo[h]quinoline chloride complex with 4methoxypyridine, were synthesized in a few minutes in $63-99 \%$ yields by irradiating the reaction mixture with microwaves (Godbert et al, 2007). The availability of this class of complexes in a few minutes offers the possibility of a combinatorial approach for the preparation of libraries of homologous compounds of potential interest for large-scale screening studies. MWAS of $\left[\mathrm{Cu}_{2}(\mathrm{pz})_{2}\left(\mathrm{SO}_{4}\right)\left(\mathrm{H}_{2} \mathrm{O}\right)_{2}\right]_{n}(\mathrm{pz}=$ pyrazine) produced monocrystal suitable for X-ray diffraction studies, reducing reaction time and with higher yield than the classical hydrothermal procedures (Amo-Ochoa et al, 2007). The iridium complexes, obtained by cyclometalation of 5-(3-cyanophenyl)-2,3-diphenylpyrazine by $0.22 \mathrm{~g}$ of $\mathrm{IrCl}_{3} \cdot \mathrm{H}_{2} \mathrm{O}$ in 2-ethoxyethanol under a $100 \mathrm{~W}$ MW for $30 \mathrm{~min}$, featured emission at $632 \mathrm{~nm}$ in chloroform solution, by reaction with sodium acetylacetonate (Inoue \& Seo, 2010). The products were found to be useful as a phosphorescent compound for use in organic lightemitting devices. MWAS of the ligands bis(2-pyridylmethyl)amine (BMPA), Me 3-[bis(2pyridylmethyl)amino]propanoate (MPBMPA), 3-[bis(2-pyridylmethyl)amino]propanamide (PABMPA), 3-[bis(2-pyridylmethyl)amino]propionitrile (PNBMPA), (3-aminopropyl)bis(2pyridylmethyl)amine (APBMPA), and lithium 3-[bis(2-pyridylmethyl)amino]propanoate (LiPBMPA) were reported (Pimentel et al, 2007). A series of 2-(1-alkyl/aryl-1H-1,2,3-triazol4-yl)pyridine (pytrz) ligands were synthesized using microwave-assisted Huisgen-MeldalFokin 1,3-dipolar cycloaddition and were used to prepare homoleptic and heteroleptic ruthenium(II) complexes with 4,4'-dimethyl-2,2'-bipyridine as second ligand (Happ, 2009). The iridium-quinoxaline complex 4 (where $X$ is $H$ or $F$ ) was prepared from iridium trichloride hydrate as metal source precursor in ethylene glycol by $\mathrm{MWH}$ for 4-5 min (Zhang et al, 2008). The complex had high solubility in common organic solvents, and can be used as electrophosphorescent material with high luminescence efficiency.

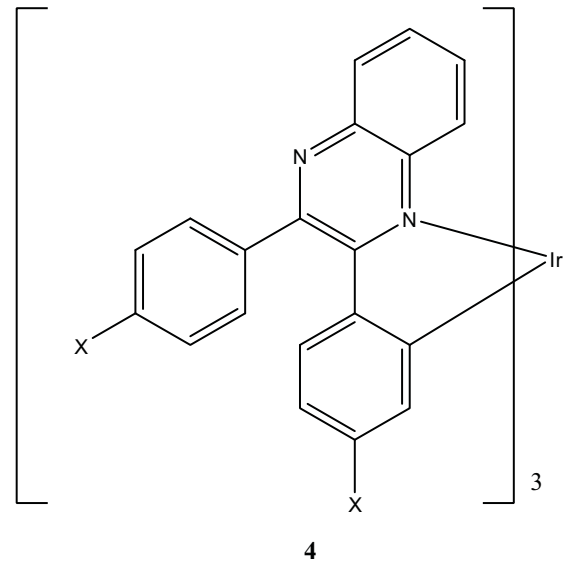

Complexes of such classic polypyridine ligands as 2,2'- or 4,4'-bipyridine (bipy) for closely related 1,10-phenantroline (phen), which in terms of its coordination properties is similar to 2,2'-bipyridine $\}$ and their derivatives were also prepared by $\mathrm{MWH}$, for instance $\left[\mathrm{Co}\right.$ (phen) $\left.{ }_{2} \mathrm{Cl}_{2}\right] \mathrm{ClO}_{4}$ (Jin et al, 2009). A metal organic-inorganic coordination framework formulated as $\left\{\left[\mathrm{Cu}\left(4,4^{\prime} \text {-bipy) }\left(\mathrm{H}_{2} \mathrm{O}\right)_{3}\left(\mathrm{SO}_{4}\right)\right] \cdot 2 \mathrm{H}_{2} \mathrm{O}\right\}_{n}\right.$ were similarly synthesized (Phetmung et al, 2009). The resulting compound was an $1 \mathrm{D}$ polymer in which 4,4'-bipy acted as a bridging ligand supporting the formation of infinite $\left[\mathrm{Cu}\left(4,4^{\prime}\right.\right.$-bipy $\left.)\left(\mathrm{H}_{2} \mathrm{O}\right)_{3}\left(\mathrm{SO}_{4}\right)\right]$ chains. Several 
reports are dedicated to noble metals, in particular ruthenium complexes; thus, microwave mediated reaction of $\left[\mathrm{Ru}(\mathrm{COD}) \mathrm{Cl}_{2}\right]_{n}$ with 4,4'-di-tert-butyl-2,2'-bipyridine (tbbpy) in DMF gave $97.5 \% \mathrm{Ru}$ (tbbpy) ${ }_{2} \mathrm{Cl}_{2}$ which on treatment with 5,5',6,6'-tetramethyl-2,2'-bibenzimidazole (tmbibim) $/ \mathrm{NH}_{4} \mathrm{PF}_{6}$ gave $63 \% \quad\left[\mathrm{Ru}(\text { tbbpy })_{2}(\right.$ tmbibim) $]\left(\mathrm{PF}_{6}\right)_{2}$ (Walther et al, 2005). Ruthenium(II) polypyridine complex $\left[\mathrm{Ru}(\mathrm{Hdpa})_{3}\right]\left(\mathrm{ClO}_{4}\right)_{2}\{\mathrm{Hdpa}=$ bis(2-pyridyl)amine $\}$ was prepared from $\mathrm{RuCl}_{3} \cdot 3 \mathrm{H}_{2} \mathrm{O}$ in a few minutes in 91\% yield (Xiao et al, 2002). Poly(bipyridine)ruthenium complexes $\left[\mathrm{RuCl}_{2}(\mathrm{dcmb})_{2}\right]\left(\mathrm{dcmb}=4,4^{\prime}\right.$-dimethoxycarbonyl-2,2'bipyridine $)$ and $\left[\mathrm{Ru}(\mathrm{dcmb})_{3-n}(\mathrm{tbbpy})_{n}\right]\left(\mathrm{PF}_{6}\right)_{2}(n=0-3$ and tbbpy $=4,4$ '-di-tert-butyl-2,2'bipyridine) were also synthesized (Schwalbe et al., 2008). With the same tbbpy ligand, the oxodiperoxo complex $\mathrm{MoO}\left(\mathrm{O}_{2}\right)_{2}$ (tbbpy) was isolated from the reaction of $\mathrm{MoO}_{2} \mathrm{Cl}_{2}$ (tbbpy) in water under $\mathrm{MWH}$ at $120^{\circ} \mathrm{C}$ for $4 \mathrm{~h}$ (Amarante, 2009). It was established that the MoVI centre is seven-coordinated with a geometry which strongly resembles a highly distorted bipyramid. The crystal structure is formed by the close packing of the columnar-stacked complexes. Interactions between neighbouring columns are essentially of van der Waals type mediated by the need to effectively fill the available space. The authors noted that their synthesis route was surprising, since all known standard procedures for the synthesis of this type of complex involved a peroxide source such as $\mathrm{H}_{2} \mathrm{O}_{2}$ or tert-butyl hydroperoxide (TBHP). Rh ${ }^{I I I}$ complexes $\left[\mathrm{Ru}(\mathrm{L})_{2}\right]\left[\mathrm{PF}_{6}\right]_{2}\left(\mathrm{~L}=\mathrm{L}^{1}\right.$ or $\left.\mathrm{L}^{2}\right)$ of enantiomerically pure, chiral terpyridyl-type ligands ligands $\mathrm{L}^{1}$ ('dipineno'-[5,6:5",6"]-fused 2,2':6',2"-terpyridine, 2,6bis(6,6-dimethyl-5,6,7,8-tetrahydro-5,7-methanoquinolin-2-yl)pyridine) and L2 ('dipineno'[4,5:4",5"]-fused 2,2':6',2"-terpyridine, 2,6-bis(7,7-dimethyl-5,6,7,8-tetrahydro-6,8methanoisoquinolin-3-yl)pyridine), synthesized in high yields starting from 2,6diacetylpyridine and enantiopure $\alpha$-pinene, with $\mathrm{Rh}^{\mathrm{III}}$ and $\mathrm{Ru}^{\mathrm{II}}$ were prepared (Ziegler et al, 1999) and studied spectroscopically. These complexes had a helically distorted terpyridyl moiety, as shown by the considerable optical activity in the ligand centered and metal to ligand charge transfer transitions. Additionally, the MWAS (from $\mathrm{Bpy}_{2} \mathrm{OsCl}_{2} \cdot 6 \mathrm{H}_{2} \mathrm{O}$ as $\mathrm{Os}$ source) and photophysical properties of heterometallic dinuclear complex based on ruthenium and osmium tris-bipyridine units, $\mathrm{Ru}-\mathrm{mPh}_{3}-\mathrm{Os}(\mathbf{5})$, in which the metal complexes were linked via an oligophenylene bridge centrally connected in the meta position, were described (Aléo et al, 2005).

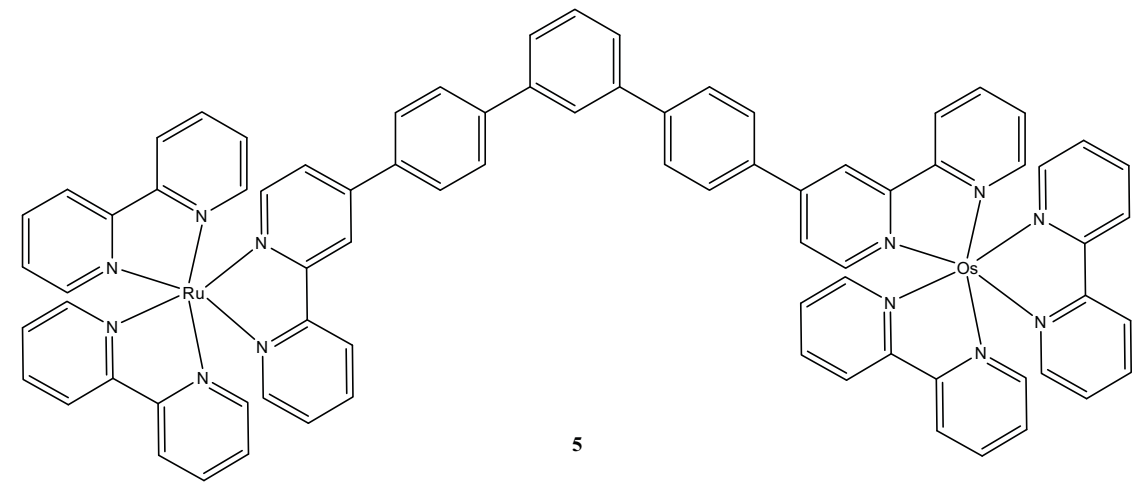

In a difference with acetylacetonates, the $\mathrm{N}$-containing complexes are more rarely applied as precursors using MW-treatment for obtaining metal alloys and nanostructures. Thus, cyanogel coordination polymers (amorphous Prussian blue analogs formed in a hydrogel 
state by the reaction of a chlorometalate with a cyanometalate in aqueous solution) can be thermally auto-reduced to form transition-metal alloys \{binary and ternary transition-metal alloys (Pd/Co, Pt/Co, Ru/Co, Ir/Co, Pd/Ni, Pt/Ni, Pt/Ru, Pd/Fe, Pd/Fe/Co) and intermetallics $\left.\left(\mathrm{Pt}_{3} \mathrm{Fe}, \mathrm{Pt}_{3} \mathrm{Co}, \mathrm{PtCo}\right)\right\}$, in particular by $\mathrm{MWH}$ (Vondrova et al, 2007). The authors showed that the cyanogel polymers are susceptible to microwave dielectric heating, which leads to a sufficient temperature increase in the sample to cause the reduction of the metal centers, thus allowing for the conversion of cyanogels to metal alloys in a few minutes instead of hours needed in the traditional furnace heating.

\subsection{Porphyrins}

MWAS techniques have been developed for the synthesis and/or rearrangements of both metal-free porphyrins (Yaseen et al, 2009; Hou et al, 2007) and their metal complexes. Thus, several substituted 5,10,15,20-tetraarylporphyrins $\{5,10,15,20$-tetraphenylporphyrin, 5,10,15,20-tetrakis(4-chlorophenyl)porphyrin, and 5,10,15,20-tetrakis(3hydroxyphenyl)porphyrin\} and insertion of five different transition metals into the porphyrin core were achieved with high yields using MW (Nascimento et al, 2007). Experimental protocols were characterized by extremely short reaction times and quite small quantities of solvents employed. 5,10,15,20-Tetrakis(2-pyridyl)porphyrin $\left(\mathrm{H}_{2} \mathrm{TPyP}\right)$ and its complex, $\mathrm{Mn}(\mathrm{III}) \mathrm{TPyP}$, were synthesized under $\mathrm{MWH}$ in the presence of propionic acid (Zhang et al, 2006). A tetrakis(terpyridinyl)porphyrin derivative and its $\mathrm{Ru}^{\mathrm{II}}$ complexes, obtained through microwave-enhanced synthesis, were found to have photovoltaic properties and nanowire self-assembly (Jeong et al, 2007). Condensation adducts of the $\mathrm{Ni}(\mathrm{II})$ and $\mathrm{Cu}(\mathrm{II})$ complexes of $\beta$-amino-meso-tetraphenylporphyrin with di-Me acetylenedicarboxylate (DMAD) and di-ethylethoxymethylenemalonate were converted into the corresponding esters of pyridinone-fused porphyrins by using different cyclization protocols, including MW (Silva et al, 2009), resulting high yields in a short period of time under closed-vessel conditions. Soluble 5,10,15,20-tetrakis(4-tertbutylphenyl)metalloporphyrins [M(TBP), $\mathrm{M}=\mathrm{Mg}, \mathrm{Cu}, \mathrm{Tb}(\mathrm{OAc}), \mathrm{Lu}(\mathrm{OAc}), \mathrm{La}(\mathrm{OAc})]$ were rapidly synthesized by microwave irradiation from 5,10,15,20-tetrakis(4-tertbutylphenyl)porphyrins $\left[\mathrm{H}_{2}(\mathrm{TBP})\right]$ or from pyrrole and 4-tert-butylbenzaldehyde with appropriate metal salts (Liu et al, 2005). The observed fluorescent properties of metalloporphyrins depend on their central metals due to heavy-atom effect. In a related work, soluble 5,10,15,20-tetrakis(4-tert-butylphenyl)magnesium porphyrins $\{\mathrm{Mg}(\mathrm{TBP})\}$, perylene tetracarboxylic derivative [N,N'-bis(1,5-dimethylhexyl)-3,4:9,10perylenebis(dicarboximide), $\mathrm{PDHEP}]$, and porphyrin-perylene tetracarboxylic complex were quickly prepared under MWH (Liu et al, 2004). It was revealed that porphyrin-perylene tetracarboxylic complex exhibited better fluorescent quantum yield and photo-electricity conversion effect than $\mathrm{Mg}(\mathrm{TBP})$ and PDHEP, respectively. MWAS methods were also developed to cleanly produce the tetra(2',6'-dimethoxyphenyl)porphyrin and its $\mathrm{Fe}, \mathrm{Zn}$, and Ni complexes (Wolfel et al, 2009). Additionally, $\mathrm{Cu}$ (II) complexes with asymmetrical (5-(3hydroxyphenyl)-10,15,20-tris-(4-carboxymethylphenyl)-21,23-Cu(II)-porphine) 6 and symmetrical $\quad(5,10,15,20-m e s o-t e t r a k i s-(4-c a r b o x y m e t h y l p h e n y l)-21,23-\mathrm{Cu}(\mathrm{II})$ porphine) $\mathbf{7}$ porphyrinic ligands were synthesized with superior yields using MW to be used in unconventional treatment of various diseases by means of photodynamic therapy (PDT) (Boscencu et al, 2010). The results of the biological in vitro tests indicated a low cytotoxicity 
of the compounds for the studied cells. At last, the one-step $15 \mathrm{~min}$ (instead of $24 \mathrm{~h}$ by classic preparation) synthesis of metalloporphyrazines with enhanced yields directly from substituted maleonitriles, involving tetramerization using hexamethyldisilazane and $p$ toluenesulfonic acid and DMF in a sealed tube under MW (Chandrasekharam et al, 2007).

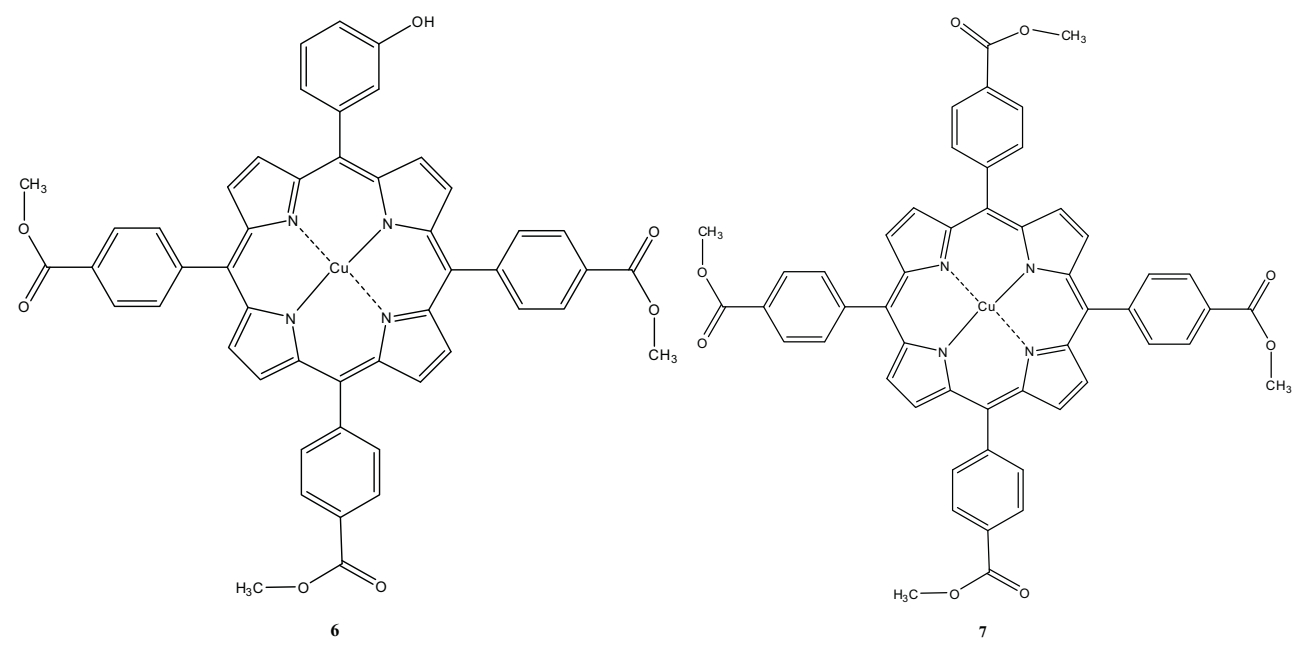

\subsection{Phthalocyanines}

Phthalocyanine $(\mathrm{Pc})$ area is industrially important, in a difference with major part of Ncontaining ligands having an academic interest only, since both metal free phthalocyanines and their several metal complexes $(\mathrm{Cu}, \mathrm{Zn}, \mathrm{Ni}, \mathrm{Fe}$, etc.) are produced during several decades in large quantities and used as pigments, in compact disk production, and catalysis, among many other applications. So, novel techniques for their production are permanently in search, as for classic Pcs as for substituted (generally $\mathrm{R}_{4} \mathrm{Pc}_{\mathrm{c}}$ for symmetrical Pcs; $\mathrm{R}=$ alkyl, aryl, $\mathrm{Cl}, \mathrm{NO}_{2}$, ethers, crowns, etc.). In particular, a variety of metal phthalocyanine complexes has been fabricated via MWH allowing absence of solvents (we note that solvent nature is very important for tetramerization of phthalonitrile and other Pc precursors). Thus, metal substituted octachlorophthalocyanines $(\mathrm{M}=\mathrm{Fe}, \mathrm{Co}, \mathrm{Ni}, \mathrm{Cu}, \mathrm{Zn})$, hexadecachlorophthalocyanines $(\mathrm{M}=\mathrm{Fe}, \mathrm{Co}, \mathrm{Ni}, \mathrm{Cu})$ and tetranitrophthalocyanines $(\mathrm{M}=$ $\mathrm{Fe}, \mathrm{Co}, \mathrm{Ni}, \mathrm{Cu}, \mathrm{Pd}$ ) were synthesized by exposure to $\mathrm{MW}$ under solvent free and reflux conditions (Safari et al, 2004; Shaabani et al, 2003). The synthesis of various axially substituted Ti phthalocyanines in high yield using MW without solvent was reported (Maree, 2005). The times of reaction, as expected, were short (generally <10 min). Substituted Fe and Co octachloro-, tetranitro-, tetracarboxy- or polyphthalocyanines were easily prepared by $\mathrm{MWH}$ of the starting materials under solvent free condition, which reduced reaction time considerably and used as epoxidation catalysts of cyclooctene in homogeneous and heterogeneous conditions by iodosylbenzene as an oxidant (Bahadoran \& Dialameh, 2005). Their catalytic activities showed that the electron withdrawing groups on the phthalocyanine ring have a very small effect on stability of the catalyst during the reactions. The tetrasubstituted metal-free phthalocyanine $8\left(\mathrm{R}=\mathrm{SO}_{2} \mathrm{NH}-p-\mathrm{C}_{6} \mathrm{H}_{4} \mathrm{Me}\right)$ and its 
nickel and zinc metallophthalocyanines bearing four 14-membered tetraaza macrocycles moieties on peripheral positions were synthesized by cyclotetramerization reaction of phthalonitrile derivative $\mathbf{9}$ in a multi-step reaction sequence (Biyiklioglu et al., 2007). Additionally, a reaction mixture containing perfluoro-phthalonitrile reacted in a vessel with application of microwave energy for a reaction period sufficient to yield a fluorinated phthalocyanine (Fraunhofer-Gesellschaft et al, 2009), having wide ranging applications, e.g., corrosion-related applications, coating-related applications, catalysis, and the production of optical and electronic materials.

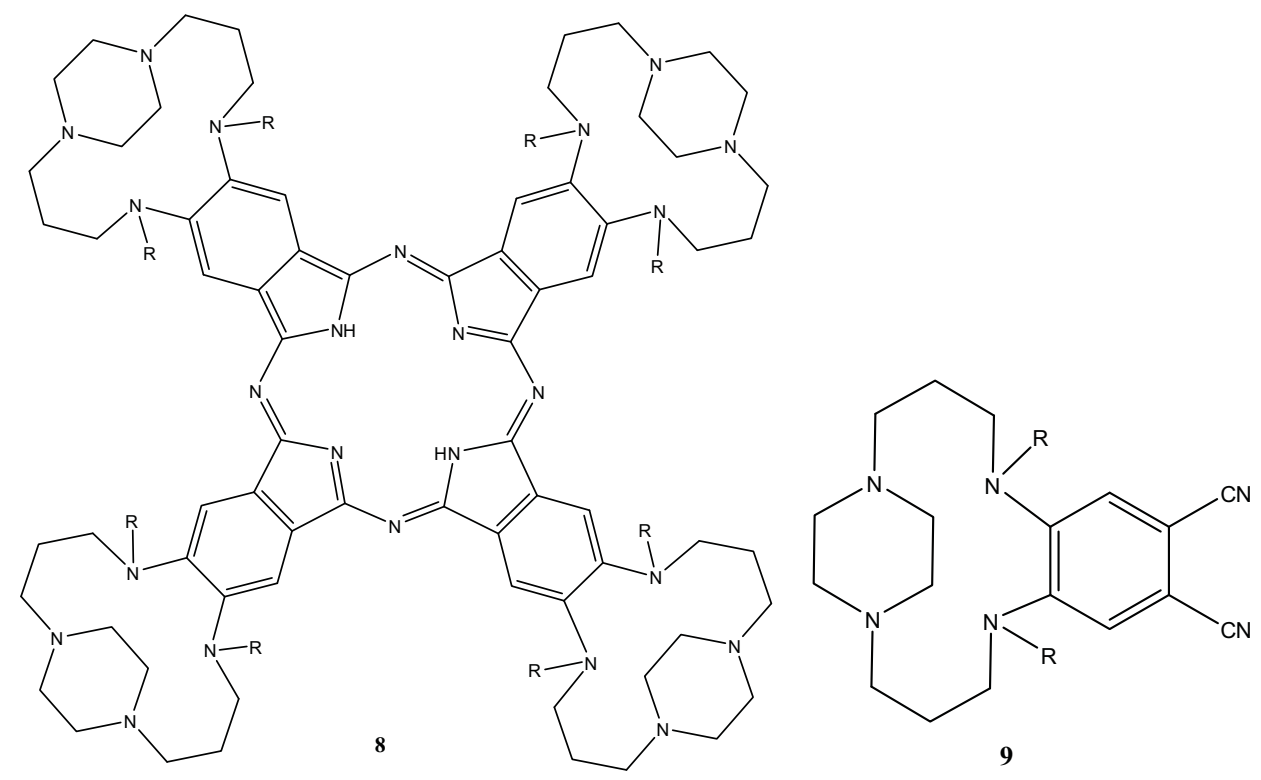

Thermal and microwave reactions between $\left[\mathrm{PcSn}^{\mathrm{IV}} \mathrm{Cl}_{2}\right]$ and the potassium salts of eight fatty acids led to cis- $\left[\left(\mathrm{RCO}_{2}\right)_{2} \mathrm{Sn}{ }^{\mathrm{IVPC}}\right]$ compounds $\left\{\mathrm{R}=\left(\mathrm{CH}_{2}\right)_{n} \mathrm{Me}(n=4,6,8,10,12,14,16)\right.$ and $(\mathrm{CH})_{7}-$ cis- $\mathrm{CH}: \mathrm{CH}\left(\mathrm{CH}_{2}\right)_{7} \mathrm{Me}$ \} in yields ranging from 54 to $90 \%$ (Beltran et al, 2005). Some products revealed anticorrosion properties. Triazol-5-one substituted phthalocyanines were prepared quickly by the reactions (1) of 4-nitrophthalonitrile with anhydrous metal $(\mathrm{M}=\mathrm{Co}$, $\mathrm{Cu}, \mathrm{Zn}, \mathrm{Ni})$ salts in DBU (1,8-diazabicyclo[5,4,0]undec-7-ene) and DMAE (dimethylaminoethanol) by MW. Microwave yields were found to be higher than those of the conventional synthesis methods (Kahveci et al, 2006). We note that some metal-free substituted phthalocyanines \{2,9(10),16(17),23(24)-tetra(3,5-dimethylphenoxy) phthalocyanine, 2,9(10),16(17), 23(24)-tetra(4-tert-butylphenoxy) phthalocyanine, and 2,9(10),16(17),23(24)-tetra(3,5-di-tert-butyl-4-hydroxyphenyl) phthalocyanine\} were also obtained by similar routes with higher yields in comparison with conventional methods (Seven et al, 2009). These Pc-compounds had high thermal stability, which was determined at $520^{\circ} \mathrm{C}$ (midpoint), $549^{\circ} \mathrm{C}$, and $400^{\circ} \mathrm{C}$, respectively, as a maximum weight loss temperature. 

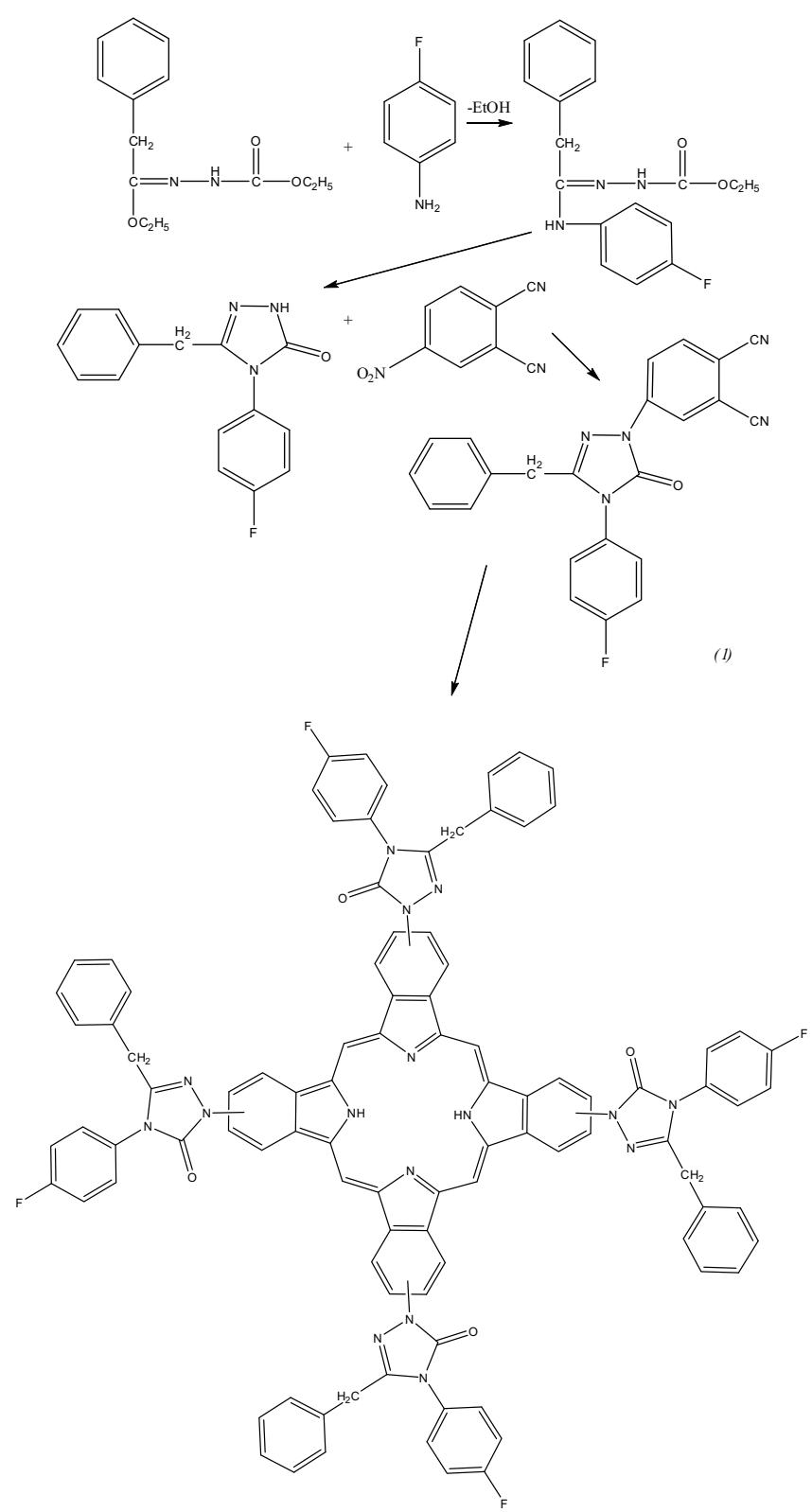

Bis- and sub-phthalocyanines, as well as mixed phthalocyanine-porphyrin complexes, were also reported as MW-fabricated. Thus, starting with phthalic and 4-tert-butylphthalic acid derivatives, the bisphthalocyanines of rare earth elements and Hf and $\mathrm{Zr}$ were MWprepared (Kogan et al, 2002). Sub-phthalocyanine (SubPc) derivatives with different kind of substituent groups were synthesized from various phthalonitriles using conventional and microwave heating sources (Kim et al, 2009). Compared to the conventional synthesis, it was 
found that SubPc derivatives were synthesized in a shorter reaction time with a higher synthetic yield by MW. A soluble phthalocyanine-porphyrin complex $\{\mathrm{Lu}(\mathrm{TBP}$ or)Pc $\}$ was quickly obtained by $\mathrm{MWH}$; $\mathrm{Lu}$ (TBPor)Pc was shown to have better photoelectric conversion properties than porphyrin $\{\mathrm{Lu}(\mathrm{TBP}$ or $) \mathrm{OAc}\}$, phthalocyanine $\left\{\mathrm{H}_{2}(\mathrm{TBP})\right\}$, and $\mathrm{Lu}$ (TBPor)OAc/ $\mathrm{H}_{2}$ (TBPc) blend (Liu et al, 2004). More information on MW-synthesis of phthalocyanines was reported: Ga (Masilela \& Nyokong, 2010), and other metals (Co, Ni, $\mathrm{Cu}, \mathrm{Mg}, \mathrm{Al}, \mathrm{Pd}, \mathrm{Sn}, \mathrm{Tb}, \mathrm{Lu}, \mathrm{Ce}, \mathrm{La}, \mathrm{Zn}$ ) (Hu et al, 2002; Park et al, 2001).

\section{Complexes with $\mathrm{N}, \mathrm{O}$-containing ligands}

These coordination compounds are widely represented by a series of oximes, amines, imines, Schiff bases, as well as such cyclic N,O-ligands as oxadiazoline. Cluster complexes have been also reported, in particular those that cannot be obtained by standard nonmicrowave techniques. Thus, tetradentate $\mathrm{N}_{2} \mathrm{O}_{2}$ ligand [HO(Ar) $\left.\mathrm{CH}: \mathrm{N}-\left(\mathrm{CH}_{2}\right)_{2}-\mathrm{N}: \mathrm{CH}(\mathrm{Ar}) \mathrm{OH}\right]$ $\left(\mathrm{Ar}=o-\mathrm{C}_{6} \mathrm{H}_{4}\right)$ and manganese(II), cobalt(II), nickel(II), and zinc(II) diimine complexes ML were synthesized by classical and MW techniques (Pagadala et al., 2009). It was proposed that, probably, the metal is bonded to the ligand through the phenolic oxygen and the imino nitrogen. The reaction of $\mathrm{Ni}\left(\mathrm{ClO}_{4}\right)_{2} \cdot 6 \mathrm{H}_{2} \mathrm{O}$ with 2-hydroxybenzaldehyde and an aqueous solution of methylamine in acetonitrile/MeOH under $\mathrm{MWH}$ and controlled temperature/pressure gave trinuclear cluster $\left[\mathrm{Ni}_{3}(\operatorname{mimp})_{5}-(\mathrm{MeCN})\right] \mathrm{ClO}_{4} \quad(\mathrm{mimp}=2-$ methyliminomethylphenolate anion) in only $29 \mathrm{~min}$ and also resulted in higher yields in contrast to other synthesis methods (Zhang et al, 2009). This complex displayed dominant ferromagnetic interactions through $\mu_{3}-\mathrm{O}$ (oxidophenyl) and $\mu_{2}-\mathrm{O}$ (oxidophenyl) binding modes. Another cluster, unusual for a specific group of complexes, was found for an oxime complex. Thus, the microwave-assisted reaction of $\mathrm{Fe}\left(\mathrm{O}_{2} \mathrm{CMe}\right)_{2}$ with salicylaldoxime $\left(\mathrm{saoH}_{2}\right)$ in pyridine produced an octametallic cluster $\left[\mathrm{Fe}_{8} \mathrm{O}_{4}(\mathrm{sao})_{8}(\mathrm{py})_{4}\right]$ in crystalline form in $2 \mathrm{~min}$ (Gass et al, 2006). The core of the complex contained a cube encapsulated in a tetrahedron while sao ${ }^{2-}$ exhibited an unique coordination mode $\eta^{2}: \eta^{1}: \eta^{1}: \mu_{3}$ among the structurally characterized metal complexes containing the sao- ligand. The authors noted that $\left[\mathrm{Fe}_{8} \mathrm{O}_{4}\right]^{4+}$ core is uncommon, observed earlier only in one other complex: $\left[\mathrm{Fe}_{8} \mathrm{O}_{4}(\mathrm{pz})_{12} \mathrm{Cl}_{4}\right](\mathrm{pz}=$ pyrazolate anion). The MW-heating had not only led to the isolation of a beautiful and unusual $\left\{\mathrm{Fe}^{\mathrm{III}} 8\right\}$ cluster, impossible to produce under ambient reaction conditions, but has also greatly improved the reaction rate and enhanced the yield in comparison to solvothermal methods.

Among other oxime complexes, the metal-mediated iminoacylation of ketoximes $\mathrm{R}^{1} \mathrm{R}^{2} \mathrm{C}: \mathrm{NOH}$ $\left(\mathrm{R}^{1}=\mathrm{R}^{2}=\mathrm{Me} ; \mathrm{R}^{1}=\mathrm{Me}, \mathrm{R}^{2}=\mathrm{Et} ; \mathrm{R}^{1} \mathrm{R}^{2}=\mathrm{C}_{4} \mathrm{H}_{8} ; \mathrm{R}^{1} \mathrm{R}^{2}=\mathrm{C}_{5} \mathrm{H}_{10}\right)$ upon treatment with the platinum(II) complex trans- $\left[\mathrm{PtCl}_{2}\left(\mathrm{NCCH}_{2} \mathrm{CO}_{2} \mathrm{Me}\right)_{2}\right]$ with an organonitrile bearing an acceptor group proceeded under mild conditions in dry $\mathrm{CH}_{2} \mathrm{Cl}_{2}$ or in microwave field to give the trans-[ $\left.\mathrm{PtCl}_{2}\left\{\mathrm{NH}: \mathrm{C}\left(\mathrm{CH}_{2} \mathrm{CO}_{2} \mathrm{Me}\right) \mathrm{ON}: \mathrm{CR}^{1} \mathrm{R}^{2}\right\}_{2}\right]$ isomers in moderate yield (Lasri et al, 2006). Nine cobaloximes of the type trans-[Co(dmgH $\left.)_{2}(\mathrm{~B}) \mathrm{X}\right]$, where $\mathrm{dmgH}^{-}=$ dimethylglyoximate anion, $\mathrm{X}^{-}=\mathrm{Cl}^{-}, \mathrm{Br}^{-}$or $\mathrm{I}^{-}$and $\mathrm{B}=$ pyrazine, $\mathrm{Pz}$ (1 to 3), pyrazine carboxylic acid, PzCA (4 to 6), pyrazine carboxamide, PzAM (7 to 9), imidazole (Imi) or histidine (His), were prepared (an example of the complex, N, $\mathrm{N}^{\prime}$-dihydrogenpiperazonium dichloridobis(dimethylglyoximato- $\mathrm{k}^{2} \mathrm{~N}, \mathrm{~N}^{\prime}$ ) cobaltate(III) dihydrate, $\mathrm{PpH}_{2}\left[\mathrm{Co}(\mathrm{dmgH})_{2} \mathrm{Cl}_{2}\right]_{2} \cdot 2 \mathrm{H}_{2} \mathrm{O}$, is shown by formula 10) (Martin et al, 2008; Dayalan et al, 
2009). The free ligands Pz, PzCA and PzAM showed antibacterial activity in the order: Pz > $\mathrm{PzCA}>\mathrm{PzAM}$ whereas, the free equatorial ligand $\mathrm{dmgH}_{2}$ was inactive against all the bacteria tested. The cobaltoximes were more active than the corresponding pyrazine and its derivatives as axial ligand in the complexes. It was revealed that the bromo complexes dissociated at higher temperatures compared to the chloro complexes, the iodo cobaloximes being unstable even at low temperature decomposing without any sharp change in mass. Iodocobaloximes were found to be more active than the corresponding chloro- and bromocobaloximes with the antibacterial activity order for the axial halides as $\mathrm{I}^{-}>\mathrm{Cl}^{-}>\mathrm{Br}^{-}$and that of the axial nitrogen heterocycles as histidine > imidazole. Additionally, a 3D coordination polymer, $\left[\mathrm{Cd}\left(\mu_{3}-\mathrm{HIDC}\right)(\mathrm{bbi})_{0.5}\right]_{n}\left\{\mathrm{H}_{3} \mathrm{IDC}=4,5\right.$-imidazoledicarboxylic acid, bbi $=1,1^{\prime}-(1,4-$ butanediyl)bis(imidazole)\}, was synthesized under MWH solvothermal conditions (Liu et al, 2008). Its crystal structure consisted of 2-D brickwall-like networks of $\left[\mathrm{Cd}\left(\mu_{3}-\mathrm{HIDC}\right)\right]_{n}$, which are further linked through $\mu_{2}$-bbi to generate a 3D structure.

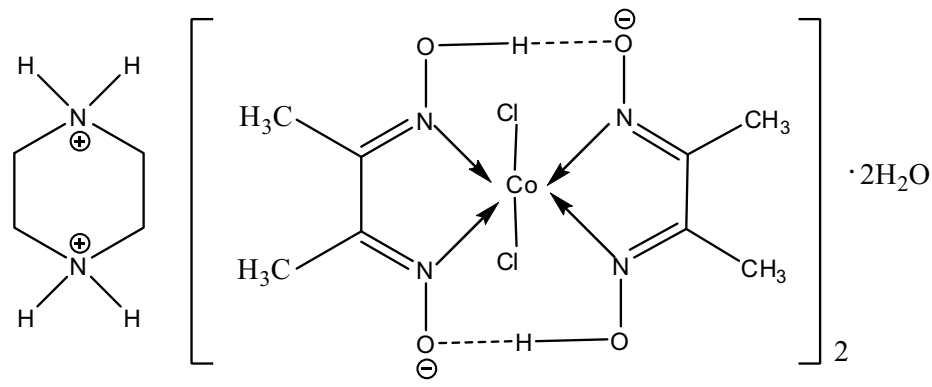

10

Microwave-assisted [2+3] cycloaddition of nitrones to the nitrile ligands in cis- or trans$\left[\mathrm{PtCl}_{2}(\mathrm{PhCN})_{2}\right]$ occurred under ligand differentiation and allowed for selective synthesis of cis- or trans-[ $\mathrm{PtCl}_{2}$ (oxadiazoline)(PhCN)] (Desai et al, 2004). Reaction of the trans-substituted mono-oxadiazoline complexes with a nitrone different from the one used for the first cycloadditionj step gave access to mixed bis-oxadiazoline compounds trans[ $\mathrm{PtCl}_{2}$ (oxadiazoline-a)(oxadiazoline-b)]. The corresponding cis-configured complexes, however, did not undergo further cycloaddition. In case of palladium complexes, the reaction between the nitrone $p-\mathrm{MeC}_{6} \mathrm{H}_{4} \mathrm{CH}: \mathrm{N}(\mathrm{Me}) \mathrm{O}$ and trans- $\left[\mathrm{PdCl}_{2}(\mathrm{RCN})_{2}\right](\mathrm{R}=\mathrm{Ph}, \mathrm{Me})$ in the corresponding $\mathrm{RCN}$ (or of the nitrone in neat $\mathrm{RCN}$ in the presence of $\mathrm{PdCl}_{2}$ ) proceeded at $45^{\circ} \mathrm{C}(\mathrm{R}=\mathrm{Ph})$ or reflux $(\mathrm{R}=\mathrm{Me})$ for 1 day and gave the $\Delta 4-1,2,4$-oxadiazoline complexes $\left[\mathrm{PdCl}_{2}\left\{\mathrm{Na}: \mathrm{C}(\mathrm{R}) \mathrm{ON}(\mathrm{Me}) \mathrm{CbH}\left(\mathrm{C}_{6} \mathrm{H}_{4} \mathrm{Me}-p\right)\right\}_{2}(\mathrm{Na}-\mathrm{Cb})\right](\mathrm{R}=\mathrm{Ph}, \mathrm{Me})$ in $\sim 50$ and $\sim 15 \%$ yields, respectively (Bokach et al, 2005). The reaction time can be drastically reduced by focused MW of the reaction mixture.

Phenylantimony chloride and Sb chloride complexes with Schiff base ligands having N-S and $\mathrm{N}-\mathrm{O}$ donor systems were synthesized under MW using a domestic microwave oven from hours to a few seconds with improved yield as compared with conventional heating (Mahajan et al, 2008). The treatment with the ligands and their phenylantimony derivatives at dose levels of $20 \mathrm{mg}$ per rat per day did not cause any significant change in body weight, but a significant reduction in the weights of reproductive organs was observed. Transition 
metal complexes of $\mathrm{Cu}(\mathrm{II}), \mathrm{Ni}(\mathrm{II}), \mathrm{Co}(\mathrm{II}), \mathrm{Mn}(\mathrm{II}), \mathrm{Zn}(\mathrm{II}), \mathrm{Hg}(\mathrm{II})$, and $\mathrm{Sn}(\mathrm{II})$ were synthesized from the Schiff base (L) derived from 4-aminoantipyrine and 4-fluoro-benzaldehyde using traditional synthetic methodology and microwave-induced organic reaction enhancement (MORE) technique (Ali et al, 2010). Neat reactants were subjected to microwave irradiation giving the required products more quickly and in better yield compared to the classical methodology. As an example of use of Schiff base complexes for catalytic purposes, we note an octahedral titanium binaphthyl-bridged Schiff base complex 11, investigated in respect of catalytic behavior toward epoxidation of allylic alcohols (Soriente et al, 2005). It was established that a mixture of monoterpene alcohol 12, tert-Bu hydroperoxide, the complex 11, and $\mathrm{CH}_{2} \mathrm{Cl}_{2}$, being irradiated with microwave for $15 \mathrm{~min}$, gave $87 \%$ terpene epoxy alcohol 13.

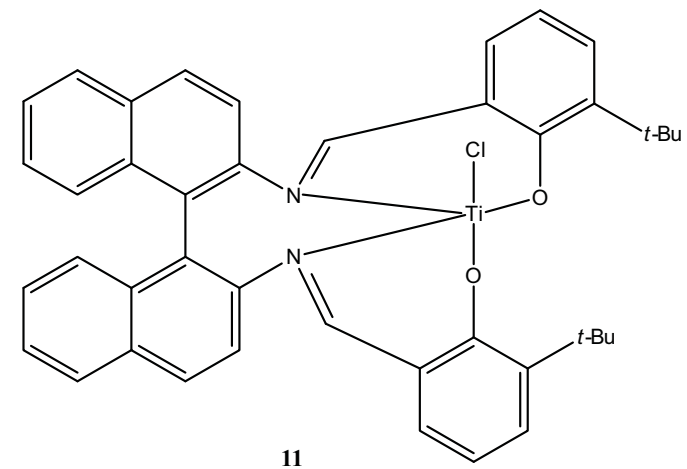<smiles>CC(C)=CCCC(C)=CCO</smiles>

12<smiles>CC(C)=CCCC1(C)OC1CO</smiles>

13

Four ligands i.e. N,N'-bis(3-carboxy-1-oxopropanyl)-1,2-dimethylethylenediamine (CDMPE), $\mathrm{N}, \mathrm{N}$-bis(3-carboxy-1-oxoprop-2-enyl)-1,2-dimethylethylenediamine (CDMPE-2) N,N'-bis(3carboxy-1-oxopropanyl)-1,2-diethylethylenediamine (CDEPE), N,N'-bis(3-carboxy-1oxoprop-2-enyl)-1,2-diethylethylenediamine (CDEPE-2) and their manganese complexes were prepared by microwave method (Bhojak et al, 2008). Antibacterial activity of the ligands and complexes were also reported on $S$. caureus and $E$. coli. Complexes of $\mathrm{Mn}$ (II) with 4 amide group containing ligands (Bhojak et al, 2007) \{N, N'-bis-(3-carboxy-1-oxopropanyl)1,2-ethylenediamine (CPE), N,N'-bis-(3-carboxy-1-oxo-propanyl)-1,2-phenylenediamine (CPP), N,N'-bis-(2-carboxy-1-oxophenelenyl)-1,2-phenylenediamine (CPPP), N,N'-bis-(3carboxy-1-oxoprop-2-enyl)-1,2-phenylenediamine (CPP-2), obtained by MW-heating of amine and carboxylic acid\} were MW-synthesized. Typical preparation of these complexes included simple steps: a slurry of ligand (i.e. CPE, СPP, СРPP or CPP-2) was prepared in water or in water-ethanol mixture; in this a solution of $\mathrm{Mn}\left(\mathrm{CH}_{3} \mathrm{COO}\right)_{2} \cdot 4 \mathrm{H}_{2} \mathrm{O}$ was added, and the resulting mixture was irradiated in a microwave oven for 2 to 6 minutes at medium power level $(600 \mathrm{~W})$ maintaining the occasional shaking. Proposal structures of complexes are shown by formulae 14-17. The antibacterial activity of the ligands and complexes was studied. Additionally, the Chinese-lantern-type $\mathrm{Co}_{2}\left(\mathrm{O}_{2} \mathrm{CBut}\right)_{4}\left\{2,6-\left(\mathrm{NH}_{2}\right)_{2} \mathrm{C}_{5} \mathrm{H}_{3} \mathrm{~N}\right\}_{2}$ complex reacted with $\mathrm{RCN}(\mathrm{R}=\mathrm{Me}$ or $\mathrm{Pr}$ ) under microwave irradiation to give the mononuclear amidine complexes $\mathrm{Co}\left(\mathrm{O}_{2} \mathrm{CBut}\right)_{2}\left\{\mathrm{H}_{2} \mathrm{~N}\left(\mathrm{C}_{5} \mathrm{H}_{3} \mathrm{~N}\right) \mathrm{NHC}(\mathrm{R}): \mathrm{NH}\right\}$ ( $\mathrm{R}=$ Me or Pr) (Bokach et al, 2006). 

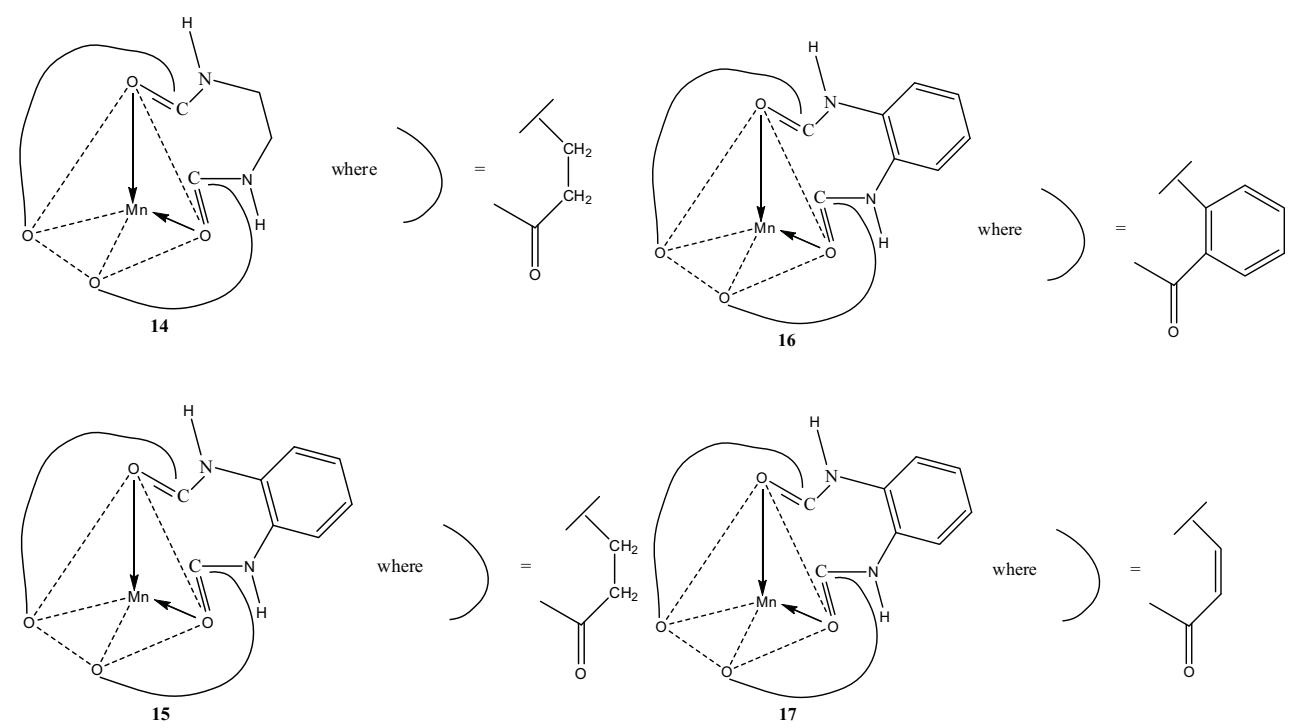

Al-containing mesoporous silicates (Al-MCM-41 and Al-HMS) supported Mn(salen) catalysts were prepared by three different methods: impregnation of salen ligand and support with dichloromethane and then irradiated by microwave (method A), direct solidstate interaction between salen complex and support under microwave irradiation (method B), as well as the conventional ion exchange (method C) (Yin et al, 2005; Zhang et al, 2003). The effect of catalyst preparation methods on the catalytic activity and selectivity in the styrene epoxidation indicate that the catalyst of Mn(Salen)/ Al-HMS-IP prepared by method A showed similar activity to the neat complex and the best selectivity for styrene epoxide. In comparison with the traditional adsorption method, the MW-assisted approach was efficient and environmentally friendly, and improved the loadings of Mn(III)-salen complexes on HMS via a strengthening axial coordination of the surface $\mathrm{NH}_{2}$ groups of HMS toward the $\mathrm{Mn}(\mathrm{III})$-salen complexes (Fu et al, 2007). The effects of several extrinsic physical fields, such as the magnetic field, the ultrasonic wave and the MW, on the rate and yield of chitosan$\mathrm{Fe}(\mathrm{II})$ complexing reaction were investigated (Jiang et al, 2008), showing that ultrasound had the greatest effect on the reaction rate and complexing capacity, followed by the magnetic field and the MW. A mechanism for the enhancement of the complexing reaction by the three physical fields was proposed.

\section{Complexes with S- and N,S-containing ligands}

According to the available literature, microwave-synthesized complexes of S-containing ligands without other donor heteroatoms are represented by coordination compounds of dithiolene. Thus, dithiolene-transition metal complexes 18 were obtained by a series of steps (Kim et al, 2009) including microwave heating in the first steps of the mixture of benzaldehyde and $\mathrm{KCN}$ in $\mathrm{EtOH}$. 


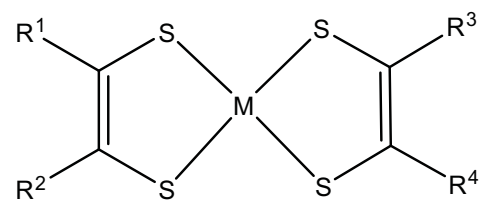

18

N,S-Complexes are represented by a series of different types of compounds: thiolates, thioimidazoles, thiazoles, thiosemicarbazones, among others. Thus, the solid phase reaction of 1-alkyl-2-\{(o-thioalkyl)phenylazo\}imidazoles (SRaaiNR) and $\mathrm{RuCl}_{3}$ on silica gel surface upon MW yielded $[\mathrm{Ru}(\mathrm{SRaaiNR})(\mathrm{SaaiNR})]\left(\mathrm{PF}_{6}\right)$ (Mondal et al, 2009). $\mathrm{BiPh}_{3}$ was treated with thiols of varying $\mathrm{pKa}$ and functionality (2-mercaptobenzothiazole, 2-mercaptobenzoxazole, 2-mercaptopyrimidine, 2-mercapto-1-methylimidazole and 2-mercaptobenzoic acid) in a 1:3 ratio under a variety of reaction conditions: with toluene or mesitylene under standard reflux conditions and under microwave irradiation, and solvent free with conventional and microwave heating (Andrews et al, 2007). As a result, several reactions yielded the trissubstitution product in good yield and high purity; 2-mercaptobenzoic acid gave the complex $\mathrm{Bi}_{2} \mathrm{~L}_{3}$ in all reactions carried out in solvent and $\mathrm{PhBiL}$ when solvent free, both complexes containing the doubly deprotonated dianion ( $\left.\mathrm{L}=-\mathrm{O}_{2} \mathrm{C}-\mathrm{C}_{6} \mathrm{H}_{4}-\mathrm{S}-\right)$. The authors noted that reactions carried out in the microwave reactor generally gave comparable yields to the conventional methods but in significantly shorter times; however, the solvent free microwave reactions of 2-mercaptobenzoxazole and 2-mercaptopyrimidine caused partial decomposition to give microcrystalline $\mathrm{Bi}_{2} \mathrm{~S}_{3}$. $\mathrm{MWH}$ of racemic cis- $\left[\mathrm{Ru}(\mathrm{bpy})_{2}(\mathrm{Cl})_{2}\right](\mathrm{bpy}=$ 2,2'-bipyridine) or racemic cis- $\left[\mathrm{Ru}(\text { phen })_{2}(\mathrm{Cl})_{2}\right]$ (phen = phenanthroline) with either $(\mathrm{R})-(+)-$ or (S)-(-)-Me $p$-tolyl sulfoxide yielded the ruthenium bis(diimine) sulfoxide complexes, for example 19 (Pezet et al, 2000). This source of energy improved both yields and reaction rates with a very good diastereoselectivity (73-76\%) and represented a significant advance in the asymmetric synthesis of octahedral ruthenium complexes.
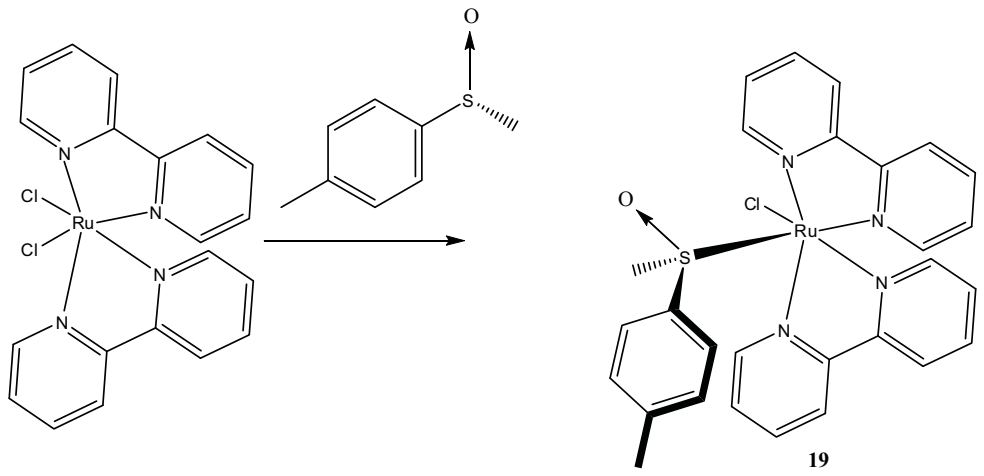

A lot of complexes of thiosemicarbazone and its derivatives have been MW-obtained. Thus, molybdenum(VI) complexes $\mathrm{MoO}_{2}(\mathrm{~L})_{2}$ of the ligands HL $\{3,4,5-$ trimethoxybenzaldehydethiosemicarbazone trimethoxybenzaldehydesemicarbazone trimethoxybenzaldehydebenzothiazoline (TBBZTH) and 3,4,5-trimethoxybenzaldehyde-S- 
benzyldithiocarbazate (TBDTCZH)\} were MW-fabricated(Maanju et al, 2007) by the reactions between dioxobis(2,4-pentanedionato-O,O')molybdenum(VI) and the ligands TBTSCZH, TBSCZH, TBBZTH and TBDTCZH by MW-assisted and conventional thermal methods. All four ligands and their complexes were screened for their biological activity on several pathogenic fungi and bacteria and the data show good activity of these complexes and ligands. The synthesis of some $\mathrm{Mn}(\mathrm{II})$, oxovanadium(V) and dioxomolybdenum(VI) complexes with 5chloro-1,3-dihydro-3-[2-(phenyl)ethylidene]-2H-indol-2-one thiosemicarbazone $\left(\mathrm{L}^{1} \mathrm{H}\right)$ and 5chloro-1,3-dihydro-3-[2-(phenyl)ethylidene]-2H-indol-2-one semicarbazone $\left(\mathrm{L}^{2} \mathrm{H}\right)$ were carried out in unimolar and bimolar ratios in an open vessel under MW using a domestic microwave oven. In the case of the oxovanadium complexes, the metal was found to be in the penta- and hexa-coordinated environments. The ligands and complexes possessed antimicrobial properties. Trigonal bipyramidal and octahedral complexes of Sn(IV) were synthesized by the reaction of dimethyltin(IV) dichloride with 4-nitrobenzanilidethiosemicarbazone $\left(\mathrm{L}^{1} \mathrm{H}\right)$, 4chlorobenzanilidethiosemicarbazone $(\mathrm{L} 2 \mathrm{H})$, 4-nitrobenzanilidesemicarbazone $\left(\mathrm{L}^{3} \mathrm{H}\right)$ and 4chlorobenzanilidesemicarbazone $\left(\mathrm{L}^{4} \mathrm{H}\right)$ from dimethyltin(IV) dichloride and monobasic bidentate ligands using MW as the thermal energy source (Singh et al, 2008). The antifungal, antibacterial and antifertility activities were examined and the results were indeed very encouraging. A series of mixed ligand ruthenium(II) containing diimines and thiosemicarbazones with general formula $\left[\mathrm{Ru}(\mathrm{N}-\mathrm{N})_{2}(\mathrm{~N}-\mathrm{S})\right]\left(\mathrm{PF}_{6}\right)_{2}$ where $\mathrm{N}-\mathrm{N}=$ bipyridine or 1,10-phenanthroline and N-S = 9-anthraldehyde thiosemicarbazone and the 4-alkyl substituted $(\mathrm{R}=\mathrm{Me}$, Et and phenyl) analogs were synthesized using microwave energy (Beckford et al, 2009; Beckford et al, 2010). The compounds quenched the fluorescence of the complex between ethidium bromide and calf-thymus DNA with the Stern-Volmer quenching consisted in the range 1.18-2.71·104 $\mathrm{M}^{-1}$. Additionally, the $\mathrm{Pd}(\mathrm{II})$ and $\mathrm{Pt}(\mathrm{II})$ complexes were synthesized using microwave heating by mixing metal salts in 1:2 molar ratios with heterocyclic ketimines, 3acetyl-2,5-dimethylthiophene thiosemicarbazone $\left(\mathrm{C}_{9} \mathrm{H}_{13} \mathrm{~N}_{3} \mathrm{OS}_{2}\right)$ and 3-acetyl-2,5dimethylthiophene semicarbazone $\left(\mathrm{C}_{9} \mathrm{H}_{13} \mathrm{~N}_{3} \mathrm{OS}\right)$, obtained by reactions of 3-acetyl-2,5dimethylthiophene with thiosemicarbazide and semicarbazide hydrochloride (Sharma et al, 2010). The authors proposed that the ligands coordinate to the metal atom in a monobasic bidentate manner and square planar environment around the metal atoms. The antiamoebic activity of both the ligands and their palladium compounds against the protozoan parasite Entamoeba histolytica was tested. Other data on MW-obtaining thiosemicarbazone complexes were discussed in (Chaudhary et al, 2009; Shen et al, 2008).

In case of thiophene derivatives, MW-assisted condensation of salicylaldehyde with 2amino-3-carboxyethyl-4,5-dimethylthiophene in the absence of solvent was efficiently performed to form a potentially tridentate Schiff base, 2-(N-salicylideneamino)-3carboxyethyl-4,5-dimethylthiophene (HSAT), which acted as neutral tridentate with ONO donor sequence towards the lanthanide(III) ions, forming 1:2 metal-ligand complexes of the type $\left[\mathrm{Ln}(\mathrm{HSAT})_{2} \mathrm{Cl}_{3}\right.$ ] where $\mathrm{Ln}=\mathrm{La}(\mathrm{III}), \mathrm{Ce}(\mathrm{III}), \mathrm{Pr}(\mathrm{III}), \mathrm{Nd}(\mathrm{III}), \mathrm{Sm}(\mathrm{III}), \mathrm{Eu}(\mathrm{III})$ and $\mathrm{Gd}(\mathrm{III})$ (Kumasi et al, 2009). Additionally, it is known that thiophene can react with elemental iron in the form of metal atoms in cryosynthesis conditions or its carbonyls carrying out the desulfurization of the ligand. In reactions with iron carbonyls, the use of MWH evidently led (Singh et al, 1996) to acceleration of reported reactions of thiophene and its tellurium analogue and its derivatives with $\left[\mathrm{Fe}_{3}(\mathrm{CO})_{12}\right]$. The following dechalcogenation reactions take place, forming binuclear complexes 20-21 (reactions 2). Among other organometallic compounds, prepared this way, it is necessary to mention chromium, molybdenum, and tungsten carbonyls (Van Atta et al, 2000). 




20

21

Cyanobipyridine-derived zinc(II) bis(thiolate) complexes [ $\left.\mathrm{Zn}(\mathrm{L})(\mathrm{SAr})_{2}\right]$ (L = 2-methyl-4-(4biphenyl)-6-(2-pyridyl)nicotinonitrile and 2-methyl-4-(4-(diphenylamino)phenyl)-6-(2pyridyl)nicotinonitrile, $\mathrm{Ar}=\mathrm{Ph}, 4-\mathrm{MeOC}_{6} \mathrm{H}_{4}, 2$-naphthalenyl) were prepared rapidly and efficiently by a microwave-assisted cross-coupling/complexation sequence and display luminescence that can be modulated using intrinsic functionality and ancillary ligands (Bagley et al, 2010). Organotin complexes of thiol- and thione-containing Schiff bases were MW-prepared and tested for antifungal activity, using $\mathrm{Ph}_{3} \mathrm{SnCl}, \mathrm{Ph}_{3} \mathrm{SiCl}, \mathrm{Ph}_{2} \mathrm{SnCl}_{2}$ as metal source and the sodium salts of ligands, $2-\mathrm{HSC}_{6} \mathrm{H}_{4} \mathrm{~N}: \mathrm{CMeCH}_{2}(i-\mathrm{Pr})\left(\mathrm{L}{ }^{1} \mathrm{H}\right)$ and (i$\mathrm{PrCH}_{2} \mathrm{C}(\mathrm{Me}): \mathrm{NNHC}(\mathrm{S}) \mathrm{NH}_{2}\left(\mathrm{~L}^{2} \mathrm{H}\right)$, synthesized by condensation of 4-methyl-2-pentanone with 2-aminobenzenethiol and thiosemicarbazide, respectively (Gaur et al, 2005). Pentacoordinated complexes $\mathrm{Ph}_{3} \mathrm{SnL}^{1}, \mathrm{Ph}_{3} \mathrm{SiL}^{1}, \mathrm{Ph}_{2} \mathrm{SnClL}^{1}, \mathrm{Me}_{2} \mathrm{SnClL}^{1}, \mathrm{Ph}_{3} \mathrm{SnL}^{2}, \mathrm{Ph}_{3} \mathrm{SiL}^{2}$ and hexacoordinated complexes $\mathrm{Ph}_{2} \mathrm{SnL}_{2}$ and $\mathrm{Me}_{2} \mathrm{SnL}_{2}{ }_{2}$ were isolated and tested against a number of microorganisms exhibiting inhibition of growth of Aspergillus niger, Fusarium oxysporum and Alternaria alternata. MWAS and spectroscopic studies of dimethyl-, diphenyland triphenyl- $\mathrm{Si}(\mathrm{IV})$ chelates derived from the reactions of organochlorosilanes with the sodium salt of a biologically active $\mathrm{N}$-donor ligand [1-(furan-2-yl)ethylidene][4-[(pyridin-2yl)sulfamoyl]phenyl]amine was reported (Singh et al, 2005). The biological activity of the ligand and its corresponding complexes with regard to antifungal and antibacterial activity against pathogenic fungi and bacteria was revealed; all the compounds also acted as nematicides and insecticides, by reducing the number of nematodes (Meloidogyne incognita) and insects (Trogoderma granarium).

Antimony complexes with substituted thioimines (22) were prepared by reaction of $\mathrm{Ph}_{3} \mathrm{Sb}$ and [1-(2-naphthyl)ethylidene]hydrazinecarbodithionic acid phenyl ester, [1-(2thienyl)ethylidene]hydrazinecarbodithionic acid phenyl methyl ester, [1-(2pyridine)ethylidene]hydrazinecarbodithionic acid phenyl ester, and and [1-(2furanyl)ethylidene]hydrazinecarbodithionic acid phenyl ester by MWH (Mahajan et al, 2007). Reactions of $\mathrm{Ph}_{3} \mathrm{Sb}$ and monobasic bidentate ligands having $\mathrm{N}^{\urcorner} \mathrm{S}$ donor set in 1:1 and 1:2 molar ratios proceeded with the cleavage of the antimony carbon bond of $\mathrm{Ph}_{3} \mathrm{Sb}$ and yielded monosubstituted derivatives (reactions 3-4).

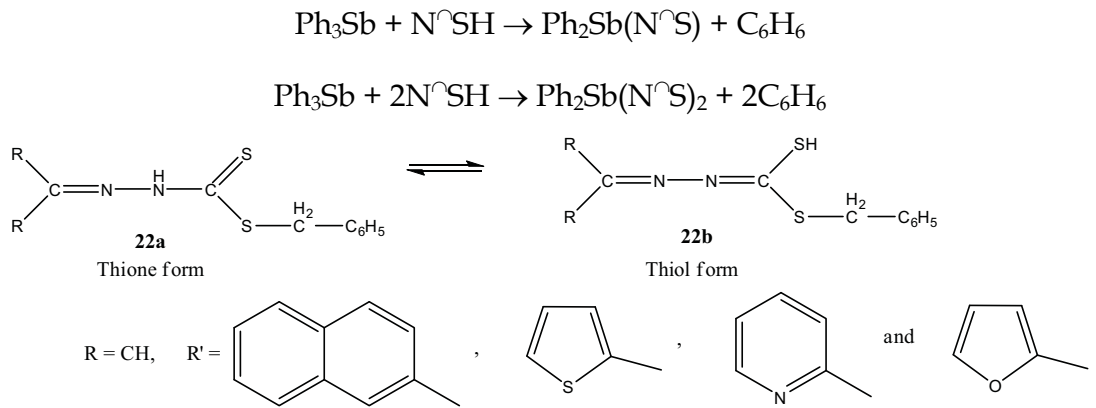


The reaction product of 2-hydroxy-N-phenylbenzamide with 2-aminobenzenethiol, 2-(2hydroxyphenyl)-2-(phenylamino)benzothiazoline $\left(\mathrm{H}_{2}\right.$-Saly.BTZ), reacted with $\mathrm{PhSbCl}_{2}$, $\mathrm{SbCl}_{3}$, and $\mathrm{BiCl}_{3}$ under varied reaction conditions (microwave, as well as conventional method) leading to corresponding antimony(III) and bismuth(III) compounds (an example is 23) (Mahajan et al, 2009). The ligand was found to bifunctional tridentate, as well as monodentate for different starting materials of metal $(\mathrm{Sb} / \mathrm{Bi})$. The complexes were more toxic than the corresponding ligand.

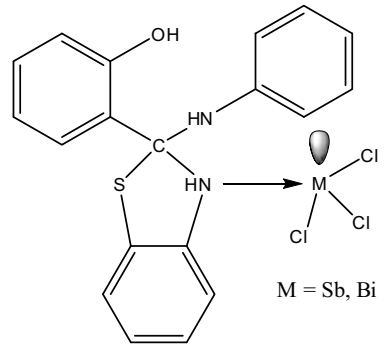

23

A highly semiconducting 1D coordination polymer architecture was obtained by the reaction of a $\mathrm{Cu}^{\mathrm{II}}$ salt with 2,2'-dipyridyldisulfide under microwave solvothermal conditions, proceeding with an unusual C-S and S-S bond cleavage of the 2,2'-dipyridyldisulfide ligand to give $\left\{\left[\mathrm{Cu}_{9} \mathrm{I}_{2}(\mathrm{~L})_{8}(\mathrm{SH})_{8}\right]\left(\mathrm{BF}_{4}\right)\right\}_{n} \quad(\mathrm{SH} \quad=$ 2-pyridylthiolate $)$ and $\left\{\left[\mathrm{Cu}^{\mathrm{II}}(2-\mathrm{dps})_{2}\right]_{2}(\mu-\right.$ S) $\}\left(\mathrm{BF}_{4}\right)_{2} \cdot 4 \mathrm{CH}_{2} \mathrm{Cl}_{2}$ (2-dps = 2,2'-dipyridylsulfide) (reaction 5) (Delgado et al, 2008). The unprecedented architecture of the first compound consisted of a 1D polymeric chain formed by the assembling of $\mathrm{Cu}_{9}$ cluster cages. In a related report of the same research group, an unprecedented microwave $\mathrm{C}\left(\mathrm{sp}^{2}\right)-\mathrm{S}$ and S-S bond activation of 2,2'-dipyridyldisulfide (2dpds) and the formation of an architecture of coordination networks obtained by reaction of $\mathrm{Cu}\left(\mathrm{HCO}_{2}\right)_{2} \cdot x \mathrm{H}_{2} \mathrm{O}$ with 2-dpds in the same conditions were described (Delgado et al, 2010). Partial oxidation of 2,2'-dipyridyldisulfide to sulfate was found to take place, resulting a $\mathrm{Cu}(\mathrm{I})$ dimetallic complex $\left[\mathrm{Cu}_{2}(\mu-\mathrm{Hpyt})_{2}(\mathrm{Hpyt})_{4}\right]\left(\mathrm{SO}_{4}\right) \sim 55 \mathrm{EtOH}(\mathrm{Hpyt}=$ pyridine $-2(1 \mathrm{H})-$ thione), a $\mathrm{Cu}(\mathrm{I}, \mathrm{II})$ polycationic coordination polymer $\left[\mathrm{Cu}\left(\mathrm{H}_{2} \mathrm{O}\right)_{6}\right]\left[\mathrm{Cu}_{6}(\mu-\mathrm{Hpyt})_{12}\right]\left(\mathrm{SO}_{4}\right)_{4} \cdot 4 \mathrm{H}_{2} \mathrm{O}$, and a dimetallic $\mathrm{Cu}(\mathrm{II})$ complex $\left[\mathrm{Cu}(2-\mathrm{dps})\left(\mu-\mathrm{SO}_{4}\right)\left(\mathrm{H}_{2} \mathrm{O}\right)\right]_{2} \cdot 3 \mathrm{H}_{2} \mathrm{O}$. The strong red and yelloworange luminescence was shown for the first two complexes.

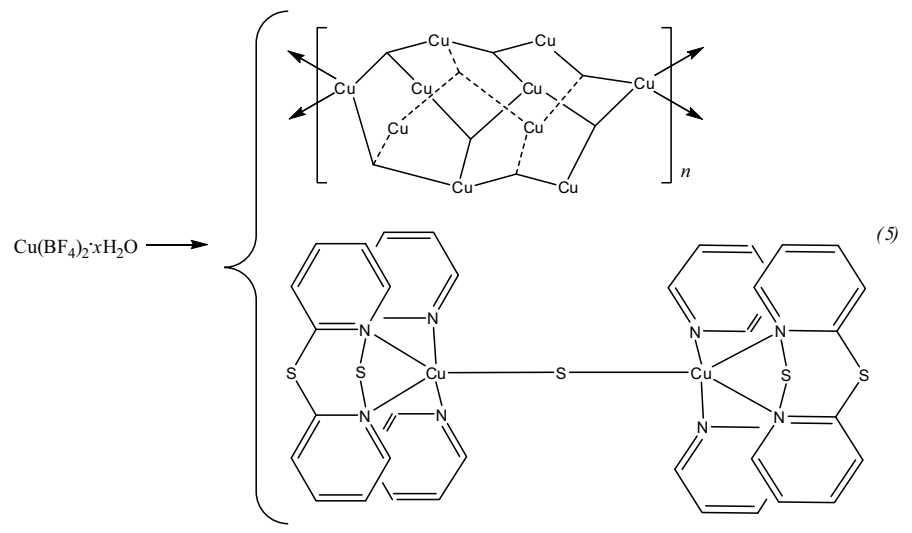




\section{6. $\sigma$ - and $\pi$-organometallic compounds}

Microwave heating has been applied to obtain a series of metal complexes with classic ligands forming $\sigma$ - and $\pi$-organometallic compounds: carbonyls, cyclopentadienyls, dienes, and arenes, among others. Generally, as well as for the case of the coordination compounds above, main advantages of MW-application are frequently higher yields and almost always considerably shorter reaction times.

\subsection{Carbonyls}

Among fundamental generalizing publications on MW-fabricated metal carbonyls, we note a review on Group 6 metals, describing, in particular, metal carbonyls synthesis in a conventional MW-oven (Holder, 2005), and a report (Ardon et al, 2004) dedicated to the preparation of a series of mixed Group 6 metal carbonyl complexes with other ligands ; cis$\left[\mathrm{Mo}(\mathrm{CO})_{4}(\mathrm{dppe})\right], \quad\left[\mathrm{CpMo}(\mathrm{CO})_{3}\right]_{2}, \quad\left[\mathrm{Cp}_{2} \mathrm{Mo}_{2}(\mathrm{CO})_{4}\left(\mu-\mathrm{RC}_{2} \mathrm{R}\right)\right], \quad\left[\mathrm{CpMo}(\mathrm{CO})_{2}\right]_{2}, \quad$ cis$\left[\mathrm{W}(\mathrm{CO})_{4}(\text { pip })_{2}\right],\left[\mathrm{Cr}(\mathrm{CO})_{5} \mathrm{Cl}\right]\left[\mathrm{NEt}_{4}\right]$, where dppe = 1,2-bis(diphenylphosphino)ethane, pip = piperidine\}. Also, mixed carbonyl-arene complexes are known; thus, the microwaveassisted synthesis of ( $\eta^{6}$-arene)tricarbonylchromium complexes from hexacarbonylchromium and arenes gave high yields of ( $\eta^{6}$-arene)chromium tricarbonyl complexes (Lee et al, 2006). In case of noble metals, by using a gas-loading accessory, microwave-assisted synthesis of $\mathrm{Ru}_{3}(\mathrm{CO})_{12}, \quad \mathrm{Ru}_{3}(\mathrm{CO})_{9}\left(\mathrm{PPh}_{3}\right)_{3}, \quad \mathrm{HRu}_{3}(\mathrm{CO})_{9}(\mathrm{C} \equiv \mathrm{CPh})$ and $\mathrm{H}_{4} \mathrm{Ru}_{4}(\mathrm{CO})_{12}$ was performed (Leadbeater et al, 2008). Ligand substitution reactions of $\mathrm{Ru}_{3}(\mathrm{CO})_{12}$ with triphenylphosphine were also studied in real time by means of a digital camera interfaced with the microwave unit. Microwave-assisted ligand substitution reactions of $\mathrm{Os}_{3}(\mathrm{CO})_{12}$ in a remarkably short period of time led to the labile complex $\mathrm{Os}_{3}(\mathrm{CO})_{11}(\mathrm{NCMe})$ in high yield without the need for a decarbonylation reagent such as trimethylamine oxide (Jung et al, 2009). Additionally, $\mathrm{MWH}$ of $\mathrm{Os}_{3}(\mathrm{CO})_{12}$ in a relatively small amount of acetonitrile was shown to be a useful first step in two-step, one-pot syntheses of the cluster complexes $\mathrm{Os}_{3}(\mathrm{CO})_{11}(\mathrm{py})$ and $\mathrm{Os}_{3}(\mathrm{CO})_{11}\left(\mathrm{PPh}_{3}\right)$. Microwave-assisted reactions of 3,3,3-tris(3'-substituted pyrazolyl)propanol ligands [(3-Rpz) ${ }_{3} \mathrm{CCH}_{2} \mathrm{CH}_{2} \mathrm{OH}, \mathrm{R}=$ $\mathrm{H}]$ and $\left[\operatorname{Re}(\mathrm{CO})_{5} \mathrm{Br}\right]$ yielded $\left[\operatorname{Re}(\mathrm{CO})_{3}\right] \mathrm{Br}$ and degradation products $\left[(\mathrm{HpzR})_{2} \operatorname{Re}(\mathrm{CO})_{3} \mathrm{Br}\right][\mathrm{R}=$ $t$-Bu (7b), Ph] (Kunz et al, 2009). These complexes were also prepared directly from $\left[\operatorname{Re}(\mathrm{CO})_{5} \mathrm{Br}\right]$ and the corresponding pyrazoles by microwave-assisted synthesis. Beginning with $\mathrm{MO}_{4^{-}}\left(\mathrm{M}={ }^{99 \mathrm{mTc}}\right.$, $\left.{ }^{186 / 188} \mathrm{Re}\right)$, the carbonyl precursor $\left[\mathrm{M}(\mathrm{CO})_{3}\left(\mathrm{H}_{2} \mathrm{O}\right)_{3}\right]^{+}$was synthesized in $3 \mathrm{~min}$ in quantitative yield in a microwave reactor (Causey et al, 2008). When di-picolyl ligand $(\mathrm{HL}=5$-[bis(2-pyridinylmethyl)amino]pentanoic acid) was added to the reaction mixture, the chelate complex $\left[\mathrm{M}(\mathrm{CO})_{3}(\mathrm{~L})\right]^{+}$was formed in high yield in 2 min using $\mathrm{MWH}$ at $150^{\circ} \mathrm{C}$. These and further syntheses under MW-heating represented a move away from traditional instant kits toward more versatile platform synthesis and purification technologies that are better suited for producing modern molecular imaging and therapy agents.

\subsection{Cyclopentadienyls}

As metal-Cp complexes, MW-obtained ferrocene derivatives are the most common. Among relatively old and already classic achievements in this area, we emphasize the following condensation reactions. Thus, according to the conventional techniques, Claisen-Schmidt 
template reactions of acetylferrocene $\mathbf{2 4}$ and ferrocene carboxaldehyde $\mathbf{2 6}$ are usually performed under classical homogeneous conditions in ethanol. Using $\mathrm{MWH}$ of the reaction system, it became possible (Villemin et al, 1994) to prepare (reactions 6 and 7) ferrocenylenones $\mathbf{2 5}$ and $\mathbf{2 7}$ without solvent in presence of solid $\mathrm{KOH}$ with higher yields in comparison with those reported earlier. It is noted that the reactions may be accelerated efficiently by microwave irradiation.
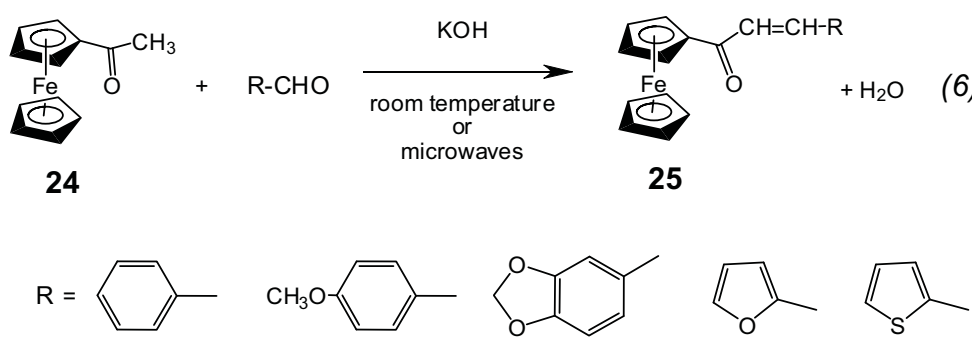

Condensation of acetylferrocene

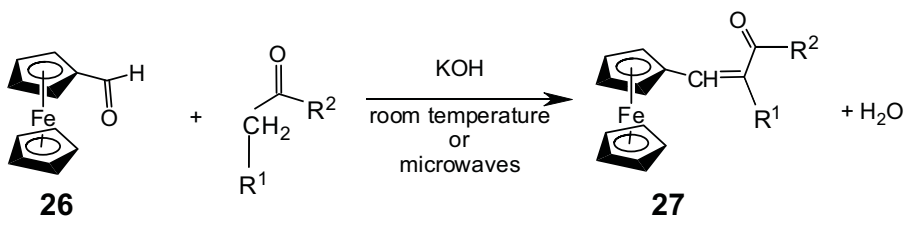<smiles>[R]CC(=O)O[Na]</smiles><smiles>O=C1CCCc2ccccc21</smiles><smiles>O=C1CC2CC1C1CCCC21</smiles><smiles>CC(=O)c1ccccc1</smiles>

Condensation of ferrocene carboxaldehyde

A significant accelerating effect by $\mathrm{MWH}$ for the ligand exchange reaction of ferrocenes was observed; this effect was due to the absorption of microwave energy by the adduct between the ferrocene and the Lewis acid (Okada et al, 2009). Six ferrocenyl $\alpha, \beta$-unsaturated ketones, FcCOCH:CHAr ( Fc = ferrocenyl, $\mathrm{Ar}=\mathrm{Ph}, 4-\mathrm{MeOC}_{6} \mathrm{H}_{4}, 2$-furyl, 4- $\mathrm{Me}_{2} \mathrm{NC}_{6} \mathrm{H}_{4}$, ferrocenyl, 4$\mathrm{O}_{2} \mathrm{NC}_{6} \mathrm{H}_{4}$ ) were prepared by $\mathrm{MW}$-assisted reaction of $\mathrm{ArCHO}$ with FcCOMe in the presence of $\quad \mathrm{KF}_{-} \mathrm{Al}_{2} \mathrm{O}_{3}$ as catalyst ( $\mathrm{Lu}$ et al, 2003). 1,5-dioxo-3-(pmethylbenzyloxyphenyl)[5]ferrocenophane (28) was MW-prepared (50 W for $30 \mathrm{~min}$ with $80^{\circ} \mathrm{C}$ ) in 2-step reaction from 4-hydroxybenzaldehyde in acetone, 4-methylbenzylbromide, $\mathrm{CsCO}_{3}$, and further addition of diacetylferrocene in 90\% yield (Patti et al, 2009). 
Additionally, the species MW-synthesized include ferrocene and acetylferrocene, piano stool complexes such as $\mathrm{CpFe}(\mathrm{CO})_{2} \mathrm{I}, \mathrm{CpFe}\left(\mathrm{PPh}_{3}\right)(\mathrm{CO}) \mathrm{I}$, and $\mathrm{CpFe}\left(\mathrm{PPh}_{3}\right)(\mathrm{CO})(\mathrm{COMe})$, and bisphosphine iron complexes. The use of microwave-assisted reactions decreased reaction times while maintaining or improving yields as compared to traditional methods (Garringer et al, 2009). Mixed ( $\eta^{6}$-arene)( $\eta^{5}$-cyclopentadienyl)iron(II) complexes are also known (Roberts, 2006; Roberts, 2006).
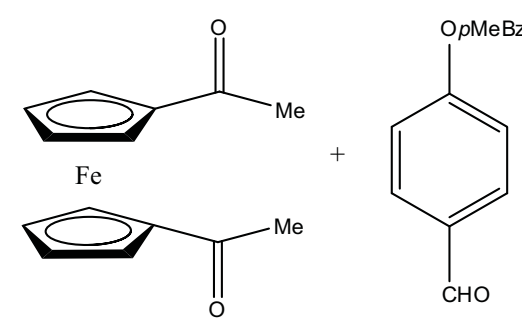

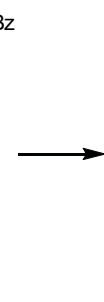

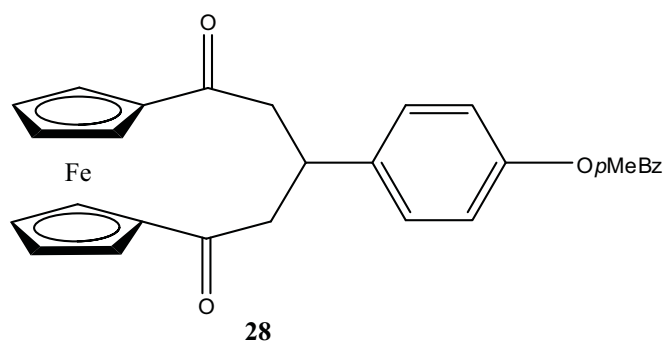

28

Group 4 is represented by all three transition metals (Ti, Zr, and Hf). Thus, the reactions of bis(cyclopentadienyl)titanium(IV) chloride with Schiff bases $\left(\mathrm{LH}_{2}\right)$, derived by condensing 3(phenyl/2-chlorophenyl/4-nitrophenyl)-4-amino-5-hydrazino-1,2,4-triazoles with salicylaldehyde or 2-hydroxyacetophenone, were studied both by conventional stirring method and also by using microwave heating, isolating $\left[\left(\eta^{5}-\mathrm{C}_{5} \mathrm{H}_{5}\right)_{2} \mathrm{Ti}(\mathrm{L})\right]$ in both cases (Banerjee et al, 2008). The ligands behaved as dibasic, tetradentate chelating agents and a six-coordinated structure were assigned to these derivatives. The same precursor was applied in reactions with bis(thiosemicarbazones) $\left(\mathrm{H}_{2} \mathrm{~L}\right)$, derived by condensing isatin with different $\mathrm{N}(4)$-substituted thiosemicarbazides, were studied both by a conventional stirring method and also using MW technology isolating binuclear $\left[\left\{\left(\eta^{5}-\mathrm{C}_{5} \mathrm{H}_{5}\right)_{2} \mathrm{TiCl}_{2}(\mathrm{~L})\right]\right.$ compounds (Banerjee et al, 2009). The ligands and complexes possessed inhibiting potential against various fungal, viral and bacterial strains. Similarly, reactions of $\left(\eta^{5}-\mathrm{C}_{5} \mathrm{H}_{5}\right)_{2} \mathrm{HfCl}_{2}$ with benzil bis(hydrazones) $\left(\mathrm{LH}_{2}\right)$, derived from benzil and aromatic acid hydrazides (benzoic, 2chlorobenzoic, 4-chlorobenzoic, 2-methylbenzoic or 4-methoxybenzoic) were studied in anhydrous THF in the presence of $n$-butylamine by both conventional methods and by $\mathrm{MWH}$, isolating binuclear complexes of type $\left[\left\{\left(\eta^{5}-\mathrm{C}_{5} \mathrm{H}_{5}\right)_{2} \mathrm{HfCl}\right\}_{2}(\mathrm{~L})\right]$ (Sinha et al, 2008). The stoichiometric reactions of titanocenedichloride or zirconocenedichloride with monofunctional bidentate ligands 29 and 30, derived from heterocyclic ketones and semicarbazide hydrochloride and 2-hydroxy-N-phenyl benzamide, resulted in the formation of unsymmetrical complexes 31 (reactions 8-11) (Poonia et al, 2007; Poonia et al, 2008). A comparison of conventional and microwave route revealed that the second way was 100 times faster. 
<smiles>OCCO</smiles><smiles>[R]C(C)=NNC(N)=O</smiles>

$30(\overbrace{\mathrm{OH}})$<smiles>[R]=C=Cc1ccc(C)cc1C</smiles>

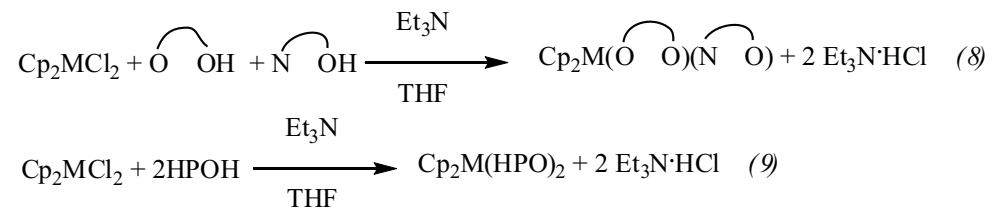

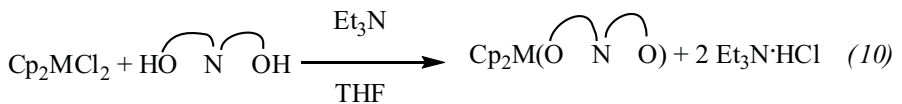

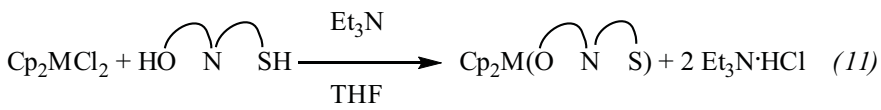<smiles></smiles> 
A few of other metal cyclopentadienyls have been also reported, for example a very efficient MWAS of $\left[\mathrm{RuCp}\left(\eta^{6}\right.\right.$-naphthalene $\left.)\right]\left[\mathrm{PF}_{6}\right]$ (Mercier et al, 2009). The synthesis of cyclopentadienyl bis-phosphine ruthenium thiolato complexes of the type [RuCp(dppm)SR] ( $\mathrm{R}=\mathrm{Ph}, \mathrm{CH}_{2} \mathrm{CH}_{2} \mathrm{Ph}, \mathrm{CH}_{2}$ (2-furyl), $\left.\mathrm{CH}_{2} \mathrm{CO}_{2} \mathrm{Et}, \mathrm{CH}_{2} \mathrm{CH}(\mathrm{NHAc}) \mathrm{CO}_{2} \mathrm{H}\right)$ from $\left[\mathrm{RuCp}\left(\mathrm{PPh}_{3}\right)_{2} \mathrm{Cl}\right]$ using conventional heating and MW using a focused monomode reactor was described (Kuhnert \& Danks, 2002). Sealed tube microwave dielectric heating of diaryl acetylenes with cyclopentadienyl Co dicarbonyl at elevated temperature in $p$-xylene provided access to metallocenes in both the cyclobutadiene $\left(\mathrm{Ar}_{4} \mathrm{C}_{4} \mathrm{CoCp}, 3-52 \%\right.$ yields) and cyclopentadienone $\left(\mathrm{Ar}_{4} \mathrm{C}_{4}(\mathrm{CO}) \mathrm{CoCp}, 14-85 \%\right.$ yields) families (Harcourt et al, 2008). In the case of an especially bulky diarylacetylene (1,1'-dinaphthylacetylene), the microwave approach allowed access to a complex that cannot be readily obtained under traditional thermal conditions.

\subsection{Arene complexes}

Microwave-mediated syntheses of $\left[(\eta\right.$-arene $\left.)(\mathrm{CO})_{3} \mathrm{Mn}\right]\left(\mathrm{PF}_{6}\right)$ complexes (Dabirmanesh et al, 1997), $\left[\mathrm{Fe}\left(\eta-\mathrm{C}_{5} \mathrm{H}_{5}\right)(\eta\right.$-arene $\left.)\right]\left[\mathrm{PF}_{6}\right]$ salts from reactions of $\mathrm{Fe}\left(\mathrm{C}_{5} \mathrm{H}_{5}\right)_{2}$ with arenes and chloroarenes, as well as $\left[\mathrm{Fe}(\eta \text {-arene })_{2}\right]\left[\mathrm{PF}_{6}\right]_{2}$ salts from reaction of arenes and $\mathrm{FeCl}_{3}$ (Dabirmanesh et al, 1993) were reported relatively long ago. Reaction times were reduced from several hours by conventional methods to a few minutes using an unmodified domestic microwave oven. Microwave heating was employed to promote arene displacement in reactions of $\left[(p-c y m e n e) \mathrm{RuCl}_{2}\right]_{2}$ or $\left[\left\{\left(1,3,5-\mathrm{C}_{6} \mathrm{H}_{3}(i-\mathrm{Pr})_{3}\right) \mathrm{RuCl}_{2}\right\}_{2}\right]$ with neutral chelate ligands L-L' [L-L': 1,1'-bis(diphenylphosphanyl)methane, 1,1'bis(diphenylphosphanyl)ferrocene, (S)-BINAP, (S,S)-DIOP, N,N'-bis(2,4,6-trimethylphenyl)1,2-ethanediylidenediamine], (R)-Ph-PHOX, and (phenylsulfanylpropyl)diphenylphosphine giving $\left[(\right.$ arene $\left.) \mathrm{Ru}(\mu-\mathrm{Cl})_{3}-\mathrm{RuCl}\left(\mathrm{L}-\mathrm{L}^{\prime}\right)\right]$ in good yield (Albrecht et al, 2009). Also, the MWAS of ( $\eta^{6}$-arene)tricarbonylchromium complexes from hexacarbonylchromium with arenes gave high yields of products $\mathbf{3 2}$ (reaction 12) (Lee et al, 2006).



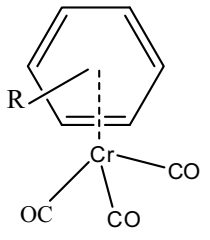

32

\subsection{Other organometallics}

The effect of the microwave irradiation on the reaction of alkynyl alkoxy carbene complexes with urea derivatives was studied (Spinella et al, 2003), showing that in these conditions $(\mathrm{CO})_{5} \mathrm{~W}: \mathrm{C}(\mathrm{OEt}) \mathrm{C} \equiv \mathrm{CPh}$ reacted with ureas, $(\mathrm{RNH}) \mathrm{C}(\mathrm{O})(\mathrm{NHR})$ (e.g., $\mathrm{R}, \mathrm{R}^{\prime}=\mathrm{H}, \mathrm{Me}$, allyl, $\mathrm{Et}$ ), with reduced reaction times to give uracil derivatives 33. It is noteworthy that the use of large amounts of solvents could be drastically reduced or even avoided and, in any case, reaction times were dramatically shortened. The MWAS of two different types of Nheterocyclic carbene-palladium(II) complexes, $(\mathrm{NHC}) \mathrm{Pd}(\mathrm{acac}) \mathrm{Cl}(\mathrm{NHC}=\mathrm{N}$-heterocyclic carbene; acac $=$ acetylacetonate $)$ and $(\mathrm{NHC}) \mathrm{PdCl}_{2}$ (3-chloropyridine), led to drastic reduction in reaction times (20 to 88 times faster, depending on the complex) (Winkelmann \& Navarro, 
2010). The complex (IPr)Pd(acac)Cl [IPr=1,3-bis(2,6-diisopropylphenyl)imidazol-2-ylidene] was similarly obtained. Bridged and unbridged N-heterocyclic carbene (NHC) ligands were metalated under $\mathrm{MW}$-conditions with $\left[\operatorname{Ir}(\mathrm{COD}) \mathrm{Cl}_{2}\right.$ to give $\operatorname{Ir}(\mathrm{I})$ mono- and biscarbene substituted catalysts $[\operatorname{Ir}(\mathrm{COD}) \mathrm{NHC}(\mathrm{Cl})]$ and $\left[\operatorname{Ir}(\mathrm{COD})(\mathrm{NHC})_{2}\right][\mathrm{X}]\left(\mathrm{X}=\mathrm{I}, \mathrm{PF}_{6}, \mathrm{BF}_{4}, \mathrm{CF}_{3} \mathrm{COO}\right.$, OTf) (Rentzsch et al, 2009). Palladium(II) carbene complexes were also reported in (Scarborough et al, 2009).<smiles></smiles>

33

Diene derivatives are represented by the first example of microwave-promoted solid-state synthesis of $\mathrm{Na}$ complex $\left[\mathrm{Na}(\mathrm{L})(\mu-\mathrm{EP}) \cdot \mathrm{H}_{2} \mathrm{O}\right]_{2}$ derived from a heteromacrocyclic compound (Tusek-Bozic et al, 2007). This alkali complex, as a diphosphonate-bridged dinuclear species, was prepared from the 15-membered mixed dioxa-diaza macrocycle 5,6,14,15-dibenzo-1,4dioxa-8,12-diazacyclopentadeca-5,14-diene (L) by reaction with $\mathrm{Na}$ Et [4- $\alpha$ (benzeneazoanilino)-N-benzyl]phosphonate $\left(\mathrm{NaEP} \cdot 1.5 \mathrm{H}_{2} \mathrm{O}\right)$. MW-heating of metal-allyl complexes can result organic products. Thus, nucleophilic attack of 3-hydroxycoumarin on $\eta^{3}$ - $\pi$-allylpalladium complex, formed from substituted cinnamyl alcohols $34\left(R^{1}=R^{2}=H\right.$, $\left.\mathrm{MeO}, \mathrm{R}^{3}=\mathrm{H} ; \mathrm{R}^{1}=\mathrm{OCH}_{2} \mathrm{Ph}, \mathrm{R}^{2}=\mathrm{MeO}, \mathrm{R}^{3}=\mathrm{H}\right)$ and acetyls $34\left(\mathrm{R}^{3}=\mathrm{COMe}\right)$ in the presence of palladium acetylacetonate and triphenylphosphine, resulted in normal addition products like 4-(3'-phenylallyl)-3-hydroxycoumarin, except for cinnamyl acetate, which provided an unusual product, 4-(1'-phenylallyl)-3-hydroxycoumarin, by conventional and MWH (Mitra et al, 2003).<smiles>[R]c1ccc(CCCO)cc1[R]</smiles>

Table 1. Main containing ligands' units present in the studied MW-synthesized complexes.

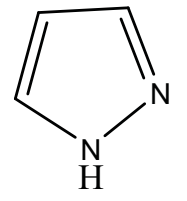

Pyrazol

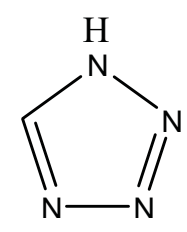

Tetrazole<smiles>c1ccc2[nH]cnc2c1</smiles>

Benzimidazole 
<smiles>c1c[nH]cn1</smiles>

Imidazole<smiles>c1nc[nH]n1</smiles>

1,2,4-Triazole<smiles>c1ccncc1</smiles>

Pyrazine<smiles>c1ccncc1</smiles>

Pyridine<smiles>c1ccc2nccnc2c1</smiles>

Quinoxaline (benzopyrazine)<smiles>CS(N)(=O)=O</smiles>

Sulfamoyl radical

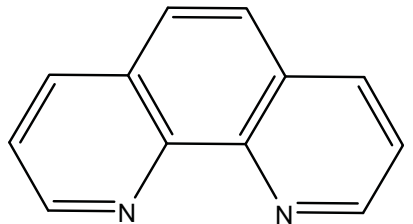

1,10-Phenantroline<smiles>c1ccc(-c2cccc(-c3ccccn3)n2)nc1</smiles>

Terpyridine<smiles>CC(=NO)C(C)=NO</smiles>

Dimethylglyoxime

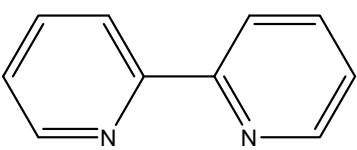

2,2'-Bipyridine<smiles>CC(=O)CC(C)=O</smiles>

2,4-pentanedione, an example of a $\beta$-diketone<smiles>Oc1ccccc1/C=N/CC/N=C/c1ccccc1O</smiles>

Salen
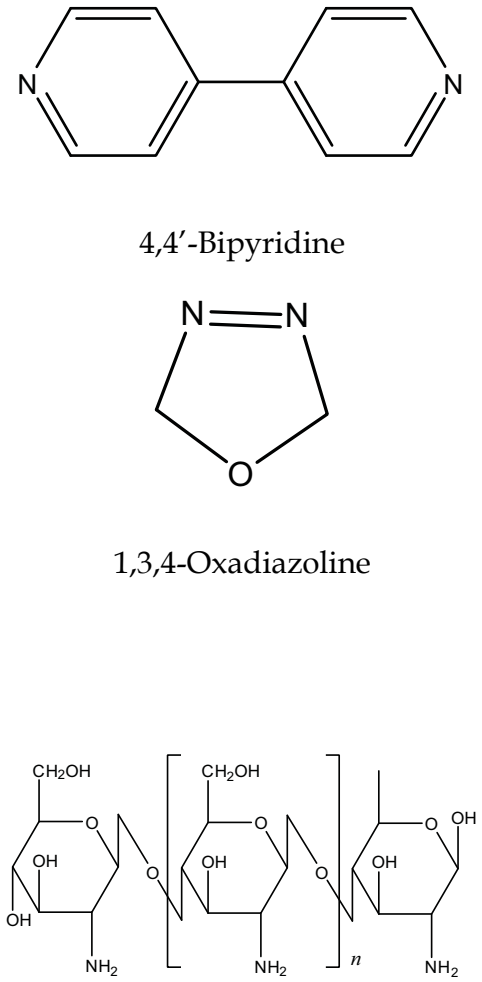

4,4'-Bipyridine<smiles>C1N=NCO1</smiles>

1,3,4-Oxadiazoline

Chitosan 
<smiles>c1cscn1</smiles>

Thiazole

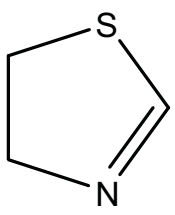

Thiazoline<smiles>S/C=C\S</smiles>

Dithiolene moiety<smiles>[R]C([R])=NN([R])C(=O)N([R])[R]</smiles>

Semicarbazone<smiles>Cc1ccc(C(C)C)cc1</smiles>

Cymene<smiles>[R]C([R])=NN([R])C(=S)N([R])[R]</smiles>

Thiosemicarbazone

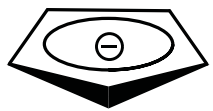

Cyclopentadienyl anion



3,4-Dimethylthiophene

\section{Microwave-assisted catalysis using metal complexes}

Several reports are dedicated to the use of metal (mainly noble metals, such as Rh, Pd, Os, which in free form are used in catalytic processes) complexes in MWAS or rearrangements of organic compounds. Thus, a highly efficient $\mathrm{C}-\mathrm{C}$ bond cleavage of unstrained aliphatic ketones bearing $\beta$-hydrogens with olefins was achieved using a chelation-assisted catalytic system consisting of $\left(\mathrm{Ph}_{3} \mathrm{P}\right)_{3} \mathrm{RhCl}$ and 2-amino-3-picoline by $\mathrm{MW}$ under solvent-free conditions (Ahn et al, 2006). The addition of cyclohexylamine catalyst accelerated the reaction rate dramatically under microwave irradiation compared with the classical heating method. Microwave-assisted Rh-diphosphane-complex-catalyzed dual catalysis, providing $[2+2+1]$ cycloadducts by sequential decarbonylation of aldehyde or formate and carbonylation of enynes within a short period of time, was reported (Lee et al, 2008). Various $\mathrm{O}-, \mathrm{N}-$, and C-tethered enynes were transformed into the corresponding products in good yields. The first enantioselective version of this microwave-accelerated cascade cyclization was realized. In the presence of chiral Rh-(S)-bisbenzodioxanPhos complex, the cyclopentenone products were achieved with ee values up to $90 \%$. Osmium complex ( $\mu$ $\mathrm{H}) \mathrm{Os}_{3}(\mu-\mathrm{O}: \mathrm{CPh})(\mathrm{CO})_{10}$ was an active catalyst for the allylic rearrangement $\mathrm{N}$-allylacetamide under MW-radiation (Afonin et al, 2008). 
An efficient method for intermolecular hydroarylation of aryl and aliphatic alkenes with indoles using a combination of $\left[\left(\mathrm{PR}_{3}\right) \mathrm{AuCl}\right] / \mathrm{AgOTf}$ as catalyst under thermal and microwave-assisted conditions was developed (Wang ert al, 2008), achieving the gold(I)catalyzed reactions of indoles with aryl alkenes in toluene at $85^{\circ} \mathrm{C}$ over a reaction time of $1-3$ $\mathrm{h}$ with $2 \mathrm{~mol} \%$ of $\left[\left(\mathrm{PR}_{3}\right) \mathrm{AuCl}\right] / \mathrm{AgOTf}$ as catalyst (yields 60-95\%). Under microwave irradiation, coupling of unactivated aliphatic alkenes with indoles gave the corresponding adducts in up to $90 \%$ yield. Additionally, metal acetates were found to be effective catalysts; thus, a rapid and efficient method for the synthesis of $\beta$-arylalkenyl nitriles by a one-pot three component coupling reaction of diphenylacetylene, $\mathrm{K}_{4} \mathrm{Fe}(\mathrm{CN})_{6}$, and aryl halides using $\mathrm{Pd}(\mathrm{OAc})_{2}$ as a catalyst and water as a solvent under MW (Velmathi et al, 2010). The method employed a cyanide source which is safe and inexpensive. Copper-catalyzed cyanation of aryl halides was improved to be more economical and environmentally friendly by using water as the solvent and ligand-free $\mathrm{Cu}(\mathrm{OAc})_{2} \cdot \mathrm{H}_{2} \mathrm{O}$ as the catalyst under MW (Ren et al, 2009). The suggested methodology was applicable to a wide range of substrates including aryl iodides and activated aryl bromides.

\section{Conclusions}

In the coordination and organometallic chemistry, the microwave-assisted synthesis is not developed such sufficiently as for the preparation of inorganic compounds, composites and materials or in the organic synthesis, where microwave heating can be considered as a common preparative tool. However, during the last decade a considerable growth of related reports has been registered. The most number of reports corresponds to MW-reactions of the $\mathrm{N}-, \mathrm{N}, \mathrm{O}-$, and $\mathrm{N}, \mathrm{S}$-containing ligands with sources of metal ions. Some MW-fabricated classic $\pi$ - and $\sigma$-organometallic compounds are also presented.

Practically in all reports, main attention of researchers is paid to extreme fastness of MWassisted reactions in comparison with classic protocols. The same reactions in the MW-field take place in 10-100 times more rapidly. Moreover, higher or comparable yields are frequently reported. Sometimes, the MW-route leads to products, which it is impossible to get via traditional routes, for instance preparation of several metal cluster complexes.

Despite of the development of novel synthesis techniques in chemistry and especially nanotechnology (for example, laser-, sputtering-, CVD-, electron- and ion-beam-, radiation-, or combustion-assisted methods, among many others, the microwave heating remains very attractive for chemists due to its obvious advantages, noted at the beginning of this chapter.

\section{Abbreviations}

2-dpds $=2,2$-dipyridyldisulfide

acac $=$ acetylacetonate

APBMPA = (3-aminopropyl)bis(2-pyridylmethyl)amine

BMPA = bis(2-pyridylmethyl)amine

bbi = 1,1'-(1,4-butanediyl)bis(imidazole)

bpd $=3$-bromo-2,4-pentanedionate ion

bpy, bipy $=2,2$-bipyridine

bpydc $=2,2$ '-bipyridine-5,5'-dicarboxylate

$\mathrm{BTEC}=1,2,4,5$-benzenetetracarboxylate anion

CDEPE = N,N'-bis(3-carboxy-1-oxopropanyl)-1,2-diethylethylenediamine 
CDEPE-2 = N,N'-bis(3-carboxy-1-oxoprop-2-enyl)-1,2-diethylethylenediamine

$\mathrm{CDMPE}=\mathrm{N}, \mathrm{N}^{\prime}$-bis(3-carboxy-1-oxopropanyl)-1,2-dimethylethylenediamine

CDMPE-2 = bis(3-carboxy-1-oxoprop-2-enyl)-1,2-dimethylethylenediamine

$\mathrm{CPE}=\mathrm{N}, \mathrm{N}^{\prime}$-bis-(3-carboxy-1-oxopropanyl)-1,2-ethylenediamine

$\mathrm{CPP}=\mathrm{N}, \mathrm{N}^{\prime}$-bis-(3-carboxy-1-oxo-propanyl)-1,2-phenylenediamine

CPP-2 = N,N'-bis-(3-carboxy-1-oxoprop-2-enyl)-1,2-phenylenediamine

CPPP = N,N'-bis-(2-carboxy-1-oxophenelenyl)-1,2-phenylenediamine

$\mathrm{DBU}=1,8$-diazabicyclo[5,4,0] undec-7-ene

$\mathrm{dcmb}=4,4$ '-dimethoxycarbonyl-2,2'-bipyridine

DMAD = di-methylacetylenedicarboxylate

DMAE $=$ dimethylaminoethanol

$\mathrm{DMF}=\mathrm{N}, \mathrm{N}$-dimethylformamide

dppe $=1,2-b i s$ (diphenylphosphino)ethane

2-dps $=2,2$-dipyridylsulfide

EMim = 1-ethyl-3-methylimidazolium

$\mathrm{H}_{2}$ bzimpy $=2,6$-bis(benzimidazol-2-yl)pyridine

Hdpa $=$ bis(2-pyridyl)amine

$\mathrm{H}_{2} \mathrm{NDC}=2$,6-naphthalenedicarboxylic acid

$\mathrm{H}_{2} \mathrm{oba}=4,4$ '-oxydibenzoic acid

$\mathrm{H}_{2}$-Saly-BTZ = 2-(2-hydroxyphenyl)-2-(phenylamino)benzothiazoline

HSAT $=2$-(N-salicylideneamino $)$-3-carboxyethyl-4,5-dimethylthiophene

$\mathrm{H}_{2} \mathrm{TPyP}=5,10,15,20$-tetrakis(2-pyridyl)porphyrin

$\mathrm{H}_{3} \mathrm{IDC}=4,5$-imidazoledicarboxylic acid

Hpyt = pyridine-2 $(1 \mathrm{H})$-thione

$\mathrm{H}_{3} \mathrm{TMA}=$ trimesic acid

$\mathrm{H}_{4}$ btec $=1,2,4,5$-benzenetetracarboxylic acid

LiPBMPA = 3-[bis(2-pyridylmethyl)amino]propanoate

$\mathrm{MW}=$ microwave irradiation

MWAS = microwave-assisted synthesis

$\mathrm{MWH}=$ microwave heating

$\operatorname{Mg}$ (TBPor) = 5,10,15,20-tetrakis(4-tert-butylphenyl)magnesium porphyrins

$\operatorname{mimp}=2$-methyliminomethylphenolate anion

MORE = microwave-induced organic reaction enhancement

MPBMPA = Me 3-[bis(2-pyridylmethyl)amino]propanoate

MWAACVD = microwave plasma aerosol-assisted chemical vapor deposition

MWPECVD = microwave plasma enhanced chemical vapor deposition

$\mathrm{OA}=$ oleic acid

OAm = oleylamine

PABMPA = 3-[bis(2-pyridylmethyl)amino]propanamide

PDHEP $=\left[\mathrm{N}, \mathrm{N}^{\prime}\right.$-bis(1,5-dimethylhexyl)-3,4:9,10-perylenebis(dicarboximide)

phen $=1,10$-phenanthroline

pip = piperidine

PNBMPA = 3-[bis(2-pyridylmethyl)amino]propionitrile

pytrz $=2-(1-a l k y l /$ aryl-1H-1,2,3-triazol-4-yl)pyridine

pyz $=$ pyrazolyl ligand

$\mathrm{Pz}=$ pyrazine 
PzAM = pyrazine carboxamide

PzCA = pyrazine carboxylic acid

$\mathrm{saoH}_{2}=$ salicylaldoxime

SRaaiNR = 1-alkyl-2-\{(o-thioalkyl)phenylazo\}imidazoles

tbbpy $=4,4$ '-di-tert-butyl-2,2'-bipyridine

TBHP = tert-butyl hydroperoxide

TBBZTH $=3,4,5$-trimethoxybenzaldehydebenzothiazoline

TBDTCZH = 3,4,5-trimethoxybenzaldehyde-S-benzyldithiocarbazate

TBSCZH = 3,4,5-trimethoxybenzaldehydesemicarbazone

TBTSCZH = 3,4,5-trimethoxybenzaldehydethiosemicarbazone

tipsepd $=3-(($ triisopropylsilyl)ethynil)-2,4-pentanedionate ion

TRISPHAT-N = 2,3-pyridinyldioxy anionic phosphate

\section{Acknowledgements}

The authors are very grateful to Professors Yurii E. Alexeev and Alexander D. Garnovskii (Southern Federal University, Rostov-na-Donu, Russia) for critical revision of the final manuscript.

\section{References}

Abdelsayed, V.; Aljarash, A.; El-Shall, M.S.; Al Othman, Z.A.; Alghamdi, A.H. (2009). Microwave synthesis of bimetallic nanoalloys and $\mathrm{CO}$ oxidation on ceria-supported nanoalloys. Chemistry of Materials, 21(13), 2825-2834.

Afonin, M. Yu.; Maksakov, V. A. (2008). Effect of microwave radiation on the allylic rearrangement catalyzed by cluster complexes with chemically labile ligands. Russ. d Coord. Chem., 34(11), 869-870.

Ahluwulia, V.K. (2007). Alternate Energy Processes in Chemical Synthesis: Microwave, Ultrasonic, and Photo Activation. Alpha Science Int'l Ltd, 280 pp.

Ahn, J.-A.; Chang, D.-H.; Park, Y.J.; Yon, Y.R.; Loupy, A.; Jun, C.-H. (2006). Solvent-free chelation-assisted catalytic C-C bond cleavage of unstrained ketone by rhodium(I) complexes under microwave irradiation. Advanced Synthesis \& Catalysis, 348(1+2), 55-58.

Albrecht, C.; Gauthier, S.; Wolf, J.; Scopelliti, R.; Severin, K. (2009). Microwave-assisted organometallic syntheses: formation of dinuclear [(arene) $\left.\mathrm{Ru}(\mu-\mathrm{Cl})_{3} \mathrm{RuCl}\left(\mathrm{L}-\mathrm{L}^{\prime}\right)\right]$ complexes (L-L': chelate ligands with $\mathrm{P}_{-}, \mathrm{N}-$, or S-donor atoms) by displacement of arene ligands. Eur. el Inorg. Chem., (8), 1003-1010.

Aléo, A. D'; Welter, S.; Cecchetto, E.; De Cola, L. (2005). Electronic energy transfer in dinuclear metal complexes containing meta-substituted phenylene units. Pure Appl. Chem., 77(6), 1035-1050.

Ali, P.; Ramakanth, P.; Meshram, J. (2010). Exploring microwave synthesis for co-ordination: synthesis, spectral characterization and comparative study of transition metal complexes with binuclear core derived from 4-amino-2,3-dimethyl-1-phenyl-3pyrazolin-5-one. el Coord. Chem., 63(2), 323-329.

Amarante, T.R.; Almeida Paz, F.A.; Gago, S.; Gonçalves, I.S.; Pillinger, M.; Rodrigues, A.E.; Abrantes, M. (2009). Microwave-Assisted Synthesis and Crystal Structure of 
Oxo(diperoxo)(4,4'-di-tert-butyl-2,2'-bipyridine)-molybdenum(VI). Molecules, 14, 3610-3620.

Amo-Ochoa, P.; Givaja, G.; Miguel, P.J.S.; Castillo, O.; Zamora, F. (2007). Microwave assisted hydrothermal synthesis of a novel CuI-sulfate-pyrazine MOF. Inorg. Chem. Commun., 10(8), 921-924.

Andrews, P.C.; Deacon, G.B.; Junk, P.C.; Spiccia, N.F. (2007). Exploration of solvent free and/or microwave assisted syntheses of bismuth(III) thiolates. Green Chemistry, 9(12), 1319-1327.

Ardon, M.; Hogarth, G.; Oscroft, D.T.W. (2004). Organometallic chemistry in a conventional microwave oven: the facile synthesis of group 6 carbonyl complexes. I Organomet. Chem., 689(15), 2429-2435.

Bagley, M.C.; Lin, Z.; Pope, S.J.A. (2010). Microwave-assisted synthesis and complexation of luminescent cyanobipyridyl-zinc(II) bis(thiolate) complexes with intrinsic and ancillary photophysical tunability. Dalton Trans., 39(13), 3163-3166.

Bahadoran, F.; Dialameh, S. (2005). Microwave assisted synthesis of substituted metallophthalocyanines and their catalytic activity in epoxidation reaction. $d$ Porphyr. Phthalocyan., 9(3), 163-169.

Bahnmueller, S.; Langstein, G.; Hitzbleck, J.; Volkmer, D.; Lu, Y.; Tonigold, M. (2009). Cobalt(II)-based redox- and catalytic active metal-organic framework (MOF) compounds. German patent DE 102008027218, 11 pp.

Banerjee, P.; Pandey, O.P.; Sengupta, S.K. (2008). Microwave assisted synthesis, spectroscopic and antibacterial studies of titanocene chelates of Schiff bases derived from 3-substituted-4-amino-5-hydrazino-1,2,4-triazoles. Transition Metal Chemistry, 33(8), 1047-1052.

Banerjee, P.; Pandey, O.P.; Sengupta, S.K. (2009). Microwave-assisted synthesis, spectroscopy and biological aspects of binuclear titanocene chelates of isatin-2,3bis(thiosemicarbazones). Applied Organometallic Chemistry, 23(1), 19-23.

Beckford, F.A.; Shaloski, M., Jr.; Leblanc, G.; Thessing, J.; Seeram, N.P.; Li, L. (2009). Mixed ligand diimine-thiosemicarbazone complexes of ruthenium(II): Synthesis, biophysical reactivity and cytotoxicity. Abstracts of Papers, 237th ACS National Meeting, Salt Lake City, UT, United States, March 22-26, 2009, CHED-585.

Beckford, F.; Shaloski, M.; Thessing, J.; Morgan, C. (2010). Microwave synthesis of mixed ligand diimine-thiosemicarbazone complexes of ruthenium(II): Reactivity with DNA and human serum albumin. Abstracts of Papers, 239th ACS National Meeting, San Francisco, CA, United States, March 21-25, 2010, INOR-225.

Beltran, H.I.; Esquivel, R.; Lozada-Cassou, M.; Dominguez-Aguilar, M.A.; Sosa-Sanchez, A.; Sosa-Sanchez, J.L.; Hoepfl, H.; Barba, V.; Luna-Garcia, R.; Farfan, N.; ZamudioRivera, L.S. (2005). Nanocap-shaped tin phthalocyanines: Synthesis, characterization, and corrosion inhibition activity. Chemistry--A European eburnal, 11(9), 2705-2715.

Beneš, L.; Melánova, K.; Zima, V.; Kalousová, J.; Votinský, J. (1997). Preparation and Probable Structure of Layered Complexes of Vanadyl Phosphate with 1-Alkanols and 1, $\omega$-Alkanediols. Inorg. Chem. 36, 2850-2854.

Berdonosov, S.S.; Kopilova, I.A.; Lebedev, V.Ya.; Chesnokov, D.E. (1992). Use of microwave irradiation for preparation of non-aqueous zirconium acetylacetonate. Neorg. Mater. 28(5), 1022. 
Besson, T.; Thiery, V.; Dubac, J. (2006). Microwave-assisted reactions on graphite. Microwaves in Organic Synthesis (2nd Edition), 1, 416-455.

Bhojak, N.; Gudasaria, D.D.; Khiwani, N.; Jain, R. (2007). Microwave Assisted Synthesis Spectral and Antibacterial Investigations on Complexes of Mn(II) With Amide Containing Ligands. E-eburnal of Chemistry, 4(2), 232-237.

Bhojak, N.; Singh, B. (2008). Microwave assisted synthesis, spectral and antibacterial investigations on complexes of $\mathrm{Mn}(\mathrm{II})$ with amide containing ligands. Rasayan eburnal of Chemistry, 1(1), 105-109.

Bilecka, I.; Djerdj, I.; Niederberger, M. (2008). One-minute synthesis of crystalline binary and ternary metal oxide nanoparticles. Chem. Communs, (7), 886-888.

Biyiklioglu, Z.; Kantekin, H.; Oezil, M. (2007). Microwave-assisted synthesis and characterization of novel metal-free and metallophthalocyanines containing four 14-membered tetraaza macrocycles. el Organomert. Chem., 692(12), 2436-2440.

Bokach, N.A.; Krokhin, A.A.; Nazarov, A.A.; Kukushkin, V.Yu.; Haukka, M.; Frausto da Silva, J.J.R.; Pombeiro, A.J.L. (2005). Interplay between nitrones and (nitrile)PdII complexes: Cycloaddition vs. Complexation followed by cyclopalladation and deoxygenation reactions. Eur. el Inorg. Chem., (15), 3042-3048.

Bokach, N.A.; Kukushkin, V.Yu.; Haukka, M.; Mikhailova, T.B.; Sidorov, A.A.; Eremenko, I.L. (2006). Co(II)-Mediated and microwave assisted coupling between 2,6diaminopyridine and nitriles. A new synthetic route to $\mathrm{N}$-(6-aminopyridin-2yl)carboximidamides. Russ. Chem. Bull., 55(1), 36-43.

Boscencu, R.; Ilie, M.; Socoteanu, R.; Sousa Oliveira, A.; Constantin, C.; Neagu, M.; Manda, G.; Vieira Ferreira, L.F. (2010). Microwave Synthesis, Basic Spectral and Biological Evaluation of Some Copper (II) Mesoporphyrinic Complexes. Molecules, 15, 3731-3743.

Causey, P.W.; Besanger, T.R.; Schaffer, P.; Valliant, J.F. (2008). Expedient Multi-Step Synthesis of Organometallic Complexes of Tc and Re in High Effective Specific Activity. A New Platform for the Production of Molecular Imaging and Therapy Agents. Inorg. Chem., 47(18), 8213-8221.

Chandrasekharam, M.; Rao, C.S.; Singh, S.P.; Kantam, M.L.; Reddy, M.R.; Reddy, P.Y.; Toru, T. (2007). Microwave-assisted synthesis of metalloporphyrazines. Tetrahedron Lett., 48(14), 2627-2630.

Chaudhary, P.; Swami, M.; Sharma, D.K.; Singh, R. V. (2009). Ecofriendly synthesis, antimicrobial and antispermatogenic activity of triorganotin(IV) complexes with 4'nitrobenzanilide semicarbazone and 4'-nitrobenzanilide thiosemicarbazone. Applied Organometallic Chemistry, 23(4), 140-149.

Chemat, F.; Poux, M.; Berlan, J. J. (1996). An original microwave-ultrasound combined reactor suitable for organic synthesis: application to pyrolysis and esterification. Microwave Power \& Electromag. Energy. 31(1), 19.

Cho, T.J.; Shreiner, C.D.; Hwang, S.-H.; Moorefield, C.N.; Courneya, B.; Godinez, L.A.; Manriquez, J.; Jeong, K.-U.; Cheng, S.Z.D.; Newkome, G.R. (2007). 5,10,15,20Tetrakis[4'-(terpyridinyl)phenyl]porphyrin and its $\mathrm{Ru}^{\mathrm{II}}$ complexes: Synthesis, photovoltaic properties, and self-assembled morphology. Chem. Commun., (43), 4456-4458.

Dabirmanesh, Q.; Roberts, R.M.G. (1993). The synthesis of iron sandwich complexes by microwave dielectric heating using a simple solid $\mathrm{CO}_{2}$-cooled apparatus in an unmodified commercial microwave oven. eburnal of Organometallic Chemistry, 460(2), C28-C29. 
Dabirmanesh, Q.; Roberts, R.M.G. (1997). The application of microwave dielectric heating to the synthesis of arene-metal complexes. Synthesis of $\left[(\eta\right.$-arene $\left.)(\mathrm{CO})_{3} \mathrm{Mn}\right] \mathrm{PF}_{6}$ complexes and $\left[(\eta\right.$-arene $)(\eta$-cyclopentadienyl)Fe $]\left[\mathrm{PF}_{6}\right]$ complexes with triphenylphosphine, tert-butylbenzenes and a sterically hindered phenol as arene ligands. eburnal of Organometallic Chemistry, 542(1), 99-103.

Dayalan, A.; Meera, P.; Balaraju, K.; Agastian, P.; Ignasimuthu, S. (2009). Halocobaloximes containing axially coordinated imidazole or histidine: microwave assisted synthesis, characterization and antibacterial activity. Journal of the Indian Chemical Society, 86(6), 628-632.

Delgado, S.; Sanz Miguel, P.J.; Priego, J.L.; Jimenez-Aparicio, R.; Gomez-Garcia, C.J.; Zamora, F. (2008). A Conducting Coordination Polymer Based on Assembled Cu, Cages. Inorg. Chem. 47(20), 9128-9130.

Delgado, S.; Santana, A.; Castillo, O.; Zamora, F. (2010). Dynamic combinatorial chemistry in a solvothermal process of $\mathrm{Cu}(\mathrm{I}, \mathrm{II})$ and organosulfur ligands. Dalton Trans., 39(9), 2280-2287.

Desai, B.; Danks, T.N.; Wagner, G. (2004). Ligand discrimination in the reaction of nitrones with $\left[\mathrm{PtCl}_{2}(\mathrm{PhCN})_{2}\right]$. Selective formation of mono-oxadiazoline and mixed bisoxadiazoline complexes under thermal and microwave conditions. Dalton Trans., (1), 166-171.

Dickhoff, J.N.; Hoeltje, N.; Kellen-Yuen, C. (2006). Microwave synthesis of 3,4-disubstituted1-H-pyrrole-2-carboxylates. Abstracts of Papers, 231st ACS National Meeting, Atlanta, GA, United States, March 26-30, 2006, CHED-432.

Dittmar, A.; Kosslick, H.; Muller, J.-P.; Pohl, M.-M. (2004). Characterization of cobalt oxide supported on titania prepared by microwave plasma enhanced chemical vapor deposition. Surface and Coatings Technology, 182(1), 35-42.

Dittmar, A.; Herein, D. (2009). Microwave plasma assisted preparation of disperse chromium oxide supported catalysts. Surface and Coatings Technology, 203(8), 992-997.

Fraunhofer-Gesellschaft; Gorun, Sergiu M.; Schnurpfeil, Guenter; Hild, Olaf; Woehrle, Dieter; Tsaryova, Olga; Gerdes, Robert. (2009). Microwave-assisted synthesis of perfluorophthalocyanine molecules. PCT Int. Appl. WO 2009139973, 20 pp.

Fu, Z.; Liao, H.; Xiong, D.; Zhang, Z.; Jiang, Y.; Yin, D. (2007). A highly-efficient and environmental-friendly method for the preparation of $\mathrm{Mn}$ (III)-salen complexes encapsulated HMS by using microwave irradiation. Microporous and Mesoporous Materials, 106(1-3), 298-303.

Gairola, A.; Umarji, A.M.; Shivashankar, S.A. (2009). Microwave irradiation-assisted method for the rapid synthesis of fine particles of $\alpha-\mathrm{Al}_{2} \mathrm{O}_{3}$ and $\alpha-\left(\mathrm{Al1}-\mathrm{XCr}_{\mathrm{x}}\right)_{2} \mathrm{O}_{3}$ and their coatings on Si(100). Ceramic Transactions, 203(Processing and Properties of Advanced Ceramics and Composites), 15-21.

Gao, F.; Yang, D.; Cui, D.; He, R. (2009). Preparation of particle-size-controllable magnetic ferroferric oxide nanoparticle microspheres by microwave heating in nonaqueous solvent. Patent of China CN 101337695, 9 pp.

Garringer, S.M.; Hesse, A.J.; Magers, J.R.; Pugh, K.R.; O'Reilly, S.A.; Wilson, A.M.C. (2009). Microwave Synthesis of Benchmark Organo-Iron Complexes. Organometallics, 28(23), 6841-6844.

Gass, I.A.; Milios, C.J.; Whittaker, A.G.; Fabiani, F.P.A.; Parsons, S.; Murrie, M.; Perlepes, S.P.; Brechin, E.K. (2006). A Cube in a Tetrahedron: Microwave-Assisted Synthesis of an Octametallic Fe III Cluster. Inorg. Chem., 45(14), 5281-5283. 
Gaur, S.; Maanju, S.; Fahmi, N.; Singh, R. V. (2005). Synthesis and biological properties of organotin and organosilicon derivatives using microwave irradiations. Main Group Metal Chemistry, 28(5), 293-300.

Giguere, R.A. (1989). In: Organic Synthesis: Theory and Application. (Hudlicky, T., Edit.). Vol. 1, JAI Press Inc., p.103-172.

Godbert, N.; Pugliese, T.; Aiello, I.; Bellusci, A.; Crispini, A.; Ghedini, M. (2007). Efficient, ultrafast, microwave-assisted syntheses of cycloplatinated complexes. European cburnal of Inorganic Chemistry, (32), 5105-5111.

Happ, B.; Winter, A.; Hager, M.D.; Friebe, C.; Schubert, U.S. (2009). Alternative bipyridines analogs via click chemistry. Polymer Preprints, 50(2), 254-255.

Harcourt, E.M.; Yonis, S.R.; Lynch, D.E.; Hamilton, D.G. (2008). Microwave-Assisted Synthesis of Cyclopentadienyl-Cobalt Sandwich Complexes from Diaryl Acetylenes. Organometallics, 27(7), 1653-1656.

Hayes, B.L. (2004). Recent Advances in Microwave-Assisted Synthesis. AldrichChimica Acta, 37(2), 66-76.

Hou, J.; Zhou, Z.-Y.; Wu, X.; Zhu, D.-X.; Li, P. (2007). Synthesis and properties of novel porphyrin compounds. Gaodeng Xuexiao Huaxue Xuebao, 28(8), 1424-1427.

Holder, A.A. (2005). Chromium, molybdenum and tungsten. Annual Reports on the Progress of Chemistry, Section A: Inorganic Chemistry, 101, 161-193.

Hsu, S.-C.; Chiang, P.-H.; Chang, C.-H.; Lin, C.-H. (2009). Catena-Poly[[tetraaquanickel(II)]$\mu_{3}$-benzene-1,3,5-tricarboxylato-3':1:2- $\kappa^{4} \mathrm{O}^{1}: \mathrm{O}^{3}, \mathrm{O}^{3}: \mathrm{O}^{5}$-[tetraaquanickel(II)]- $\quad \mu_{2^{-}}$ benzene-1,3,5-tricarboxylato-2:3 $\kappa^{2} \mathrm{O}^{1}: \mathrm{O}^{3}$-[tetraaquanickel(II)]]. Acta Crystallographica, Section E: Structure Reports Online, E65(6), m625-m626.

Hu, A.T.; Tseng, T.-W.; Hwu, H.-D.; Liu, L.-c.; Lee, C.-C.; Lee, M.-C.; Chen, J.-R. (2002). Synthesis of phthalocyanines by microwave irradiation. US Patent 6491796.

Huh, S.; Jung, S.; Kim, Y.; Kim, S.-J.; Park, S. (2010). Two-dimensional metal-organic frameworks with blue luminescence. Dalton Transactions, 39(5), 1261-1265.

Hwang, Y.K.; Jin, T.; Kim, J.M.; Kwon, Y.-Uk; Park, S.-E.; Chang, J.-S. (2006). Microwave synthesis of metallosilicate zeolites with fibrous morphology. eburnal of Nanoscience and Nanotechnology, 6(6), 1786-1791.

Inoue, H.; Seo, S. (2010). Cyclometalated organometallic complexes as phosphorescent compounds for use in light-emitting elements, light-emitting devices, and electronic devices. US Patent 010105902, 35 pp.

Jiang, Y.; Wang, Z.-m.; Ye, S.-q.; Guo, H.; Guo, S.-y. (2008). Effects of extrinsic physical fields on coordination reaction for chitosan-Fe(II). Huanan Ligong Daxue Xuebao, Ziran Kexueban, 36(7), 62-66, 71.

Jin, J.; Meng, Q.; Liu, J.; Niu, S. (2009). Synthesis, crystal structure and Photo-physical property of a series of $\mathrm{Co}^{n+}(n=2,3)$ coordination supramolecules. Liaoning Shifan Daxue Xuebao, Ziran Kexueban, 32(3), 336-340.

Jung, J.Y.; Newton, B.S.; Tonkin, M.L.; Powell, C.B.; Powell, G.L. (2009). Efficient microwave syntheses of the compounds $\mathrm{Os}_{3}(\mathrm{CO})_{11} \mathrm{~L}, \mathrm{~L}=\mathrm{NCMe}, \mathrm{py}, \mathrm{PPh}_{3}$. el Organomet. Chem., 694(21), 3526-3528.

Kahveci, B.; Sasmaz, S.; Ozil, M.; Kantar, C.; Kosar, B.; Buyukgungor, O. (2006). Synthesis and Properties of Triazol-5-one Substituted Phthalocyanines by Microwave Irradiation. Turk. el Chem., 30, 681-689.

Kim, J.H.; Heo, J.; Kang, B.M.; Son, D.-H.; Lee, G.-D.; Hong, S.-S.; Park, S.S. (2009). Microwave syntheses of subphthalocyanine derivatives and their properties. Kongop Hwahak, 20(2), 154-158. 
Kim, C.H.; Lee, H.D.; Park, S. S.; Son, D.H.; Hwang, T.G.; Jeon, S.Y. (2009). Method for preparing dithiolene-metal complex. Patent KR 2009034208, 16 pp.

Kogan, E.G.; Ivanov, A.V.; Tomilova, L.G.; Zefirov, N.S. (2002). Synthesis of mono- and bisphthalocyanine complexes using microwave irradiation. Mendeleev Commun., (2), 54-55.

Kubrakova, I.V. (2000). Effect of Microwave Radiation on Physicochemical Processes in Solutions and Heterogeneous Systems: Applications in Analytical Chemistry. cburnal of Analytical Chemistry, 55(12), 1113-1122. Translated from Zhurnal Analiticheskoi Khimii, 55(12), 2000, 1239-1249.

Kuhnert, N.; Danks, T.N. (2002). Microwave accelerated synthesis of cyclopentadienyl bisphosphine ruthenium (II) thiolato complexes using focused microwave irradiation. d Chem. Res., Synopses, (2), 66-68.

Kumari, B.S.; Rijulal, G.; Mohanan, K. (2009). Microwave assisted synthesis, spectroscopic, thermal and biological studies of some lanthanide(III) chloride complexes with a heterocyclic Schiff base. Synthesis and Reactivity in Inorganic, Metal-Organic, and Nano-Metal Chemistry, 39(1), 24-30.

Kunz, P.; Berghahn, M.; Brueckmann, N.E.; Dickmeis, M.; Kettel, M.; Spingler, B. (2009). Functionalized tris(pyrazolyl)methane ligands and $\operatorname{Re}(\mathrm{CO})_{3}$ complexes thereof. $Z$. Anorg. Allg. Chem. 635(3), 471-478.

Lagashettya, A.; Havanoorb, V.; Basavarajab, S.; Balajib, S.D.; Venkataraman, A. (2007). Microwave-assisted route for synthesis of nanosized metal oxides. Science and Technology of Advanced Materials, 8, 484-493.

Lang, J.; Tatsumi, K.; Kawaguchi, H.; Lu, J.; Ge, P.; Ji, W.; Shi, S. (1996). Microwave Irradiation Synthesis of $\mathrm{Mo}(\mathrm{W}) / \mathrm{Tl} / \mathrm{S}$ Linear Chains and Their Nonlinear Optical Properties in Solution. Inorg. Chem. 35, 7924-7927.

Leadbeater, N.E. (2010). Microwave Heating as a Tool for Sustainable Chemistry. CRC Press, 282 pp.

Lasri, J.; Charmier, M.A.J.; Guedes da Silva, M.F.C.; Pombeiro, A.J.L. (2006). Direct synthesis of (imine)platinum(II) complexes by iminoacylation of ketoximes with activated organonitrile ligands. Dalton Trans., (42), 5062-5067.

Leadbeater, N.E.; Shoemaker, K.M. (2008). Preparation of ruthenium and osmium carbonyl complexes using microwave heating: demonstrating the use of a gas-loading accessory and real-time reaction monitoring by means of a digital camera. Organometallics, 27(6), 1254-1258.

Lee, Y.T.; Choi, S.Y.; Lee, S.I.; Chung, Y.K.; Kang, T.J. (2006). Microwave-assisted synthesis of ( $\eta^{6}$-arene)tricarbonylchromium complexes. Tetrahedron Letters, 47(37), 6569-6572.

Lee, H.W.; Lee, L.N.; Chan, A.S.C.; Kwong, F.Y. (2008). Microwave-assisted rhodiumcomplex-catalyzed cascade decarbonylation and asymmetric Pauson-Khand-type cyclizations. Eur. el Org. Chem., (19), 3403-3406.

Lin, Z.; Wragg, D.S.; Morris, R.E. (2006). Microwave-assisted synthesis of anionic metalorganic frameworks under ionothermal conditions. Chem. Commun., (19), 2021-2023.

Liu, B.; Zou, R.-Q.; Zhong, R.-Q.; Han, S.; Shioyama, H.; Yamada, T.; Maruta, G.; Takeda, S.; $\mathrm{Xu}, \mathrm{Q}$. (2008). Microporous coordination polymers of cobalt(II) and manganese(II) 2,6-naphthalenedicarboxylate: preparations, structures and gas sorptive and magnetic properties. Microporous and Mesoporous Materials, 111(1-3), 470-477.

Liu, H.-K.; Tsao, T.-H.; Zhang, Y.-T.; Lin, C.-H. (2009). Microwave synthesis and singlecrystal-to-single-crystal transformation of magnesium coordination polymers 
exhibiting selective gas adsorption and luminescence properties. Cryst. Eng. Comm., 11(7), 1462-1468.

Liu, M.O.; Tai, C.-H.; Chen, C.-W.; Chang, W.-C.; Hu, A.T. (2004). The fluorescent and photoelectric conversion properties of porphyrin-perylene tetracarboxylic complex. Jburnal of Photochemistry and Photobiology, A: Chemistry, 163(1-2), 259-266.

Liu, M.O.; Tai, C.-H.; Hu, A.T. (2005). Synthesis of metalloporphyrins by microwave irradiation and their fluorescent properties. Materials Chemistry and Physics, 92(2-3), 322-326.

Liu, M.O.; Hu, A.T. (2004). Microwave-assisted synthesis of phthalocyanine-porphyrin complex and its photoelectric conversion properties. II Organomet. Chem., 689(15), 2450-2455.

Liu, W.; Ye, L.; Liu, X.; Yuan, L.; Lu, X.; Jiang, J. (2008). Rapid synthesis of a novel cadmium imidazole-4,5-dicarboxylate metal-organic framework under microwave-assisted solvothermal condition. Inorg. Chem. Commun., 11(10), 1250-1252.

Lu, J.; Chen, W. (2003). Microwave-assisted synthesis of ferrocenyl unsaturated ketones in solid phase. Huaxue Yanjiu Yu Yingyong, 15(2), 265-266, c3.

Luo, K.-j.; Xu, L.-l.; Peng, J.-b.; Wei, X.Q.; Xie, M.-k.; Jiang, Q.; Zhang, Li-f. (2007). Microwave synthesis and electroluminescent characteristic of phosphorescent cyclometalated platinum complexes with long chain $\beta$-diketonate ancillary ligands. Sichuan Daxue Xuebao, Gongcheng Kexueban, 39(5), 53-58.

Luo, K.-j.; Xu, L.-1.; Wei, X.-q.; Xie, M.-g.; Jiang, Q. (2007). Rapid synthesis of phosphorescent cyclometalated platinum complexes by microwave irradiation. Huaxue Yanjïu $Y u$ Yingyong, 19(9), 991-993.

Maanju, S.; Poonia, K.; Chaturvedi, S.; Singh, R.V. (2007). Synthesis, characterization and biological activity of dioxomolybdenum(VI) complexes with nitrogen-sulfur and nitrogen-oxygen donor ligands. International eburnal of Chemical Sciences, 5(3), 12471257.

Mahajan, K.; Fahmi, N.; Singh, R.V. (2007). Synthesis, characterization and antimicrobial studies of $\mathrm{Sb}(\mathrm{III})$ complexes of substituted thioimines. Indian eburnal of Chemistry, 46A, 1221-1225.

Mahajan, K.; Swami, M.; Joshi, S.C.; Singh, R.V. (2008). Microwave-assisted synthesis, characterization, biotoxicity and antispermatogenic activity of some antimony(III) complexes with N-O and N-S donor ligands. Appl. Organomet. Chem., 22(7), 359-368.

Mahajan, K.; Swami, M.; Singh, R.V. (2009). Microwave synthesis, spectral studies, antimicrobial approach, and coordination behavior of antimony(III) and bismuth(III) compounds with benzothiazoline. Russian eburnal of Coordination Chemistry, 35(3), 179-185.

Maree, S.E. (2005). Microwave assisted axial ligand substitution of titanium phthalocyanines. el Porphyr. Phthalocyan., 9(12), 880-883.

Martin, S.; Revathi, C.; Dayalan, A.; Mathivanan, N.; Shanmugaiya, V. (2008). Halocobaloximes containing coordinated pyrazine, pyrazine carboxylic acid and pyrazine carboxamide: microwave assisted synthesis, characterization and antibacterial activity. Rasayan eburnal of Chemistry, 1(2), 378-389.

Martínez-Palou, R. (2007). Ionic Liquid and Microwave-Assisted Organic Synthesis: A "Green" and Synergic Couple. II Mex. Chem. Soc. 2007, 51(4), 252-264.

Masilela, N.; Nyokong, T. The synthesis and photophysical properties of water soluble tetrasulfonated, octacarboxylated and quaternised 2,(3)-tetra-(2 pyridiloxy) Ga 
phthalocyanines.

http:/ / eprints.ru.ac.za/1525/1/nyokong_synthesis_and_photophysical3.pdf.

Matsumura-Inoue, T.; Tanabe, M.; Minami, T.; Ohashi, T. (1994). Aremarkably rapid synthesis of ruthenium(II) polypyridine complexes by microwave irradiation. Chem. Lett. 2443.

Meng, G.; Song, H.; Dong, Q.; Peng, D. (2004). Application of novel aerosol-assisted chemical vapor deposition techniques for SOFC thin films. Solid State Ionics, 175(14), 29-34.

Mercier, A.; Yeo, W.C.; Chou, J.; Chaudhuri, P.D.; Bernardinelli, G.; Kundig, E.P. (2009). Synthesis of highly enantiomerically enriched planar chiral ruthenium complexes via Pd-catalysed asymmetric hydrogenolysis. Chem. Commun., (35), 5227-5229.

Meshram, H. M.; Reddy, G. S. (2003). Microwave thermolysis. Part III. A rapid and convenient coupling of 2-naphthols in solvent-free condition. Indian eburnal of Chemistry, Section B: Organic Chemistry Including Medicinal Chemistry, 42B(10), 2615-2617.

Mitra, A.K.; Karchaudhuri, N.; De, Aparna; M., Jayati; Mahapatra, T. (2003). Unusual regioselectivity in nucleophilic addition to allylpalladium complex in conventional heating and under microwave irradiation. ARKIVOC, (9), 96-103.

Mondal, T. K.; Wu, J.-S.; Lu, T.-H.; Jasimuddin, Sk.; Sinha, C. (2009). Syntheses, structures, spectroscopic, electrochemical properties and DFT calculation of $\mathrm{Ru}(\mathrm{II})-$ thioarylazoimidazole complexes. . I Organomet. Chem., 694(21), 3518-3525.

Munery, S.; Jaud, J.; Bonvoisin, J. (2008). Synthesis and characterization of bis(bipyridine)ruthenium(II) complexes with bromo or protected ethynyl $\beta$-diketonato ligands. Inorg. Chem. Commun., 11(9), 975-977.

Nakashima, K.; Masuda, Y.; Matsumura-Inoue, T.; Kakihana, M. (2008, Volume Date 2009). Microwave-assisted synthesis of (tris-acetylacetonato)(2,9-dimethyl-4,7-diphenyl1,10-phenanthroline)terbium(III) complex with outstanding high green luminescence. eburnal of Luminescence, 129(3), 243-245.

Nascimento, B.F.O.; Pineiro, M.; Rocha Gonsalves, A.M.d'A.; Silva, M.R.; Beja, A.M.; Paixao, J.A. (2007). Microwave-assisted synthesis of porphyrins and metalloporphyrins: a rapid and efficient synthetic method. el Porphyr. Phthalocyan., 11(2), 77-84.

Okada, Y.; Nakano, S. (2009). Studies on ferrocene derivatives. Part XVIII. Microwave irradiation effect on the ligand exchange reaction between ferrocene derivatives and aromatic compound. Inorg. Chim. Acta, 362(13), 4853-4856.

Okamura, I.; Nagata, A. (2003). Property of a thin zirconia electrolyte film using solid oxide fuel cell grown by ECR plasma CVD method. Shinku, 46(3), 310-313.

Oliver Kappe, C.; Dallinger, D.; Murphree, S. (2009). Practical Microwawe Synthesis for Organic Chemists: Strategies, Instruments, and Protocols. Wiley-VCH, $310 \mathrm{pp}$.

Oliver Kappe, C. (2009). Controlled Microwave Heating in Modern Organic Synthesis. Angew. Chem. Int. Ed. 2004, 43, 6250 -6284.

Ouyang, Z.-Y.; Xiao, X.-M.; Zhang, J.-Y.; Xu, S.-S. (2009). Synthesis and spectrum study of compound dysprosium (III)-bis(2-benzimidazolylmethyl)amine and its interaction with DNA. Guangpu Shiyanshi, 26(1), 67-70.

Pagadala, R.; Ali, P.; Meshram, J.S. (2009). Microwave assisted synthesis and characterization of $\mathrm{N}, \mathrm{N}^{\prime}$-bis(salicylaldehydo)ethylenediimine complexes of $\mathrm{Mn}(\mathrm{II})$, $\mathrm{Co}(\mathrm{II}), \mathrm{Ni}(\mathrm{II})$, and Zn(II). el Coord. Chem., 62(24), 4009-4017.

Paredes, S. P.; Fetter, G.; Bosch, P.; Bulbulian, S. (2006). Iodine sorption by microwave irradiated hydrotalcites. eburnal of Nuclear Materials, 359(3), 155-161. 
Paredes, S. P.; Fetter, G.; Bosch, P.; Bulbulian, S. Sol-gel synthesis of hydrotalcite - like compounds. eburnal of Materials Science, 2006, 41(11), 3377-3382.

Park, S.S.; Jung, K.S.; Lee, J.Y.; Park, J.H.; Lee, G.D.; Suh, C.S. (2001). Microwave synthesis of metal phthalocyanine. Kongop Hwahak , 12(7), 750-754.

Patti, A.; Pedotti, S.; Paolo Ballistreri, F.; Trusso Sfrazzetto, G. (2009). Synthesis and Characterization of Some Chiral Metal-Salen Complexes Bearing a Ferrocenophane Substituent. Molecules, 14, 4312-4325.

Pelletier, J.; Pantel, R.; Oberlin, J. C.; Pauleau, Y.; Gouy-Pailler, P. (1991). Preparation of copper thin films at ambient temperature by microwave plasma-enhanced chemical vapor deposition from the copper (II) acetylacetonate-argon-hydrogen system. $\mathcal{I}$ Appl. Phys. 70(7), 3862-3866.

Pezet, F.; Daran, J.-C.; Sasaki, I.; Aiet-Haddou, H.; Balavoine, G.G.A. (2000). Highly Diastereoselective Preparation of Ruthenium Bis(diimine) Sulfoxide Complexes: New Concept in the Preparation of Optically Active Octahedral Ruthenium Complexes. Organometallics, 19(20), 4008-4015.

Phetmung, H.; Wongsawat, S.; Pakawatchai, C.; Harding, D.J. (2009). Microwave synthesis, spectroscopy, thermal analysis and crystal structure of an one-dimensional polymeric $\left\{\left[\mathrm{Cu}\left(4,4 \text { '-bipy) }\left(\mathrm{H}_{2} \mathrm{O}\right)_{3}\left(\mathrm{SO}_{4}\right)\right] \cdot 2 \mathrm{H}_{2} \mathrm{O}\right\}_{n}\right.$ complex. Inorg. Chim. Acta, 362(7), 2435-2439.

Pimentel, L.C.F.; de Souza, A.L.F.; Fernandez, T.Lopez; Wardell, J.L.; Antunes, O.A.C. (2007). Microwave-assisted synthesis of N,N-bis(2-pyridylmethyl)amine derivatives. Useful ligands in coordination chemistry. Tetrahedron Lett., 48(5), 831833.

Pombeiro, A.J.L.; Martins, L.M.D.R.S.; Alegria, E.C.B.A.; Kirilova, M.V. (2007). Complexes of rhenium with pyrazole or tris(1-pyrazolyl)methanes and their preparation and use as catalysts in partial oxidation, peroxidation or carboxylation of ethane and cyclohexane in mild conditions. Port. Pat. Appl. PT 103735, 25 pp.

Poonia, K.; Maanju, S.; Chaudhary, P.; Singh, R.V. (2007). Use of microwave technology for the synthesis of organotitanium(IV) and organozirconium(IV) complexes with $\mathrm{HPOH}, \mathrm{HO} \backslash \mathrm{N} \backslash \mathrm{OH}$ and $\mathrm{HO} \backslash \mathrm{N} \backslash \mathrm{SH}$ type of ligands. Transition Metal Chemistry, 32, 204-208.

Poonia, K.; Swami, M.; Chaudhary, A.; Singh, R.V. (2008). Microwave assisted synthesis, characterization and antimicrobial studies of unsymmetric imine complexes of organotitanium(IV) and organozirconium(IV). Indian eburnal of Chemistry, 47A, 9961003.

Raner, K.D.; Strauss, C.R.; Trainor, R.W. J. (1995). A new microwave reactor for batchwise organic synthesis. el Org. Chem. 60, 2456.

Ren, Y.; Wang, W.; Zhao, S.; Tian, X.; Wang, J.; Yin, W.; Cheng, L. (2009). Microwaveenhanced and ligand-free copper-catalyzed cyanation of aryl halides with $\mathrm{K}_{4}\left[\mathrm{Fe}(\mathrm{CN})_{6}\right]$ in water. Tetrahedron Lett., 50(32), 4595-4597.

Rentzsch, C.F.; Tosh, E.; Herrmann, W.A.; Kuehn, F.E. (2009). Iridium complexes of Nheterocyclic carbenes in $\mathrm{C}-\mathrm{H}$ borylation using energy efficient microwave technology: influence of structure, ligand donor strength and counter ion on catalytic activity. Green Chemistry, 11(10), 1610-1617.

Roberts, R.M.G. (2006). Synthesis of ( $\eta^{6}$-arene)( $\eta^{5}$-cyclopentadienyl) iron (II) complexes with heteroatom and carbonyl substituents. Part I: Oxygen and carbonyl substituents. $I$ Organomet. Chem., 691(12), 2641-2647. 
Roberts, R.M.G. (2006). Synthesis of ( $\eta^{6}$-arene)( $\eta^{5}$-cyclopentadienyl)iron(II) complexes with heteroatom and carbonyl substituents. Part II. Amino substituents. I Organomet. Chem., 691(23), 4926-4930.

Roussy, G.; Pearce, J.A. (1995). Foundations and Industrial Applications of Microwave and Radio Frecuency Fields. John Wiley \& Sons. Chichester-New York-Brisbane-TorontoSingapore.

Safari, N.; Jamaat, P.R.; Pirouzmand, M.; Shaabani, A. (2004). Synthesis of metallophthalocyanines using microwave irradiation under solvent free and reflux conditions. J. Porphyr. Phthalocyan., 8(10), 1209-1213.

Salazar, G.A.; Determan, J.J.; Yang, C.; Omary, M.A. (2009). Synthesis and photophysics of novel rhenium(I) pyrazolyl-triazine complexes. Abstracts of Popers, 238th ACS National Meeting, Washington, DC, United States, August 16-20, 2009, INOR-183.

Scarborough, C.C.; Bergant, A.; Sazama, G.T.; Guzei, I.A.; Spencer, L.C.; Stahl, S.S. (2009). Synthesis of PdII complexes bearing an enantiomerically resolved seven-membered N-heterocyclic carbene ligand and initial studies of their use in asymmetric Wacker-type oxidative cyclization reactions. Tetrahedron, 65(26), 5084-5092.

Schwalbe, M.; Schaefer, B.; Goerls, H.; Rau, S.; Tschierlei, S.; Schmitt, M.; Popp, J.; Vaughan, G.; Henry, W.; Vos, J.G. (2008). Synthesis and characterisation of poly(bipyridine)ruthenium complexes as building blocks for heterosupramolecular arrays. European eburnal of Inorganic Chemistry, (21), 3310-3319.

Seven, O.; Dindar, B.; Gultekin, B. (2009). Microwave-Assisted Synthesis of Some Metal-Free Phthalocyanine Derivatives and a Comparison with Conventional Methods of their Synthesis. Turk. \& Chem., 33, 123-134.

Shaabani, A.; Safari, N.; Bazgir, A.; Bahadoran, F.; Sharifi, N.; Jamaat, P.R. (2003). Synthesis of the tetrasulfo- and tetranitrophthalocyanine complexes under solvent-free and reflux conditions using microwave irradiation. Synth. Commun., 33(10), 1717-1725.

Shangzhao Shi and Jiann-Yang Hwang (2003). Microwave-assisted wet chemical synthesis: advantages, significance, and steps to industrialization. eburnal of Minerals \& Materials Characterization \& Engineering, 2 (2), 101-110.

Sharma, K.; Singh, R.; Fahmi, N.; Singh, R.V. (2010). Microwave assisted synthesis, characterization and biological evaluation of palladium and platinum complexes with azomethines. Spectrochimica Acta, Part A: Molecular and Biomolecular Spectroscopy, 75A(1), 422-427.

Shen, Y.; He, B.-j.; Li, B.-j.; Lin, J.-j. (2008). Synthesis and bioactivity of salicylaldehyde thiosemicarbazone and its metal complexes under microwave irradiation. Huaxue Gongchengshi, 22(7), 68-70.

Shi, Z.-F.; Jin, J.; Li, L.; Xing, Y.-H.; Niu, S.-Y. (2009). Syntheses, structures, and surface photoelectric properties of Co-btec complexes. Wuli Huaxue Xuebao, 25(10), 20112019.

Silva, A.M.G.; Castro, B.; Rangel, M.; Silva, A.M.S.; Brandao, P.; Felix, V.; Cavaleiro, J.A.S. (2009). Microwave-enhanced synthesis of novel pyridinone-fused porphyrins. Synlett, (6), 1009-1013.

Singh, K.; McWhinnie, W.R.; Li Chen, H.; Sun, M.; Hamor, T.A. (1996). Reactions of heterocyclic organotellurium compounds with triiron dodecacarbonyl: reactions of thiophenes revisited. I Chem. Soc., Dalton Trans. 1545-1549. 
Singh, R.V.; Jain, M; Deshmukh, C.N. (2005). Microwave-assisted synthesis and insecticidal properties of biologically potent organosilicon(IV) compounds of a sulfonamide imine. Appl. Organomet. Chem., 19(7), 879-886.

Singh, R.V.; Chaudhary, P.; Poonia, K.; Chauhan, S. (2008). Microwave-assisted synthesis, characterization and biological screening of nitrogen-sulphur and nitrogen-oxygen donor ligands and their organotin(IV) complexes. Spectrochimica Acta, Part A: Molecular and Biomolecular Spectroscopy, 70A(3), 587-594.

Sinha, S.; Srivastava, A.K.; Sengupta, S.K.; Pandey, O.P. (2008). Microwave assisted synthesis, spectroscopic and antibacterial studies of bis(cyclopentadienyl)hafnium(IV) derivatives with benzil bis(aroyl hydrazones). Transition Metal Chemistry, 33(5), 563-567.

Soriente, A.; De Rosa, M.; Lamberti, M.; Tedesco, C.; Scettri, A.; Pellecchia, C. (2005). Synthesis, crystal structure and application in regio- and stereoselective epoxidation of allylic alcohols of a titanium binaphthyl-bridged Schiff base complex. I Mol. Catal. A: Chemical, 235(1-2), 253-259.

Spinella, A.; Caruso, T.; Pastore, U.; Ricart, S. (2003). Improving methodology for the preparation of uracil derivatives from Fischer carbene complexes. Microwave activation. el Organomet. Chem., 684(1-2), 266-268.

Takahashi, S.; Shojiya, M.; Kawamoto, Y.; Konishi, A. (2003). Preparation and characterization of amorphous $\mathrm{GaF}_{3}$ and $\mathrm{GaF}_{3}-\mathrm{BaF}_{2}$ thin films by ECR microwave plasma-enhanced CVD. Thin Solid Films, 429(1-2), 28-33.

Tan, N.Y.; Xiao, X.M.; Li, Z.L.; Matsumura-Inoue, T. (2004). Microwave synthesis, characterization and DNA-binding properties of a new cobalt(II) complex with 2,6bis(benzimidazol-2-yl)pyridine. Chinese Chemical Letters, 15(6), 687-690.

Tusek-Bozic, L.; Marotta, E.; Traldi, P. (2007). Efficient solid-state microwave-promoted complexation of a mixed dioxa-diaza macrocycle with an alkali salt. Synthesis of a sodium ethyl 4-benzeneazophosphonate complex. Polyhedron, 26(8), 1663-1668.

Van Atta, S.L.; Duclos, B.A.; Green, D.B. (2000). Microwave-Assisted Synthesis of Group 6 (Cr, Mo, W) Zerovalent Organometallic Carbonyl Compounds. Organometallics. 19(12), 2397 (2000).

Velmathi, S.; Vijayaraghavan, R.; Pal, R.P.; Vinu, A. (2010). Microwave Assisted Ligand Free Palladium Catalyzed Synthesis of $\beta$-Arylalkenyl Nitriles Using Water as Solvent. Catalysis Lett., 135(1-2), 148-151.

Villemin, D.; Martin, B.; Puciova, M.; Toma, S. (1994). Dry synthesis under microwave irradiation: Synthesis of ferrocenylenones. el Organomet. Chem. 484, 27.

Vondrova, M.; Burgess, C.M.; Bocarsly, A.B. (2007). Cyanogel Coordination Polymers as Precursors to Transition Metal Alloys and Intermetallics - from Traditional Heating to Microwave Processing. Chem. Mater., 19(9), 2203-2212.

Walther, D.; Schebesta, S.; Rau, S.; Schaefer, B.; Gruessing, A. (2005). Procedure for the production of light-emitting ruthenium(II) compounds. Patent DE 102004009551, 6 pp.

Wang, X.-F.; Zhang, Y.-B.; Huang, H.; Zhang, J.-P.; Chen, X.-M. (2008). Microwave-Assisted Solvothermal Synthesis of a Dynamic Porous Metal-Carboxylate Framework. Crystal Growth \& Design, 8(12), 4559-4563.

Wiesbrock, F.; Hoogenboom, R.; Schubert, U.S. (2004). Microwave-Assisted Polymer Synthesis:

State-of-the-Art and Future Perspectives. Macromol. Rapid Commun. 25, 1739-1764. 
Wang, M.-Z.; Wong, M.-K.; Che, C.-M. (2008). Gold(I)-catalyzed intermolecular hydroarylation of alkenes with indoles under thermal and microwave-assisted conditions. Chemistry--A European eburnal, 14(27), 8353-8364.

Winkelmann, O.H.; Navarro, O. (2010). Microwave-Assisted Synthesis of N-Heterocyclic Carbene-Palladium(II) Complexes. Advanced Synthesis \& Catalysis, 352(1), 212-214.

Wolfel, A.M.; Walters, B.M.; Zovinka, E.P. (2009). Microwave metallation of porphyrins. Abstracts of Papers, 238th ACS National Meeting, Washington, DC, United States, August 16-20, 2009, CHED-214.

Xiao, X.; Sakamoto, J.; Tanabe, M.; Yamazaki, S.; Yamabe, S.; Matsumura-Inoue, T. (2002). Microwave synthesis and spectroelectrochemical study on ruthenium(II) polypyridine complexes. eburnal of Electroanalytical Chemistry, 527(1-2), 33-40.

Xu, X.-x.; Fan, H.-t. (2007). Microwave synthesis of Co(III) complex and its crystal structure. Hefei Gongye Daxue Xuebao, Ziran Kexueban, 30(4), 458-460.

Yamauchi, T.; Tsukahara, Y.; Sakamoto, T.; Kono, T.; Yasuda, M.; Baba, A.; Wada, Y. (2009). Microwave-assisted synthesis of monodisperse nickel nanoparticles using a complex of nickel formate with long-chain amine ligands. Bulletin of the Chemical Society of elopan, 82(8), 1044-1051.

Yaseen, M.; Ali, M.; NajeebUllah, M.; Munawar, M.A.; Khokhar, I. (2009). Microwaveassisted synthesis, metalation, and Duff formylation of porphyrins. I Heterocyclic Chem., 46(2), 251-255.

Yin, D.; Liu, J.; Zhang, Y.; Gao, Q.; Yin, D. (2005). Immobilization of Mn(salen) complex on aluminum-containing mesoporous materials by microwave heating for epoxidation of styrene. Studies in Surface Science and Catalysis, 156(Nanoporous Materials IV), 851-858.

Zabova, H.; Sobek, J.; Cirkva, V.; Solcova, O.; Kment, S.; Hajek, M. (2009). Efficient preparation of nanocrystalline anatase $\mathrm{TiO}_{2}$ and $\mathrm{V} / \mathrm{TiO}_{2}$ thin layers using microwave drying and/or microwave calcination technique. eburnal of Solid State Chemistry, 182(12), 3387-3392.

Zhang, G.; Wang, C.; Wu, Q.; Song, X.; Ran, F. (2008). Method for synthesizing quinoxalineseries ligand-iridium complexes. Patent CN 101215299, 15 pp.

Zhang, Z.-y.; Hao, W.; Hu, W.-x. (2006). Synthesis of 5,10,15,20-tetrakis(2-pyridyl)porphyrin and its Mn(III) complex. Hecheng Huaxue, 14(5), 497-499.

Zhang, S.-H.; Tang, M.-F.; Ge, C.-M. (2009). Microwave synthesis, crystal structure and magnetic behavior of a Schiff base trinuclear nickel cluster. Z. Anorg. Allg. Chem., 635(9-10), 1442-1446.

Zhang, Y.; Yin, D.; Fu, Z.; Li, C.; Yin, D. (2003). Preparation of Mn(salen)/Al-MCM-41 catalyst under microwave irradiation and its catalytic performance in epoxidation of styrene. CuihuaXuebao, 24(12), 942-946.

Ziegler, M.; Monney, V.; Stoeckli-Evans, H.; Von Zelewsky, A.; Sasaki, I.; Dupic, G.; Daran, J.-C.; Balavoine, G.G.A. (1999). Complexes of new chiral terpyridyl ligands. Synthesis and characterization of their ruthenium(II) and rhodium(III) complexes. I Chem. Soc., Dalton Trans.: Inorg. Chem., (5), 667-676.

Zoller, F.; Riss, P. J.; Montforts, F.-P.; Roesch, F. (2010). Efficient post-processing of aqueous generator eluates facilitates ${ }^{68} \mathrm{Ga}$-labelling under anhydrous conditions. Radiochimica Acta, 98(3), 157-160. 




\author{
Advances in Induction and Microwave Heating of Mineral and \\ Organic Materials
}

Edited by Prof. StanisÅ,aw Grundas

ISBN 978-953-307-522-8

Hard cover, 752 pages

Publisher InTech

Published online 14, February, 2011

Published in print edition February, 2011

The book offers comprehensive coverage of the broad range of scientific knowledge in the fields of advances in induction and microwave heating of mineral and organic materials. Beginning with industry application in many areas of practical application to mineral materials and ending with raw materials of agriculture origin the authors, specialists in different scientific area, present their results in the two sections: Section 1-Induction and Microwave Heating of Mineral Materials, and Section 2-Microwave Heating of Organic Materials.

\title{
How to reference
}

In order to correctly reference this scholarly work, feel free to copy and paste the following:

Oxana V. Kharissova, Boris I. Kharisov and Ubaldo Ortiz Méndez (2011). Microwave-Assisted Synthesis of Coordination and Organometallic Compounds, Advances in Induction and Microwave Heating of Mineral and Organic Materials, Prof. StanisÅ,aw Grundas (Ed.), ISBN: 978-953-307-522-8, InTech, Available from: $\mathrm{http}$ ://www.intechopen.com/books/advances-in-induction-and-microwave-heating-of-mineral-and-organicmaterials/microwave-assisted-synthesis-of-coordination-and-organometallic-compounds

\section{INTECH}

open science | open minds

\section{InTech Europe}

University Campus STeP Ri

Slavka Krautzeka 83/A

51000 Rijeka, Croatia

Phone: +385 (51) 770447

Fax: +385 (51) 686166

www.intechopen.com

\section{InTech China}

Unit 405, Office Block, Hotel Equatorial Shanghai

No.65, Yan An Road (West), Shanghai, 200040, China

中国上海市延安西路 65 号上海国际贵都大饭店办公楼 405 单元

Phone: +86-21-62489820

Fax: +86-21-62489821 
(C) 2011 The Author(s). Licensee IntechOpen. This chapter is distributed under the terms of the Creative Commons Attribution-NonCommercialShareAlike-3.0 License, which permits use, distribution and reproduction for non-commercial purposes, provided the original is properly cited and derivative works building on this content are distributed under the same license. 